\title{
The Vertical Distribution of Ozone in the Mesosphere and Lower Thermosphere
}

\author{
MARK Allen, ${ }^{1}$ JONATHAN I. LUNINE, and YUK L. YUNG \\ Division of Geological and Planetary Sciences, California Institute of \\ Technology
}

\begin{abstract}
An assessment is made of the ability of current theory to explain the phenomenology of upper atmospheric ozone as revealed by the sizeable body of measurements presently available. The chemistry of ozone in the mesosphere and lower thermosphere is closely coupled to the chemistries of other oxygen/hydrogen-containing species, which must be considered concurrently. To provide insight into the sensitivity of model calculations to the choice of values used for key chemical rate constants and climatological parameters, simple analytical expressions for ozone are derived for those situations when it is in photochemical steady state, the mesosphere during daylight hours and the lower thermosphere throughout the full diurnal period. The model is found to reproduce the detailed Aladdin 74 rocket measurements of ozone from 50 to $95 \mathrm{~km}$, numerous other measurements of mid-latitude ozone in the lower mesosphere, the secondary maximum in the ozone vertical distribution at the mesopause, and the diurnal variability of ozone seen in the radio measurements of Wilson and Schwartz (1981) and other observations. The agreement with the Aladdin 74 data results from adjusting some key parameters within the uncertainties of laboratory measurements or known natural climatological variability. The variety of mid-latitude observations can be understood in terms of the estimated variability of environmental factors: diurnal, seasonal, and solar cycles in the solar illumination; the abundance of water vapor, and the details of the thermal profile of the atmosphere. The ozone secondary maximum results from the onset of the coupling between active-hydrogen and active-oxygen chemistry and its observed variability may be a consequence of secular changes in mesopause dynamics. Above $\sim 95 \mathrm{~km}$, ozone observations are consistently higher than model results and cannot be accounted for by the set of reactions currently included in the model.
\end{abstract}

\section{INTRODUCTION}

Ozone in the terrestrial atmosphere between the stratopause $(\sim 50 \mathrm{~km}$ altitude) and the homopause $(\sim 100 \mathrm{~km}$ altitude), encompassing the mesosphere and lower thermosphere, is a subject worthy of detailed study, because its presence is a key factor in upper atmospheric processes that are of significant importance to human activities and the evolution of the terrestrial ecosystem. As a result of its optical and chemical properties, ozone affects the thermal structure and dynamics of the upper atmosphere [London, 1980] and its state of ionization, particularly in the $D$ region where negative ions are important [Chamberlain, 1978]. Thus, the behavior of upper atmospheric ozone is ultimately associated with such diverse phenomena as the operations of low earth-orbit satellites (as in the case of the premature fall of Skylab) [National Academy of Sciences, 1981] (NAS), the chemical evolution of the whole atmosphere on geological times [Hunten and Strobel, 1974; Liu and Donahue, 1974a, b; Hunten and Donahue, 1976], the upper stratospheric ozone layer (and the viability of biological activity on the surface of the earth) [Hudson and Reed, 1979], and clarity in long range communications [NAS, 1981]. Since at least one region of the solar spectrum that is known to influence the distribution of ozone in the mesosphere has been observed to vary over the course of the 27-

\footnotetext{
Also at Earth and Space Sciences Division, Jet Propulsion Laboratory.
}

Copyright 1984 by the American Geophysical Union.

Paper number 3D1922.

0148-0227/84/003D-1922\$05.00 day solar rotation [Rottman et al., 1982] and the 11-year solar cycle [Mount et al., 1980; Mount and Rottman, 1981; Rottman, 1981 ], ozone is associated with a clearly established coupling between solar variability and terrestrial phenomena.

An understanding of the ozone chemistry above the stratopause can be of great assistance to the larger program of stratospheric ozone research because high altitude ozone is affected by some of the same chemical cycles that are important in controlling stratospheric ozone [World Meteorological Organization, 1981] (WMO). Since a smaller group of reactions is sufficient for describing the behavior of mesospheric ozone, there is an opportunity to test key parts of stratospheric models under the simplified conditions of the upper atmosphere. This is important because current stratospheric models with fully updated kinetic rate constants underestimate the observed ozone distribution between 35 and $50 \mathrm{~km}$ [Ko and Sze, 1983; L. Froidevaux, private communication, 1983], but the cause of this deficit is unclear due to the difficulty in assessing the effects of any particular catalytic cycle for ozone loss in the stratosphere.

Such are the motivations for trying to understand in detail the behavior of ozone in the mesosphere and lower thermosphere. While much is known about the stratosphere and upper thermosphere, there is in general surprisingly little data on the chemical composition in the intervening atmosphere because this altitude range is too high for effective use of stratospheric measurement techniques and too low for in situ satellite measurements [NAS, 1981]. However, in the case of ozone, detection is relatively easy and it has been monitored by ground-based telescopes [for example, Wilson and Schwartz, 1981], by in situ rocket measurements [for example, Weeks et al., 1978], and from 
satellites [Krueger et al., 1980]. Increasingly sophisticated models of mesospheric/lower thermospheric ozone chemistry have been published in the past decade. Nicolet [1971, 1980] has presented the set of reactions important for the hydrogen/oxygen chemistry. The papers by Hunt [1971, 1973], Thomas and Bowman [1972], Whitten and Turco [1974], Koshelev [1976], Moreels et al. [1977], Logan et al. [1978], Keneshea et al. [1979], Crutzen and Solomon [1980], Wang et al. [1981], Battaner and Rodrigo [1981], Rusch and Liu [1981], Prather [1981], Garcia and Solomon [1983], and Solomon et al. [1983] all present model profiles of ozone for part or all of the altitude range between the stratopause and the homopause. As a result of this cumulative work, a general understanding of the key chemical and atmospheric parameters affecting the ozone distribution has developed. Some of these papers present limited comparisons between model distributions and the observations available at the time. Since most of this work appeared, there have been significant changes in important reaction rate constants and improvements in the calculations of radiative transfer in the upper atmosphere and the treatment of relevant background atmosphere parameters. Moreover, in recent years the quantity and quality of ozone observational data has significantly improved, allowing more definitive intercomparisons between measurements and models. Thus, a new study benefitting from this recent progress seemed warranted with the purpose of identifying remaining shortcomings in our understanding of upper atmospheric ozone. In this paper the particular focus will be on the details of the vertical distribution of ozone and the diumal and other naturally occurring variations in the ozone distribution at mid-latitudes.

The work presented in this paper is part of a larger research program focused on using observational data in conjunction with model calculations specific to the circumstances 'of the observations to derive values for the physical properties of the mesosphere and lower thermosphere and to test proposed reaction mechanisms of importance to the aeronomy of this altitude range. The first phase of this program was presented in Allen et al. [1981] (hereinafter Paper I). In this paper, we reported the derivation of values for vertical eddy diffusion that are consistent with the altitude distribution of several long-lived trace species. Preliminary results from our ozone modeling were used to constrain the values for eddy diffusion near the mesopause. In the course of the work reported in Paper I, we found that key hydrogen/oxygen reaction rate constants had to be varied from the experimental values. Only briefly discussed in Paper I, these points are more fully developed in the current work.

We begin our considerations of upper atmospheric ozone with a review of the chemical processes affecting its vertical distribution. Simple analytical expressions for the ozone concentrations at different altitudes are derived which approximate the key elements of the ozone chemistry. These equations provide simple explanations of the sensitivity of model computations to the choice of rate constants and climatological parameters. In light of this understanding, we compare our model calculations with a detailed measurement of an ozone profile and refine some of our model parameters within the limits allowed by the uncertainties in their values. Our model so modified is used to assess the variation in ozone expected to result from perturbations in key climatological parameters. These predictions are then compared with the variability observed in the large accumulated body of mid-latitude measurements to verify our model description of ozone processes in the upper atmosphere.

\section{ChEMISTRY OF OZONE IN THE UPPER ATMOSPHERE}

To understand the chemical behavior of ozone in the mesosphere and lower thermosphere, one must simultaneously consider the chemistry of several compounds containing oxygen and/or hydrogen atoms. In particular, ozone is one of three important active-oxygen species, the others being atomic oxygen and the hydroxyl radical. These species result from breaking $\mathrm{O}-\mathrm{O}$ bonds and are collectively destroyed when O-O bonds are reformed [cf. DeMore and Yung, 1982]. Considering this group of species together is similar to the odd-oxygen concept used in modeling stratospheric chemistry [Johnston and Podolske 1978; Chang and Duewer, 1979]. The cycling between $\mathrm{O}, \mathrm{O}_{3}$, and $\mathrm{OH}$ and the recycling of active-oxygen back to the inactive-oxygen reservoir, $\mathrm{O}_{2}$, is affected by the presence of active-hydrogen species, $\mathrm{H}, \mathrm{OH}$, and $\mathrm{HO}_{2}$. The abundance of these species relative to each other and the recycling between activehydrogen and the inactive-hydrogen reservoirs, $\mathrm{H}_{2} \mathrm{O}$ and $\mathrm{H}_{2}$ (and in a minor way $\mathrm{H}_{2} \mathrm{O}_{2}$ ), must be understood to explain in turn the distribution of ozone. Analysis in terms of the behavior of active- and inactive-oxygen and hydrogen is employed in this paper only for the purposes of clarifying the net processes affecting ozone. The numerical calculations were performed by solving the full continuity equation, including transport, for each atomic and molecular species.

The important chemical reactions affecting the distribution of $\mathrm{O}_{3}$ above the stratopause, as determined by decades of research, are listed in Table 1 . This group of reactions is a subset of that used in Paper I. The concepts of activeoxygen and active-hydrogen to be utilized shortly are illustrated in the table by noting the net production or loss in active-O and/or active-H that results from each reaction [cf., Johnston and Podolske, 1978, Table 3]. In the next section, we will show how well this reaction scheme can reproduce a detailed observational $\mathrm{O}_{3}$ profile with some modification of reaction rate constants. A full discussion of the values chosen for the rate constants is saved for then. Not included in Table 1 are reactions involving molecules that have nitrogen and/or halogen atoms, reactions that are known to be important for understanding ozone chemistry in the stratosphere [WMO, 1981, and references therein]. This omission is valid because the combined importance of nitrogen- and chlorine-catalyzed destruction of $\mathrm{O}_{3}$ is less than $10-15 \%$ of the total $\mathrm{O}_{3}$ loss rate at $50 \mathrm{~km}$ [Frederick, 1980; WMO, 1981] and less than $1 \%$ at $55 \mathrm{~km}$ [Frederick, 19801.

Most recently, Thomas et al. [1980], Barth [1981], and Prather [1981] review the key reaction cycles affecting ozone above the stratopause. An extensive discussion of the continuity equation for the important active-oxygen and active-hydrogen species in the mesosphere has been presented by Nicolet $[1971,1980]$. In this section we will give a more qualitative overview of ozone chemistry and 
TABLE 1. Important Reactions For Ozone Above The Stratopause

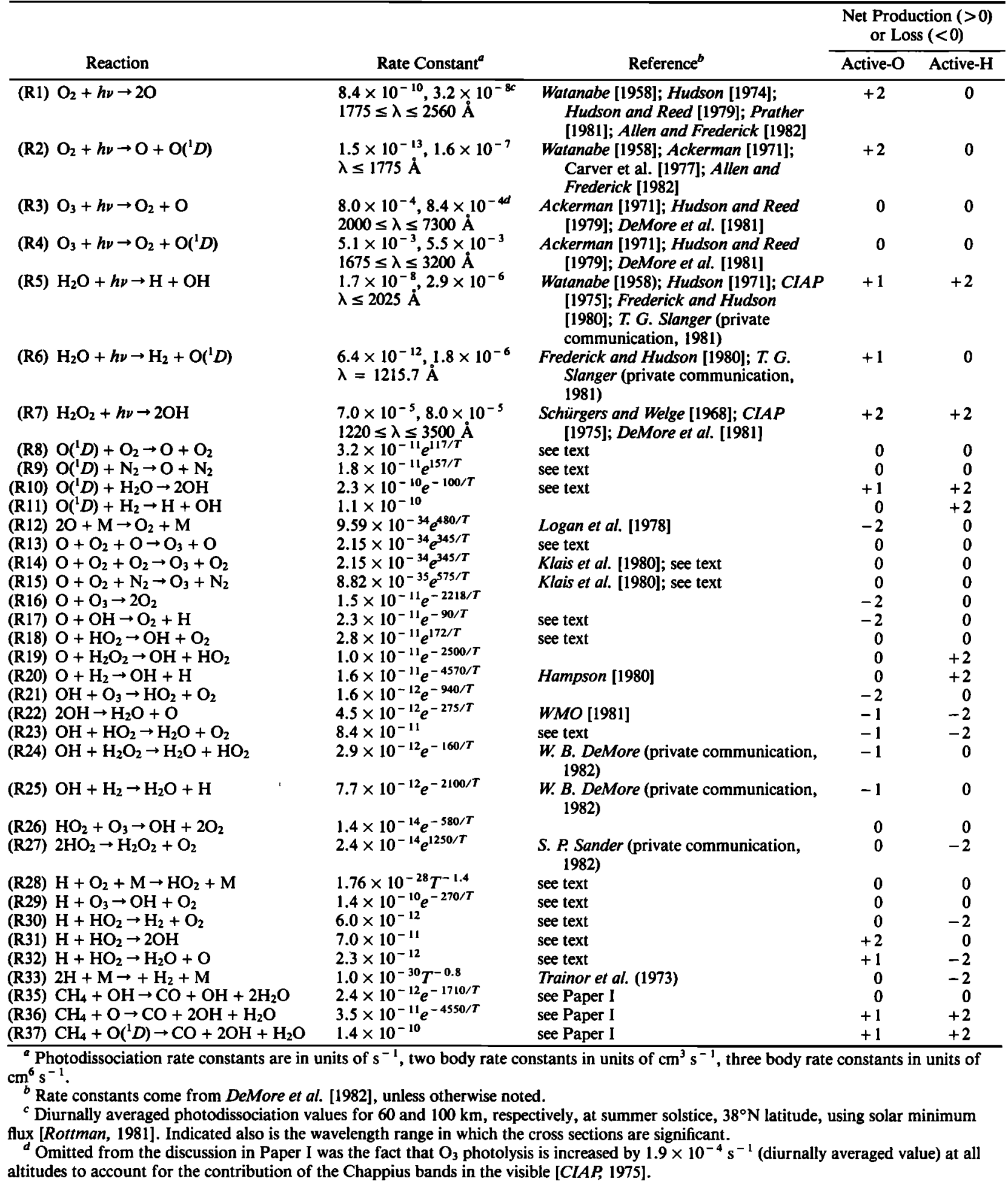

derive simple analytical expressions, where possible, to be used to predict the $\mathrm{O}_{3}$ distribution in terms of parameters that are easy to determine. This also allows identification of the sensitivity of $\mathrm{O}_{3}$ vertical and diurnal profiles to certain factors. In the following section, the sensitivity analysis will be used to identify key rate constants which, if revised, would allow better agreement between model results and observations. The suggested changes to the rate constant values will be compared with recent experimental results.

Using the reactions and rate constants listed in Table 1 and the atmospheric and computer models described in Paper I, a diurnal calculation was performed (comparable to model 2 of Paper I). The most important reactions for cycling among active- $O$ species and interchange between active-and inactive-O are pictured in Figure 1 . Some of the properties of these species culled from the results of the 


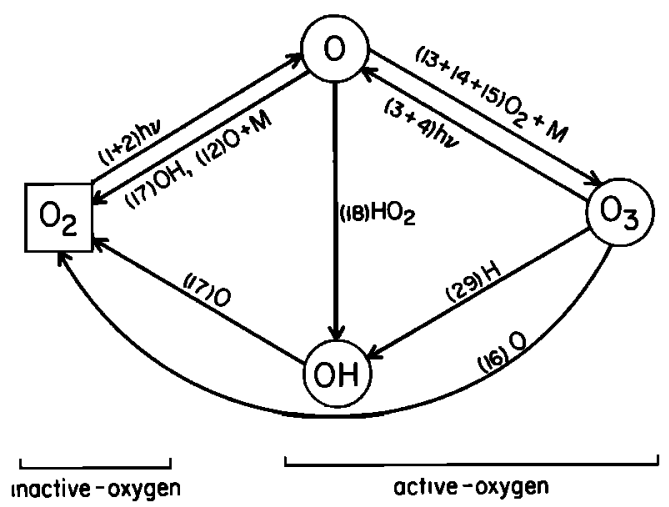

Fig. 1. Important reactions for recycling among active-oxygen species and for conversion from active-oxygen to inactive-oxygen and vice versa. Numbers in parentheses are reaction indices of Table 1.

aforementioned diurnal calculation are illustrated in Figure 2. Shown in Figure $2 a$ are the chemical lifetimes at noon and midnight of $\mathrm{O}, \mathrm{O}_{3}$, and the active-oxygen group treated as a single entity. These are compared with the time scale for eddy diffusive transport. The consequent time-varying apportionment of active-O between $\mathrm{O}$ and $\mathrm{O}_{3}$ is displayed in Figure 2b. As was discussed in Paper I, transport can directly affect the distribution of a species when its chemical lifetime is comparable to the mass transport time scale. When the chemical time scale is very short (up to $\sim 1$ hour), the diurnal behavior of the particular species is driven by the changing solar zenith angle. When in addition the production and loss terms balance, the species is in photochemical steady state and transport is not important. However, mass transport indirectly does affect these latter species when their chemistry involves longer-lived species controlled by transport (as will be seen, an important effect for $\mathrm{O}_{3}$ ).
In the thermosphere ( $\geq 85 \mathrm{~km}$ ), the lifetime of atomic $O$ is consistently longer than 1 day throughout the diurnal cycle (Figure 2a). On the other hand, $\mathrm{O}_{3}$ is always extremely short-lived ( -10 minutes). As a consequence, active- $O$ is predominantly atomic $O$ (Figure $2 b$ ). If the lifetimes of all active-O species were short, the time scale for conversion of active- $\mathrm{O}$ to $\mathrm{O}_{2}$ would be greater than the lifetime of any of the individual active- $O$ species. In the thermosphere, the active- $\mathrm{O}$ group concept is not fully operative because of the long chemical lifetime of active-O, with the result that the lifetime of active-O is approximately equal to (actually slightly less than) that of atomic $O$. In these circumstances diurnal calculations cannot be performed by adopting active- $\mathrm{O}$ as a single species with subsequent partitioning among the group constituents by equilibrium considerations. As a result of the relative lifetimes of $\mathrm{O}$ and $\mathrm{O}_{3}$ in the thermosphere, $\mathrm{O}_{3}$ behaves as an active- $\mathrm{O}$ tracer in equilibrium with atomic $O$. Since the atomic $O$ distribution is affected by eddy diffusion (Figure $2 a$ and Paper I), then the $\mathrm{O}_{3}$ profile will also be sensitive to mass transport rates.

At the mesopause $(\sim 80 \mathrm{~km})$, there is a significant transformation of the active-O chemical cycle. In the mesosphere, active-O as a group becomes short-lived (and therefore the cycling among the group constituents very rapid) during daylight hours with the nature of the dominant species dependent on the exact altitude. At night below $-75 \mathrm{~km}$, active-O is long-lived ( $\sim$ one day) but now $\mathrm{O}_{3}$ is the dominant component (Figure $2 b$ ).

\section{Analytical Expressions for the $\mathrm{O}_{3}$ Abundance}

When the lifetime of $\mathrm{O}_{3}$ is relatively short and the production and loss terms nearly in balance, simple analytical expressions describing the time variability of the $\mathrm{O}_{3}$ concentration can be derived assuming that $\mathrm{O}_{3}$ is in photochemical

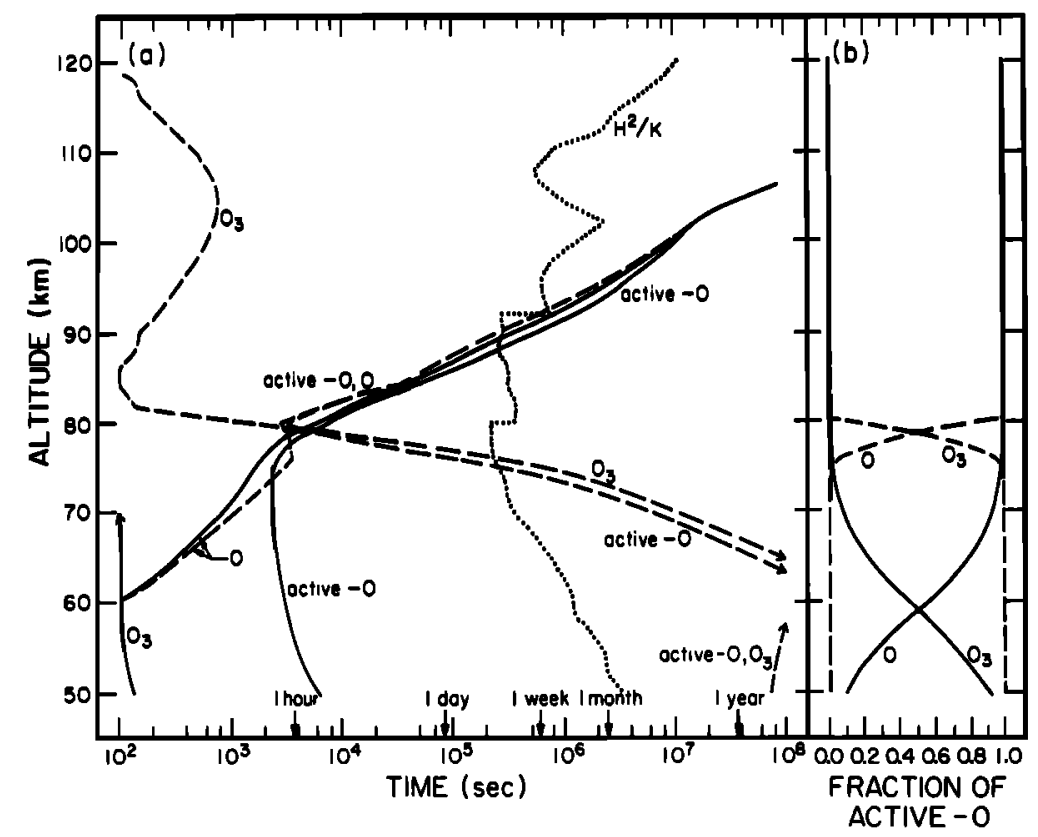

Fig. 2. Active-oxygen species above the stratopause. (a) Chemical lifetimes at noon (solid lines) and midnight (dashed lines) compared with eddy diffusion time scale $\left(\mathrm{H}_{2} / \mathrm{K}\right)$. (b) The relative fraction of active-oxygen as atomic $\mathrm{O}$ and $\mathrm{O}_{3}$ at noon (solid lines) and midnight (dashed lines). 


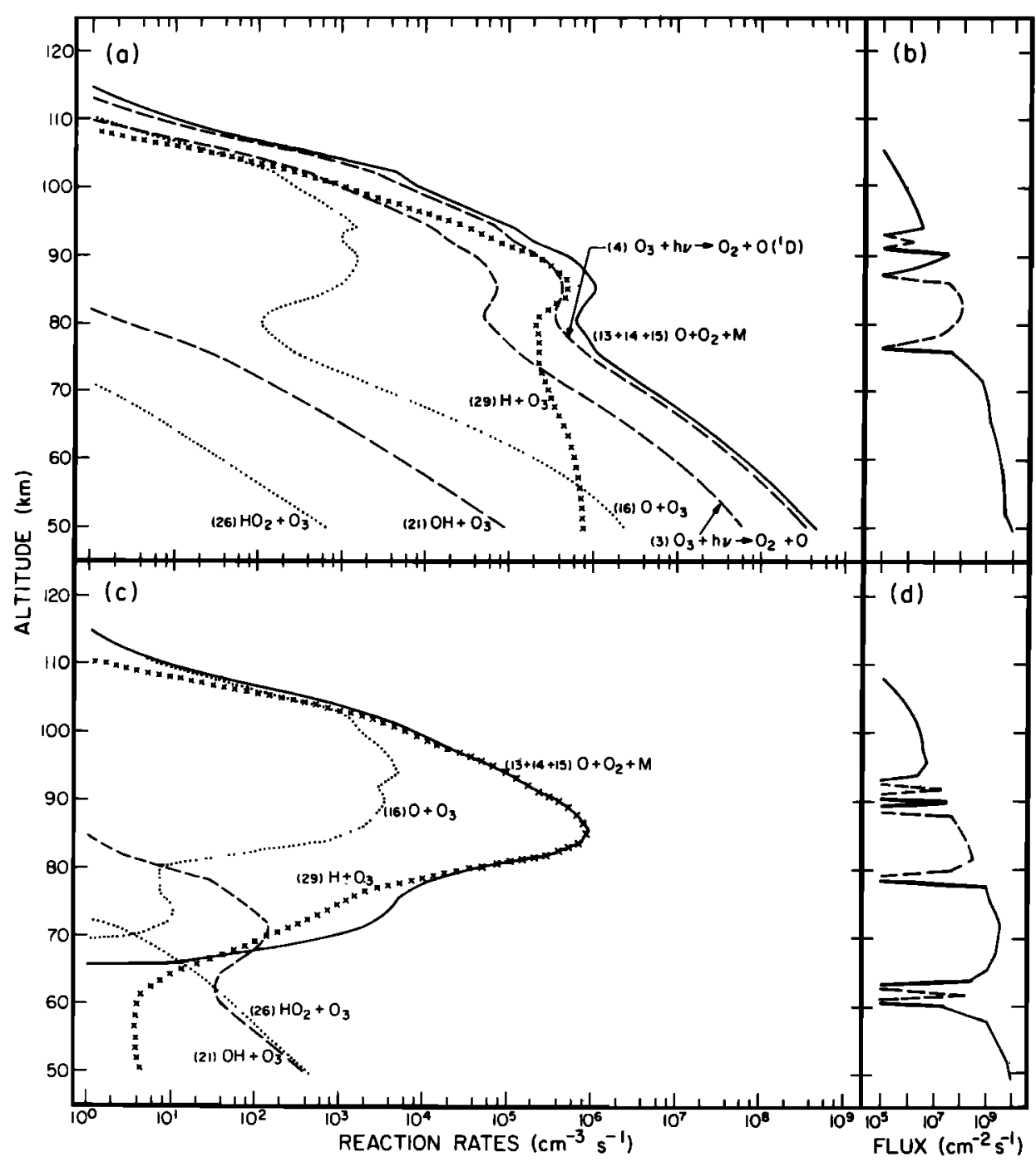

Fig. 3. Ozone chemistry. The rates of reactions important for the production and loss of $\mathrm{O}_{3}$ at (a) noon and $(c)$ midnight. The vertical transport of $\mathrm{O}_{3}$ at $(b)$ noon and $(d)$ midnight (upward flux: solid lines; downward flux: dashed lines).

steady state. Such equations are most useful if the $\mathrm{O}_{3}$ concentration is expressed in terms of the background abundances of long-lived species and measurable physical parameters. (Previously, Bates and Nicolet [1950] presented such an analysis for a pure oxygen atmosphere only.) We shall now derive analytical expressions for the daylight period below $80 \mathrm{~km}$ and for the full diurnal cycle above $80 \mathrm{~km}$, as these are situations in which $\mathrm{O}_{3}$ chemistry satisfies the conditions of photochemical steady state.

Shown in Figure 3 are the reactions most important for producing and destroying $\mathrm{O}_{3}$. The rates of these reactions (and some less important ones) are presented in Figures $3 a$ and $3 c$ for noon and midnight, respectively. Figures $3 b$ and $3 d$ give the resulting values for vertical $\mathrm{O}_{3}$ transport to show the relative importance of local chemistry and transport. Only one reaction is known to be significant for producing $\mathrm{O}_{3}$ in the terrestrial atmosphere:

$$
\mathrm{O}+\mathrm{O}_{2}+\mathrm{M} \rightarrow \mathrm{O}_{3}+\mathrm{M}
$$

where $\mathrm{M}$ signifies a catalytic third body. (The $R n$ numbers refer to the identifying reaction index in Table 1.) During the day, photodissociation of $\mathrm{O}_{3}((\mathrm{R} 3)$ and (R4)) is an important destruction mechanism. Chemical loss of $\mathrm{O}_{3}$ is predominantly due to reaction with atomic hydrogen,

$$
\mathrm{H}+\mathrm{O}_{3} \rightarrow \mathrm{OH}+\mathrm{O}_{2}
$$

but, below $55 \mathrm{~km}$ and above $\sim 105 \mathrm{~km}$, the atomic $\mathrm{O} /$ atomic $\mathrm{H}$ ratio becomes sufficiently large that reaction with atomic oxygen,

$$
\mathrm{O}+\mathrm{O}_{3} \rightarrow 2 \mathrm{O}_{2}
$$

is also an important $\mathrm{O}_{3}$ loss channel. Thus, a general expression for the ozone distribution during periods of photochemical steady state is

$$
\left[\mathrm{O}_{3}\right]-\frac{[\mathrm{O}]\left[\mathrm{O}_{2}\right]\left(k_{13}[\mathrm{O}]+k_{14}\left[\mathrm{O}_{2}\right]+k_{15}\left[\mathrm{~N}_{2}\right]\right)}{J_{3}+J_{4}+k_{29}[\mathrm{H}]+k_{16}[\mathrm{O}]}
$$

where the square brackets indicate concentration and each of the physical parameters and chemical abundances may 


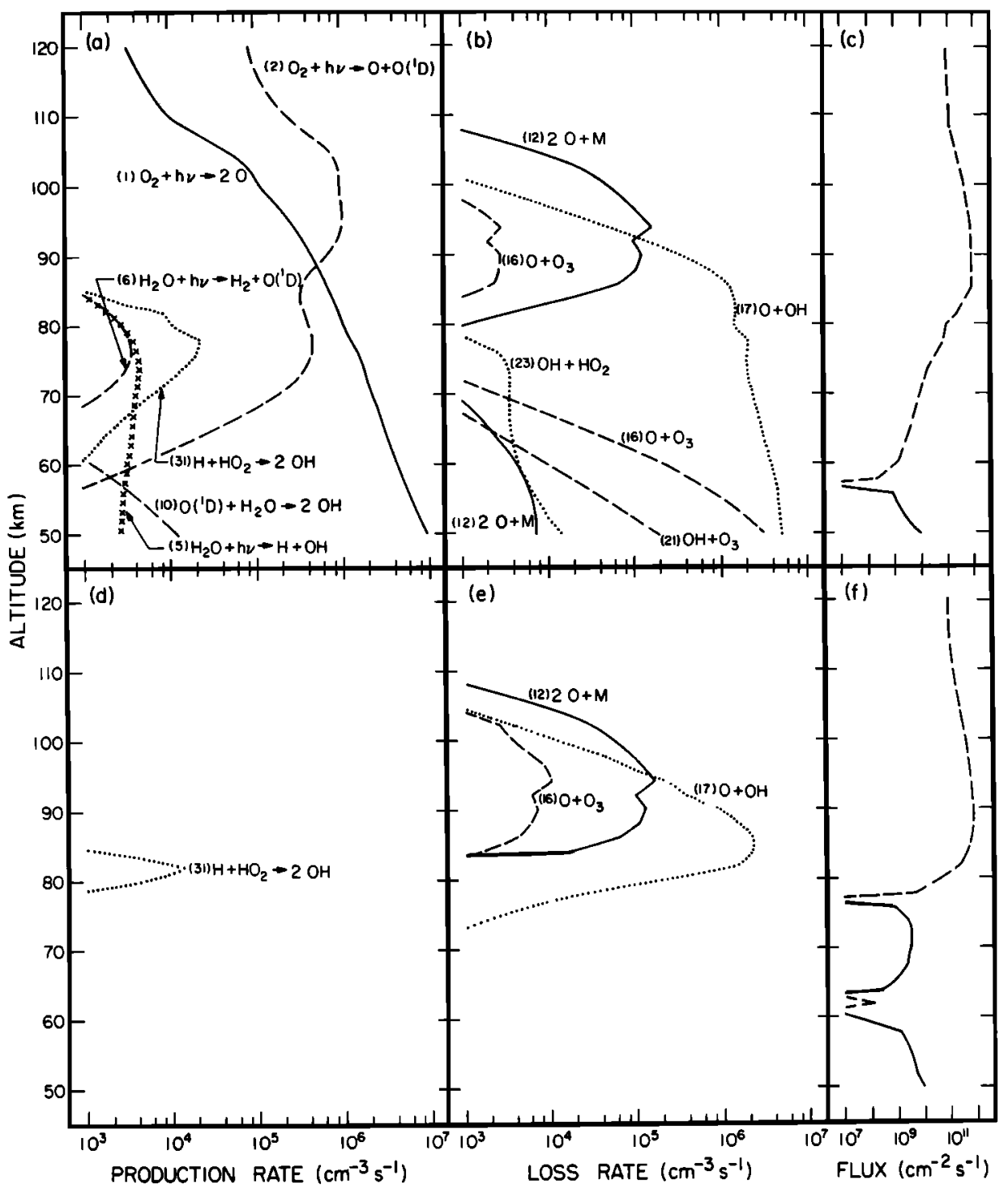

Fig. 4. Active-oxygen chemistry. The rates of production and loss of active-O at noon, $(a)$ and $(b)$, respectively, and at midnight, $(d)$ and $(e)$. The vertical transport of active-O at $(c)$ noon and at $(f)$ midnight (upward flux: solid lines; downward flux: dashed lines).

be a function of space and time. Photolytic rate constants are indicated by $J_{n}$ and kinetic rate constants by $k_{n}$.

At $50 \mathrm{~km}$, the daylight $\mathrm{O}_{3}$ distribution will reflect the local nature of the background atmosphere (the $\mathrm{O}_{2}$ and $\mathrm{N}_{2}$ densities). The temporal variability will arise from the diurnal changes in the photodissociation rate constants directly (affecting the partitioning among active- $O$ species) and indirectly by controlling the abundance of active- $O$ and active-H, both of which are short-lived. Then, for (1) to be useful, we need to replace the concentration of atomic $O$ and $H$ with expressions in terms of related long-lived species.

Since the $\mathrm{O} / \mathrm{O}_{3}$ partitioning of active- $\mathrm{O}$ is in equilibrium during daylight hours at $50 \mathrm{~km}$, the abundance of atomic $\mathrm{O}$ is related to the total amount of active- $O$. The reaction rates for the important sources and sinks of active-O are shown in Figure 4. The active-O group is in photochemical steady state; the production of active-O (see Table 1), primarily,

$$
\mathrm{O}_{2}+h v \rightarrow 2 \mathrm{O}
$$

is balanced by the loss,

$$
\mathrm{O}+\mathrm{OH} \rightarrow \mathrm{O}_{2}+\mathrm{H}
$$

such that the atomic $\mathrm{O}$ abundance is related to the abundance of the major active-H species $\mathrm{OH}$ (Figure $5 b$ ),

$$
[\mathrm{O}]-\frac{J_{1}\left[\mathrm{O}_{2}\right]}{k_{17}[\mathrm{OH}]}
$$

At $50 \mathrm{~km}$ during daylight hours, the active- $\mathrm{H}$ group as a whole is short-lived (Figure 5a), and the cycling among the group species is rapid and is dominated by the reactions illustrated in Figure 6 . The exchange between active- and inactive- $\mathrm{H}$ is in balance; thus, active- $\mathrm{H}$ is in photochemical steady state. The rates for the most important reactions are 


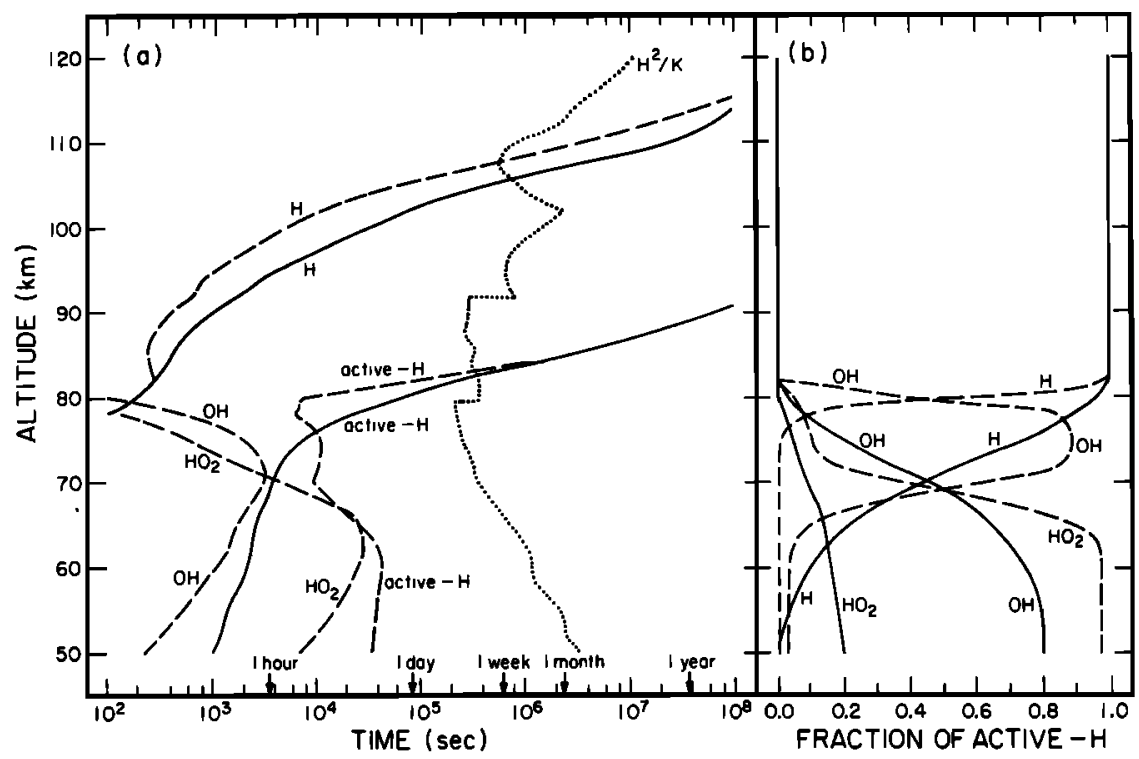

Fig. 5. Active-hydrogen species above the stratopause. (a) Chemical lifetimes at noon (solid lines) and midnight (dashed lines) compared with eddy diffusion time scales $\left(\mathrm{H}^{2} / \mathrm{K}\right)$. (b) The relative fraction of active-hydrogen in the form of $\mathrm{H}, \mathrm{OH}$, or $\mathrm{HO}_{2}$ at noon (solid lines) and midnight (dashed lines).

presented in Figure 7. Equating the production and loss of The $\mathrm{OH}$ concentration is a balance between the reactions active-H, one finds that

$$
k_{10}\left[\mathrm{O}\left({ }^{1} D\right)\right]\left[\mathrm{H}_{2} \mathrm{O}\right]-k_{23}[\mathrm{OH}]\left[\mathrm{HO}_{2}\right]
$$

$$
\mathrm{O}+\mathrm{HO}_{2} \rightarrow \mathrm{OH}+\mathrm{O}_{2}
$$

The existence of $O\left({ }^{1} D\right)$ is extremely transitory, a balance between photolytic production,

$$
\mathrm{O}_{3}+h v \rightarrow \mathrm{O}_{2}+\mathrm{O}\left({ }^{1} D\right)
$$

and loss via quenching,

$$
\mathrm{O}\left({ }^{1} D\right)+\mathrm{O}_{2} \rightarrow \mathrm{O}+\mathrm{O}_{2}
$$

and

$$
\mathrm{O}\left({ }^{1} D\right)+\mathrm{N}_{2} \rightarrow \mathrm{O}+\mathrm{N}_{2}
$$

so that

$$
\left[O\left({ }^{1} D\right)\right]-\frac{J_{4}\left[O_{3}\right]}{k_{8}\left[O_{2}\right]+k_{9}\left[N_{2}\right]}
$$

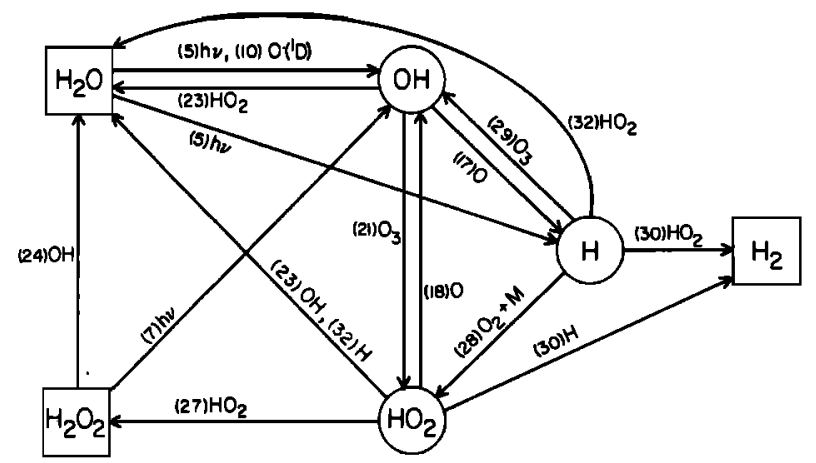

Fig. 6. Important reactions for recycling among active-hydrogen species and for conversion from active-hydrogen to inactivehydrogen and vice versa.

and $R 17$ with the result

$$
[\mathrm{OH}]-\frac{k_{18}[\mathrm{O}]\left[\mathrm{HO}_{2}\right]}{k_{17}[\mathrm{O}]}=\frac{k_{18}\left[\mathrm{HO}_{2}\right]}{k_{17}}
$$

Substituting (4) and (5) back into (3), one finds

$$
\frac{J_{4} k_{10}\left[\mathrm{H}_{2} \mathrm{O}\right]\left[\mathrm{O}_{3}\right]}{k_{8}\left[\mathrm{O}_{2}\right]+k_{9}\left[\mathrm{~N}_{2}\right]}-\frac{k_{17} k_{23}[\mathrm{OH}]^{2}}{k_{18}}
$$

Substituting an expression for $\mathrm{OH}$ derivable from (6) back into (2), we obtain an expression containing the concentrations only of active-O species and long-lived background atmosphere species,

$$
[\mathrm{O}]-\frac{J_{1}\left[\mathrm{O}_{2}\right]\left(k_{8}\left[\mathrm{O}_{2}\right]+k_{9}\left[\mathrm{~N}_{2}\right]\right)^{1 / 2} k_{23}^{1 / 2}}{\left(J_{4} k_{10} k_{17} k_{18}\left[\mathrm{H}_{2} \mathrm{O}\right]\left[\mathrm{O}_{3}\right]\right)^{1 / 2}}
$$

Upon eliminating the terms in (1) least important for daylight hours at $50 \mathrm{~km}$ (e.g., the nonphotolytic $\mathrm{O}_{3}$ loss channels) and the minor terms in (7), solving for $\mathrm{O}_{3}$ yields the result

$$
\begin{gathered}
{\left[\mathrm{O}_{3}\right]_{50} \approx} \\
\frac{J_{1}^{2 / 3}\left(k_{9} k_{23}\right)^{1 / 3}\left(k_{14}\left[\mathrm{O}_{2}\right]+k_{15}\left[\mathrm{~N}_{2}\right]\right)^{2 / 3}\left[\mathrm{~N}_{2}\right]^{1 / 3}\left[\mathrm{O}_{2}\right]^{4 / 3}}{\left(J_{3}+J_{4}\right)^{2 / 3}\left(J_{4} k_{10} k_{17} k_{18}\right)^{1 / 3}\left[\mathrm{H}_{2} \mathrm{O}\right]^{1 / 3}}
\end{gathered}
$$

Thus we have an expression for $\mathrm{O}_{3}$ in terms of long-lived atmospheric species and measurable physical parameters. The daytime variation of $\mathrm{O}_{3}$ is now explicitly related to the collective variation in the photolytic rate constants. It is interesting to note in Figure 3 that the mesosphere is a sink for stratospheric $\mathrm{O}_{3}$, but the upward transport of $\mathrm{O}_{3}$ across 


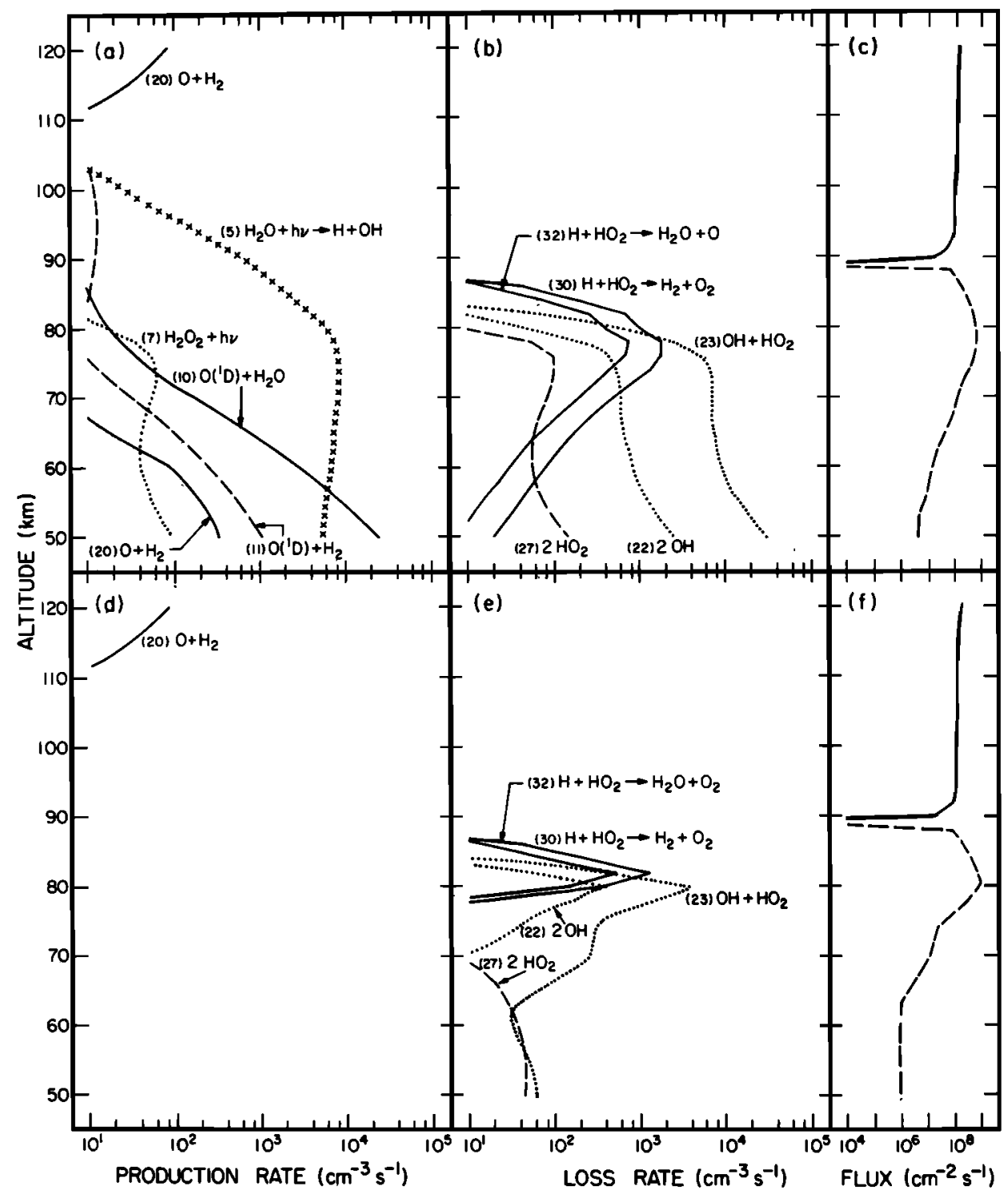

Fig. 7. Active-hydrogen chemistry. The rates of production and loss of active-H at noon, $(a)$ and $(b)$, respectively, and at midnight, $(d)$ and $(e)$. The vertical transport of active-H at $(c)$ noon and at $(f)$ midnight (upward flux: solid lines; downward flux: dashed lines).

the stratopause is small when compared with the magnitude of the local $\mathrm{O}_{3}$ production and loss terms.

The interrelated active- $\mathrm{O}$, active- $\mathrm{H}$, and $\mathrm{O}_{3}$ chemistries at 60 and $70 \mathrm{~km}$ are similar to that at $50 \mathrm{~km}$. However, in the upper mesosphere, active-H results mainly from direct photolysis of $\mathrm{H}_{2} \mathrm{O}$,

$$
\mathrm{H}_{2} \mathrm{O}+h v \rightarrow \mathrm{H}+\mathrm{OH}
$$

At $60 \mathrm{~km}$, both (R5) and (R10) are nearly equal in importance, so the expression for $\mathrm{O}_{3}$ cannot be expressed as simply as (8). At $70 \mathrm{~km}$, (R5) dominates, and, as a result, the daylight concentration of $\mathrm{O}_{3}$ is then

$$
\left[\mathrm{O}_{3}\right]_{70}=\frac{J_{1} k_{23}^{12}\left(k_{14}\left[\mathrm{O}_{2}\right]+k_{15}\left[\mathrm{~N}_{2}\right]\right)\left[\mathrm{O}_{2}\right]^{2}}{\left(J_{3}+J_{4}\right)\left(J_{5} k_{17} k_{18}\right)^{1 / 2}\left[\mathrm{H}_{2} \mathrm{O}\right]^{1 / 2}}
$$

Whereas below $60 \mathrm{~km} \mathrm{O}$ is the dominant daylight form of active- $O$, above $60 \mathrm{~km}$ atomic $O$ is the main active- $O$ species (Figure $1 b$ ). So, whereas (8) actually gives the total active- $O$ abundance at $50 \mathrm{~km}$, (9) reflects both the abundance of active-O at $70 \mathrm{~km}$ and the minor fraction of active-O, that is, $\mathrm{O}_{3}$.

During daylight hours at $80 \mathrm{~km},(\mathrm{R} 29)$ is now competitive with (R3) and (R4) as an $\mathrm{O}_{3}$ destruction channel:

$$
\left[\mathrm{O}_{3}\right]-\frac{[\mathrm{O}]\left[\mathrm{O}_{2}\right]\left(k_{14}\left[\mathrm{O}_{2}\right]+k_{15}\left[\mathrm{~N}_{2}\right]\right)}{J_{3}+J_{4}+k_{29}[\mathrm{H}]}
$$

Atomic $\mathrm{H}$ is in photochemical steady state; its density is a balance between production by (R17) and loss by

$$
\mathrm{H}+\mathrm{O}_{2}+\mathrm{M} \rightarrow \mathrm{HO}_{2}+\mathrm{M}
$$

such that

$$
[\mathrm{H}] \approx \frac{k_{17}[\mathrm{O}][\mathrm{OH}]}{k_{28}\left[\mathrm{O}_{2}\right][\mathrm{M}]}
$$


Loss of atomic $\mathrm{H}$ due to the reaction with $\mathrm{O}_{3}$ (reaction (R29)) is a factor of 2 less important than (R28). Photochemical steady state for active-O results in the expression

$$
\left(J_{1}+J_{2}\right)\left[\mathrm{O}_{2}\right] \approx k_{17}[\mathrm{O}][\mathrm{OH}]
$$

As atomic $\mathrm{H}$ is the dominant active- $\mathrm{H}$ species at the mesopause, the result of substituting for $\mathrm{OH}$ in (11) using (12) shows atomic $\mathrm{H}$ and, therefore, active- $\mathrm{H}$, being controlled by the production of active-O:

$$
[\mathrm{H}] \approx \frac{\left(J_{1}+J_{2}\right)}{k_{28}[\mathrm{M}]}
$$

The active- $\mathrm{O}$ concentration, in turn, is related to the abundance of active-H. Since active-H is roughly in photochemical steady state and its main loss pathway is now

$$
\mathrm{H}+\mathrm{HO}_{2} \rightarrow \mathrm{H}_{2}+\mathrm{O}_{2}
$$

we find that

$$
J_{5}\left[\mathrm{H}_{2} \mathrm{O}\right]-k_{30}[\mathrm{H}]\left[\mathrm{HO}_{2}\right]
$$

The production of $\mathrm{HO}_{2}$ (reaction (R28)) is balanced by its loss rates (predominantly due to (R18)), such that $\mathrm{HO}_{2}$ is in equilibrium with atomic $\mathrm{H}$,

$$
\left[\mathrm{HO}_{2}\right]=\frac{k_{28}[\mathrm{H}]\left[\mathrm{O}_{2}\right][\mathrm{M}]}{k_{18}[\mathrm{O}]}
$$

Substituting (13) and (15) into (14),

$$
\text { [O] }-\frac{\left(J_{1}+J_{2}\right)^{2} k_{30}\left[\mathrm{O}_{2}\right]}{J_{5} k_{18} k_{28}\left[\mathrm{H}_{2} \mathrm{O}\right][\mathrm{M}]}
$$

Given (13) and (16), (10) can now be rewritten to obtain the daylight $\mathrm{O}_{3}$ concentration at $80 \mathrm{~km}$,

$$
\begin{gathered}
{\left[\mathrm{O}_{3}\right]_{80} \approx} \\
\frac{\left(J_{1}+J_{2}\right)^{2} k_{30}\left(k_{14}\left[\mathrm{O}_{2}\right]+k_{15}\left[\mathrm{~N}_{2}\right]\right)\left[\mathrm{O}_{2}\right]^{2}}{J_{5} k_{18} k_{28}\left[\mathrm{H}_{2} \mathrm{O}\right][\mathrm{M}]\left[J_{3}+J_{4}+\frac{\mathrm{k}_{29}}{\mathrm{k}_{28}} \frac{\left(J_{1}+J_{2}\right)}{[\mathrm{M}]}\right)}
\end{gathered}
$$

As mentioned earlier, the mesopause is a transition region for ozone chemistry. Whereas below the mesopause, the $\mathrm{O}_{3}$ lifetime is very long during the night, at the mesopause the nighttime lifetime becomes less than 1 hour so that it is chemically active throughout the 24-hour diurnal cycle. However, both active- $\mathrm{O}$ and active- $\mathrm{H}$, although short-lived, are not in steady-state (loss far exceeds production), and, so a useful analytic expression for nighttime $\mathrm{O}_{3}$ at $80 \mathrm{~km}$ cannot be derived.

The chemistry of ozone is most simply understandable at 90 and $100 \mathrm{~km}$. The production and loss of $\mathrm{O}_{3}$ is in balance throughout the full diurnal cycle. The lifetime of atomic $O$ is -1 week at $90 \mathrm{~km}$ and 6 months at $100 \mathrm{~km}$ (Figure 2). Although the time scale for conversion of atomic $\mathrm{H}$ to some other form of active-H is short (Figure 5), atomic $\mathbf{H}$ is reformed as rapidly. Since the lifetime of active- $H$ is extremely long and the cycling within the active-H group results in atomic $\mathbf{H}$ being the dominant

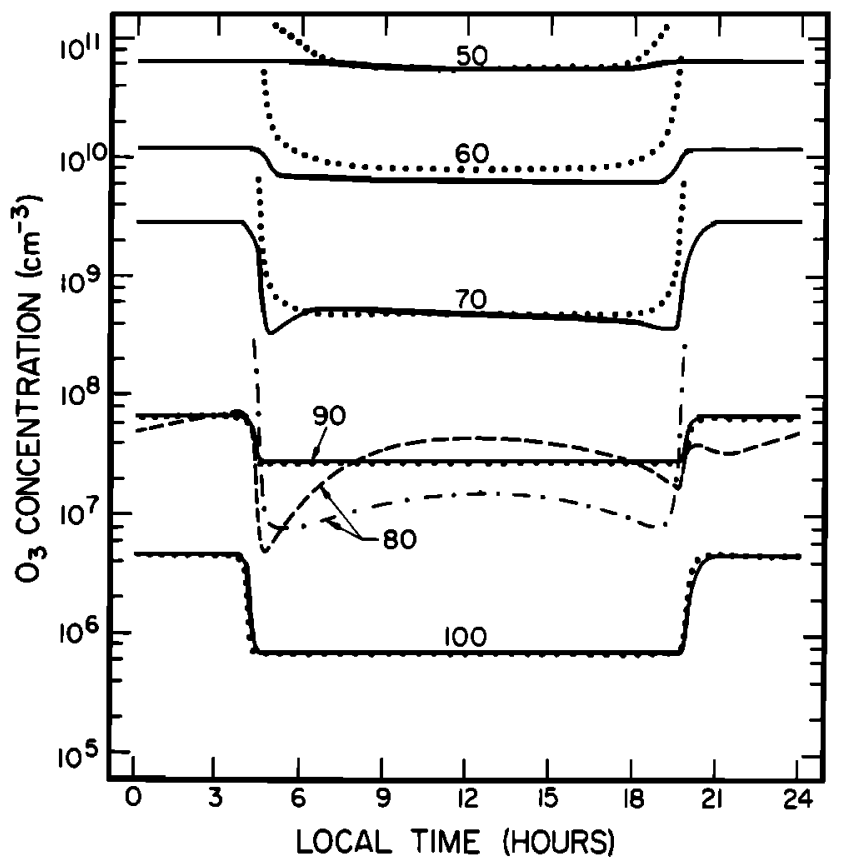

Fig. 8. The diurnal variation of ozone in the basic model of this paper. solar minimum flux, summer solstice sun at $38^{\circ} \mathrm{N}$ latitude, 7 ppmv of $\mathrm{H}_{2} \mathrm{O}$ at $\mathbf{4 0} \mathrm{km}$, eddy diffusion profile of Paper I, kinetic rate constants as tabulated in Table 1 , and temperature profile of Paper I increased by $20 \mathrm{~K}$. Results are shown for 50, 60, 70, 80, 90 , and $100 \mathrm{~km}$ altitudes (solid and dashed lines). Shown for the purposes of comparison are the diurnal profiles obtained with the analytical expressions of Table 2 (dotted and dashed-dot lines).

member throughout the diurnal cycle, the atomic $\mathrm{H}$ concentration remains constant over a 24-hour period. Therefore (1), as is, represents the diurnally varying $\mathrm{O}_{3}$ concentration, where production terms (R13)-(R15) and the chemical loss terms (R16) and (R29) are constant and the photolytic loss terms $J_{3}$ and $J_{4}$ exist only during daylight hours.

Diurnal calculations can be performed with the simple $\mathrm{O}_{3}$ expressions just derived and compared with the results of a detailed calculation solving the continuity equations to test the analytical formulae. Such a comparison is shown in Figure 8; the rate constants and abundances of long-lived species are the same in both calculations. The simplified calculations for nighttime are shown only above $80 \mathrm{~km}$, in which altitude range there are nonsingular values for the $\mathrm{O}_{3}$ densities. It is clear from Figure 8 that the $\mathrm{O}_{3}$ concentrations above $80 \mathrm{~km}$ throughout the full diurnal period can be reproduced by the analytical expression (1) very accurately. Below $80 \mathrm{~km}$, where $\mathrm{O}_{3}$ is long-lived at night, the assumption of steady state for $\mathrm{O}_{3}$ and active-O and/or active-H fails near sunrise and sunset, explaining the significant differences between the two calculations at those local times. The daytime $\mathrm{O}_{3}$ densities are accurately computed in the simple calculations for most of the daylight period at 50 and $70 \mathrm{~km}$. At $60 \mathrm{~km}$, the analytical expression employed was simply an average of the equations for 50 and $70 \mathrm{~km}$, leading to an error of $33 \%$ for most of the daylight period. Of the derivations of simple $\mathrm{O}_{3}$ expressions presented in this paper, the one most in error is for $80 \mathrm{~km}$ because of the assumption that active- $\mathrm{H}$ is in photochemical steady state. In reality, active-H is fairly long-lived during the daylight period (Figure 5), and its production and 
TABLE 2. Ozone Concentration Under Conditions of Photochemical Equilibrium

$\frac{\text { Equations }}{50 \mathrm{~km} \text { (daylight hours) } \quad\left[\mathrm{O}_{3}\right] \approx \frac{J_{1}^{2 / 3}\left(k_{9} k_{23}\right)^{1 / 3}\left(k_{14}\left[\mathrm{O}_{2}\right]+k_{15}\left[\mathrm{~N}_{2}\right]\right)^{2 / 3}\left[\mathrm{~N}_{2}\right]^{1 / 3}\left[\mathrm{O}_{2}\right]^{4 / 3}}{\left(J_{3}+J_{4}\right)^{2 / 3}\left(J_{4} k_{10} k_{17} k_{18}\right)^{1 / 3}\left[\mathrm{H}_{2} \mathrm{O}\right]^{1 / 3}}}$

$60 \mathrm{~km}$ (daylight hours)*

70 km (daylight hours)

$$
\left[\mathrm{O}_{3}\right] \approx \frac{J_{1} k_{23}^{1 / 2}\left(k_{14}\left[\mathrm{O}_{2}\right]+k_{15}\left[\mathrm{~N}_{2}\right]\right)\left[\mathrm{O}_{2}\right]^{2}}{\left(J_{3}+J_{4}\right)\left(J_{5} k_{17} k_{18}\right)^{1 / 2}\left[\mathrm{H}_{2} \mathrm{O}\right]^{1 / 2}}
$$

$80 \mathrm{~km}$ (daylight hours)

$$
\left[\mathrm{O}_{3}\right] \approx \frac{\left(J_{1}+J_{2}\right)^{2} k_{30}\left[\mathrm{O}_{2}\right]^{2}\left(k_{14}\left[\mathrm{O}_{2}\right]+k_{15}\left[\mathrm{~N}_{2}\right]\right)}{J_{5} k_{18} k_{28}[\mathrm{M}]\left[\mathrm{H}_{2} \mathrm{O}\right]\left(J_{3}+J_{4}+\frac{k_{29}\left(J_{1}+J_{2}\right)}{k_{28}[\mathrm{M}]}\right)}
$$

above $90 \mathrm{~km}$

$$
\left[\mathrm{O}_{3}\right]=\frac{[\mathrm{O}]\left[\mathrm{O}_{2}\right]\left(k_{13}[\mathrm{O}]+k_{14}\left[\mathrm{O}_{2}\right]+k_{15}\left[\mathrm{~N}_{2}\right]\right)}{J_{3}+J_{4}+k_{29}[\mathrm{H}]+k_{16}[\mathrm{O}]}
$$

$J_{\mathrm{n}}$ and $k_{\mathrm{n}}$ are photolytic and kinetic rate constants, respectively, and $n$ refers to the reaction index in Table 1 .

Expression intermediate between that for $50 \mathrm{~km}$ and that for $70 \mathrm{~km}$.

loss terms are not in balance (Figure 7). This leads to a difference between the simple analytical and detailed computations of as much as a factor of three at noon. Figure 8 shows that the analytical expressions for $\mathrm{O}_{3}$ reproduce the trends of the detailed computer model in general. At certain altitudes for particular local times, the values for $\mathrm{O}_{3}$ from the simple expressions are in such good agreement with the results of the detailed computations that these expressions can be used in other types of aeronomic models where the presence of $\mathrm{O}_{3}$ is important to the processes being considered, but a full treatment of the $\mathrm{O}_{3}$ chemistry is awkward.

\section{Numerical Sensitivity Analyses}

The simple analytical expressions we have derived for $\mathrm{O}_{3}$ densities are summarized in Table 2 . With these equations, we can calculate the sensitivity of the $\mathrm{O}_{3}$ distribution to changes in any of the input physical or atmospheric parameters. This also can be done numerically by performing a series of computer model calculations, which also tests the validity of these simple expressions. For this purpose, a sequence of steady state computer calculations with a diurnally averaged radiation field were executed, in each case one of the photolytic or kinetic rate constants being doubled. The changes in the model $\mathrm{O}_{3}$ values relative to the results of the basic model of Table 1 are presented in Table 3. The diurnally averaged steady state calculation is very similar to a late afternoon steady state calculation, which in turn yields results very close to late afternoon results of a diurnal calculation since $\mathrm{O}_{3}$ and the other key short-lived species are almost in near-instantaneous steady state during daylight hours at all altitudes.

A comparison of Table 2 and 3 reveals that almost all parameters which, when doubled, would change the $\mathrm{O}_{3}$ concentration by more than $10 \%$ are accounted for in the simple analytical expressions at the appropriate altitudes. However, Table 3 shows $\mathrm{O}_{3}$ to be fairly sensitive to certain reactions not appearing in Table 2 as a result of the nature of the steady state diurnally averaged calculations used to generate Table 3 . On the longer time scales of these computa- tions, species with chemical lifetimes greater than a day will be affected, which in turn influences the $\mathrm{O}_{3}$ distribution. On the other hand, these reactions are unimportant in terms of the details of diumal changes, the basis on which Table 2 was derived. For example, as discussed in Paper I, the atomic $O$ thermospheric distribution is a balance between photolytic production (reactions (R1) and (R2)) and downward transport. The photolytic reaction (R6) converting $\mathrm{H}_{2} \mathrm{O}$ to $\mathrm{H}_{2}$ indirectly affects $\mathrm{O}_{3}$ at $80 \mathrm{~km}$ and above because of its impact on the vertical distribution of long-lived, but not inert, $\mathrm{H}_{2} \mathrm{O}$. The photolytic reaction (R5) is the main source of active- $\mathrm{H}$ in the thermosphere, which in turn is important for controlling the $\mathrm{O}_{3}$ distribution. The reaction between atomic $\mathrm{O}$ and $\mathrm{O}_{3}$ (reaction (R16)) is indicated in Table 3 to be important at $50 \mathrm{~km}$ but has not been accounted for in the above equations. This is because $\mathrm{R} 16$ is less important than $\mathrm{O}+\mathrm{OH}$ (reaction (R17)) as a loss mechanism for active- $O$ in the basic model of Table 1 but is the primary loss channel if (R16) is doubled. Then the analytical expression for $\mathrm{O}_{3}$ at $50 \mathrm{~km}$ during daylight hours (8) would be instead

$$
\left[\mathrm{O}_{3}\right]_{50}-\frac{J_{l}^{1 / 2}\left(k_{14}\left[\mathrm{O}_{2}\right]+k_{15}\left[\mathrm{~N}_{2}\right]\right)^{1 / 2}\left[\mathrm{O}_{2}\right]}{\left(J_{3}+J_{4}\right)^{1 / 2} k_{16}^{1 / 2}}
$$

the importance of (R16) now being clear. The sensitivity of $\mathrm{O}_{3}$ at $80 \mathrm{~km}$ to $(\mathrm{R} 23)$ as seen in Table 3 shows that (R23) still is an important active-H loss process although Table 3 also indicates that (R30) is even more important, as was assumed in deriving the analytical expression at $80 \mathrm{~km}$.

\section{Model Calculations of Diurnal Variability}

Given the validity of the simple expressions in Table 2 for representing the key processes affecting $\mathrm{O}_{3}$, we can now use these equations to understand the detailed diurnal profiles of $\mathrm{O}_{3}$ generated by the computer calculations. The diumal variation of $\mathrm{O}_{3}$ resulting from a diumal calculation run with the Table 1 parameters is shown in Figure 8 and the analogous results for $\mathrm{O}, \mathrm{H}, \mathrm{OH}$, and $\mathrm{HO}_{2}$ in Figure 9. Similar calculations covering some or all of our altitude 
TABLE 3. Model Ozone Variation Resulting From Input Parameter Change

\begin{tabular}{|c|c|c|c|c|c|c|}
\hline \multirow[b]{2}{*}{ Perturbation } & \multicolumn{6}{|c|}{ Altitude, $\mathbf{k m}$} \\
\hline & 50 & 60 & 70 & 80 & 90 & 100 \\
\hline \multicolumn{7}{|l|}{ Doubling the rate constant } \\
\hline & $+58 \%$ & $+55 \%$ & $+71 \%$ & $+82 \%$ & $+21 \%$ & $+9 \%$ \\
\hline $\begin{array}{l}\text { (R2) } \mathrm{O}_{2}+h \nu \rightarrow \mathrm{O}+\mathrm{O}\left({ }^{1} D\right) \\
(\mathrm{R} 3) \mathrm{O}_{3}+h \nu \rightarrow \mathrm{O}_{2}+\mathrm{O}\end{array}$ & $-8 \%$ & $-8 \overline{\%}$ & $\begin{array}{r}+2 \% \\
-10 \%\end{array}$ & $\begin{array}{r}+34 \% \\
-4 \%\end{array}$ & $\begin{array}{r}+50 \% \\
-5 \%\end{array}$ & $+41 \%$ \\
\hline (R4) $\mathrm{O}_{3}+h v \rightarrow \mathrm{O}_{2}+\mathrm{O}\left({ }^{1} D\right)$ & $-40 \%$ & $-42 \%$ & $-42 \%$ & $\begin{array}{r}-4 \% \\
-21 \%\end{array}$ & & $\begin{array}{r}-9 \% \\
-41 \%\end{array}$ \\
\hline (R5) $\mathrm{H}_{2} \mathrm{O}+h \nu \rightarrow \mathrm{H}+\mathrm{OH}$ & $-2 \%$ & $-9 \%$ & $-24 \%$ & $-41 \%$ & $-19 \%$ & $-4 \%$ \\
\hline (R6) $\mathrm{H}_{2} \mathrm{O}+h \nu \rightarrow \mathrm{H}_{2}+\mathrm{O}\left({ }^{1} D\right)$ & -- & $+1 \%$ & $+4 \%$ & $+36 \%$ & $+24 \%$ & $+5 \%$ \\
\hline (R7) $\mathrm{H}_{2} \mathrm{O}_{2}+h \nu \rightarrow 2 \mathrm{OH}$ & -- & -- & -- & -- & --- & -. \\
\hline (R8) $\mathrm{O}\left({ }^{1} D\right)+\mathrm{O}_{2} \rightarrow \mathrm{O}+\mathrm{O}_{2}$ & $+3 \%$ & $+4 \%$ & $+1 \%$ & $+1 \%$ & $+1 \%$ & -- \\
\hline (R9) $\mathrm{O}\left({ }^{1} D\right)+\mathrm{N}_{2} \rightarrow \mathrm{O}+\mathrm{N}_{2}$ & $+9 \%$ & $+8 \%$ & $+2 \%$ & $+2 \%$ & $+1 \%$ & - \\
\hline$(\mathrm{R} 10) \mathrm{O}\left({ }^{1} D\right)+\mathrm{H}_{2} \mathrm{O} \rightarrow 2 \mathrm{OH}$ & $-10 \%$ & $-11 \%$ & $-3 \%$ & $-1 \%$ & $-1 \%$ & -.- \\
\hline (R11) $\mathrm{O}\left({ }^{1} D\right)+\mathrm{H}_{2} \rightarrow \mathrm{H}+\mathrm{OH}$ & - & $-1 \%$ & $-1 \%$ & $-2 \%$ & $-1 \%$ & $-1 \%$ \\
\hline $\begin{array}{l}\text { (R12) } 2 \mathrm{O}+\mathrm{M} \rightarrow \mathrm{O}_{2}+\mathrm{M} \\
\text { (R13) } \mathrm{O}+\mathrm{O}_{2}+\mathrm{O} \rightarrow \mathrm{O}_{3}+\mathrm{O}\end{array}$ & - & -- & -- & $-3 \%$ & $-10 \%$ & $-5 \%$ \\
\hline \multicolumn{7}{|l|}{$\left.\begin{array}{l}\text { (R14) } \mathrm{O}+\mathrm{O}_{2}+\mathrm{O}_{2} \rightarrow \mathrm{O}_{3}+\mathrm{O}_{2} \\
(\mathrm{R} 15) \mathrm{O}+\mathrm{O}_{2}+\mathrm{N}_{2} \rightarrow \mathrm{O}_{3}+\mathrm{N}_{2}\end{array}\right\}$} \\
\hline (R16) $\mathrm{O}+\mathrm{O}_{3} \rightarrow 2 \mathrm{O}_{2}$ & $-23 \%$ & $-9 \%$ & $\cdots$ & $+1 \%$ & --- & $-5 \%$ \\
\hline (R17) $\mathrm{O}+\mathrm{OH} \rightarrow \mathrm{O}_{2}+\mathrm{H}$ & $-11 \%$ & $-19 \%$ & $-25 \%$ & $-9 \%$ & $+2 \%$ & --- \\
\hline (R18) $\mathrm{O}+\mathrm{HO}_{2} \rightarrow \mathrm{OH}+\mathrm{O}_{2}$ & $-10 \%$ & $-17 \%$ & $-25 \%$ & $-35 \%$ & $-4 \%$ & $-1 \%$ \\
\hline (R19) $\mathrm{O}+\mathrm{H}_{2} \mathrm{O}_{2} \rightarrow \mathrm{OH}+\mathrm{HO}_{2}$ & - & - & - & -- & -- & $\cdots$ \\
\hline$(\mathrm{R} 20) \mathrm{O}+\mathrm{H}_{2} \rightarrow \mathrm{OH}+\mathrm{H}$ & - & - & -- & -- & - & --- \\
\hline (R21) $\mathrm{OH}+\mathrm{O}_{3} \rightarrow \mathrm{HO}_{2}+\mathrm{O}_{2}$ & -- & - & -- & - & -- & -- \\
\hline (R22) $2 \mathrm{OH} \rightarrow \mathrm{H}_{2} \mathrm{O}+\mathrm{O}$ & $+1 \%$ & $+2 \%$ & $+3 \%$ & $+2 \%$ & -- & -- \\
\hline (R23) $\mathrm{OH}+\mathrm{HO}_{2} \rightarrow \mathrm{H}_{2} \mathrm{O}+\mathrm{O}_{2}$ & $+9 \%$ & $+19 \%$ & $+30 \%$ & $+16 \%$ & --- & - \\
\hline (R24) $\mathrm{OH}+\mathrm{H}_{2} \mathrm{O}_{2} \rightarrow \mathrm{H}_{2} \mathrm{O}+\mathrm{HO}_{2}$ & -- & $\cdots$ & -- & -- & $\bar{n}$ & -- \\
\hline$(\mathrm{R} 25) \mathrm{OH}+\mathrm{H}_{2} \rightarrow \mathrm{H}_{2} \mathrm{O}+\mathrm{H}$ & $\cdots$ & - & --- & $-2 \%$ & $-1 \%$ & -- \\
\hline (R26) $\mathrm{HO}_{2}+\mathrm{O}_{3} \rightarrow \mathrm{OH}+2 \mathrm{O}_{2}$ & -- & --- & --- & -- & -- & -- \\
\hline (R27) $2 \mathrm{HO}_{2} \rightarrow \mathrm{H}_{2} \mathrm{O}_{2}+\mathrm{O}_{2}$ & -- & --- & -- & -- & $\cdots$ & -- \\
\hline (R28) $\mathrm{H}+\mathrm{O}_{2}+\mathrm{M} \rightarrow \mathrm{HO}_{2}+\mathrm{M}$ & $+2 \%$ & $+5 \%$ & $+8 \%$ & $-11 \%$ & $+3 \%$ & $+1 \%$ \\
\hline (R29) $\mathrm{H}+\mathrm{O}_{3} \rightarrow \mathrm{OH}+\mathrm{O}_{2}$ & $-4 \%$ & $-8 \%$ & $-12 \%$ & $-36 \%$ & $-37 \%$ & $-14 \%$ \\
\hline (R30) $\mathrm{H}+\mathrm{HO}_{2} \rightarrow \mathrm{H}_{2}+\mathrm{O}_{2}$ & -- & -- & $+3 \%$ & $+32 \%$ & $+5 \%$ & $+1 \%$ \\
\hline (R31) $\mathrm{H}+\mathrm{HO}_{2} \rightarrow 2 \mathrm{OH}$ & -- & -- & - & $-1 \%$ & -- & - \\
\hline (R32) $\mathrm{H}+\mathrm{HO}_{2} \rightarrow \mathrm{H}_{2} \mathrm{O}+\mathrm{O}$ & -- & --- & $+1 \%$ & $+10 \%$ & $+1 \%$ & -- \\
\hline (R33) $2 \mathrm{H}+\mathrm{M} \rightarrow \mathrm{H}_{2}+\mathrm{M}$ & -- & --- & - & -- & --- & $\cdots$ \\
\hline (R35) $\mathrm{CH}_{4}+\mathrm{OH} \rightarrow \mathrm{CO}+\mathrm{OH}+2 \mathrm{H}_{2} \mathrm{O}$ & -- & -- & -- & --- & $\cdots$ & -- \\
\hline (R36) $\mathrm{CH}_{4}+\mathrm{O} \rightarrow \mathrm{CO}+2 \mathrm{OH}+\mathrm{H}_{2} \mathrm{O}$ & - & -- & $\cdots$ & -- & --- & -- \\
\hline $\begin{array}{l}\text { (R37) } \mathrm{CH}_{4}+\mathrm{O}\left({ }^{1} \mathrm{D}\right) \rightarrow \mathrm{CO}+2 \mathrm{OH}+\mathrm{H}_{2} \mathrm{O} \\
\text { Change in solar flux from solar minimum }\end{array}$ & - & -- & -- & --- & -- & -- \\
\hline $\begin{array}{l}\text { Change in solar flux from solar minimum } \\
\text { to solar maximum }{ }^{b}\end{array}$ & --- & --- & -- & $+10 \%$ & $+29 \%$ & $+29 \%$ \\
\hline Change in solar illumination from summer solstice & & & & & & \\
\hline to winter solstice & $+11 \%$ & $+10 \%$ & $+33 \%$ & $-13 \%$ & $-33 \%$ & $-20 \%$ \\
\hline \multicolumn{7}{|l|}{ Reduction of $\mathrm{H}_{2} \mathrm{O}$ boundary condition at $40 \mathrm{~km}$} \\
\hline $\begin{array}{l}\text { from } 7 \mathrm{ppm} \text { to } 5 \mathrm{ppm} \\
\text { Temperature profile reduced by } 20 \mathrm{~K}\end{array}$ & $+5 \%$ & $+8 \%$ & $+13 \%$ & $+39 \%$ & $+17 \%$ & $+4 \%$ \\
\hline Temperature profile reduced by $20 \mathrm{~K}$ & $+34 \%$ & $+22 \%$ & $+26 \%$ & $+22 \%$ & $+40 \%$ & $+36 \%$ \\
\hline
\end{tabular}

Steady state computations performed with diurnally averaged solar insolation. The basic model described in the text is the point of reference.

${ }^{a}$ Less than $\pm 1 \%$.

${ }^{b}$ Solar minimum spectrum from Rottman [1981] and solar maximum spectrum from Mount and Rottman [1981].

range have been performed most recently by Logan et al. [1978], Keneshea et al. [1979], Rusch and Liu [1981], Prather [1981], and Wang et al. [1981]. The day-to-night variation and diurnal structure reported by the first four references is comparable to what is shown in Figure 8. Logan et al. [1978], Keneshea et al. [1979], and Rusch and Liu [1981] also display diurnal profiles for the other active$\mathrm{O}$ and $-\mathrm{H}$ species; the results are similar to our Figure 9. The diurnal variation of $\mathrm{OH}$ calculated by Herman [1979] is also qualitatively similar to our calculations. However, not in agreement with our results and the results of the other references is the $\mathrm{O}_{3}$ diurnal variability in the mesosphere of Wang et al. [1981], which is an order of magnitude larger, but not enough information is given in that paper to identify possible causes of the differences. To aid in analyzing the $\mathrm{O}_{3}$ diurnal profiles (Figure 8) in light of the simple analytical expressions derived earlier (Table 2), we show in Figure 10 the diurnal variation of the key photolytic rate constants.

Throughout the night at $50 \mathrm{~km}$, the $\mathrm{O}_{3}$ density remains unchanged (Figure 8) because the chemical loss time scale for $\mathrm{O}_{3}$ at night is much longer than 1 day (Figure 2) due to the disappearance of the photolytic loss term and of atomic $O$ and $H$ (Figure 9). The transport time scale is also too long to result in any nighttime variation in $\mathrm{O}_{3}$. During the daytime, the lifetime of atomic $O$ relative to recombination to form $\mathrm{O}_{3}$ is shorter than the $\mathrm{O}_{3}$ dissociation lifetime so that as soon as $\mathrm{O}_{3}$ is photodissociated the atomic $\mathrm{O}$ formed recombines to form $\mathrm{O}_{3}$. Therefore, the $\mathrm{O} / \mathrm{O}_{3}$ ratio remains relatively constant throughout the day. Moreover, active- $O$ is destroyed almost as rapidly as it is produced so that there is little net change in the active- $\mathrm{O}$ abundance throughout the diurnal cycle, the photolytic source of active- $O$ and indirect photolytic source of active-H maintaining a balance 


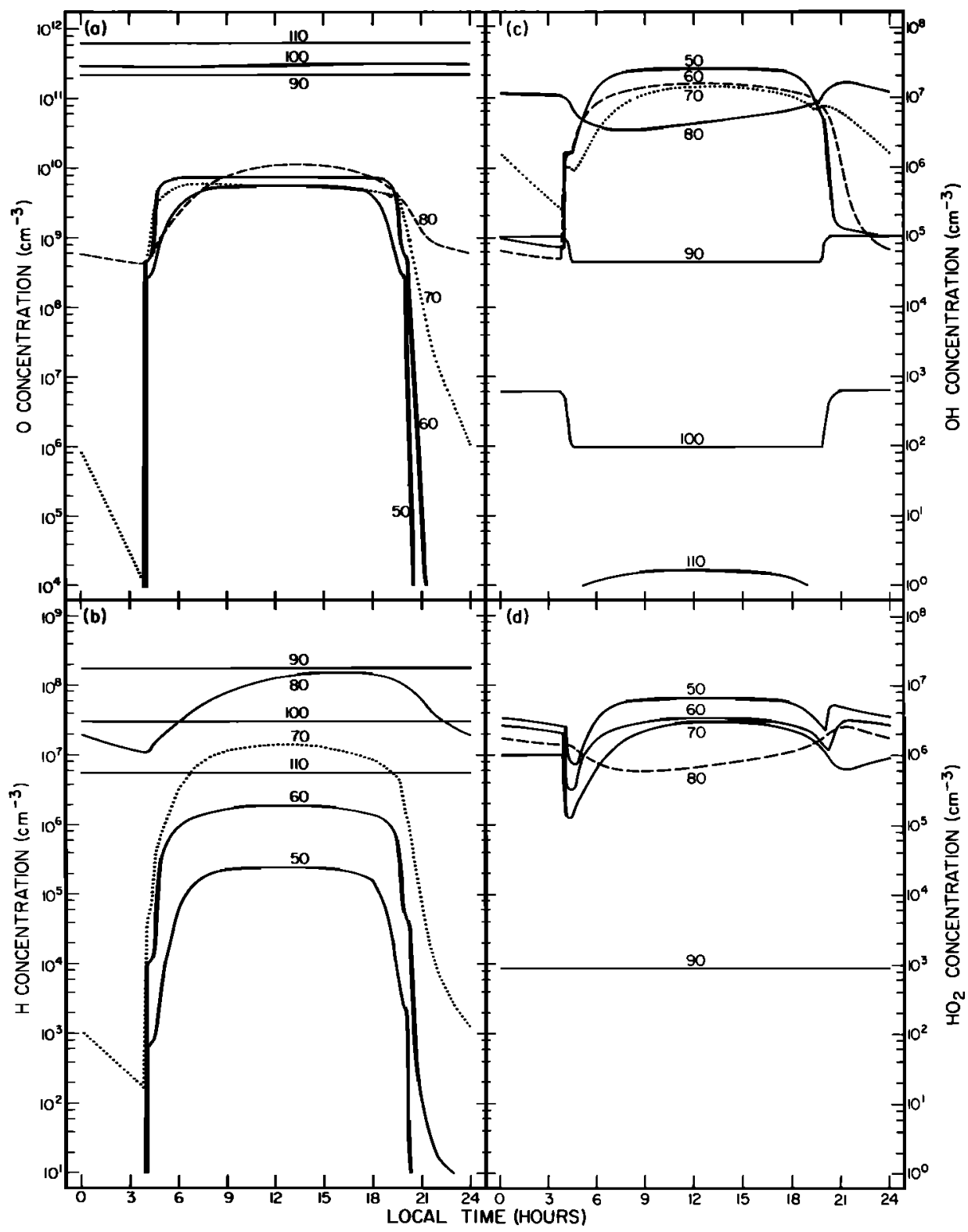

Fig. 9. The diurnal variability of $(a)$ atomic $\mathrm{O},(b)$ atomic $\mathrm{H},(c) \mathrm{OH}$, and $(d) \mathrm{HO}_{2}$ in the basic model for altitudes 50 , $60,70,80,90,100$, and $110 \mathrm{~km}$.

with changing solar zenith angle. The key photolytic rate constants vary in a similar manner throughout the daylight period so that $J_{1}^{2 / 3} /\left(J_{3}+J_{4}\right)^{2 / 3} J_{4}^{1 / 3}$ (see Table 2) changes very little. The day/night variation in $\mathrm{O}_{3}$ at $50 \mathrm{~km}$ is very small, the difference that does occur reflecting a small decrease in the active- $O$ abundance from night to day resulting from excess active- $O$ loss in the morning that is offset by excess active- $O$ production in late afternoon.

At $60 \mathrm{~km}$, the relatively constant $\mathrm{O}_{3}$ concentration at night has the same explanation as for $50 \mathrm{~km}$. A moderate decrease in the $\mathrm{O}_{3}$ density at sunrise and increase at sunset is due to the near instantaneous change in $\mathrm{O}_{3}$ photodissociation $\left(J_{3}+J_{4}\right)$ (the atmosphere having become optically thin in the key wavelength range) without a compensating variation in active-O photolytic production. A new equilibrium between $\mathrm{O}$ and $\mathrm{O}_{3}$ is established which remains in balance $\left(J_{3}+J_{4}\right.$ remaining constant) throughout the day- light hours. Also remaining in balance during the daylight period is the production and loss of active- $O$, driven directly or indirectly by photolysis. The near constancy of the active- $O$ abundance is a result of the ratio $J_{1} / J_{3}^{1 / 2}$ remaining constant with changing solar zenith angle. The daytime near balance between active-O production and loss means that active- $O$ does not vary much throughout the full diurnal cycle, although in fact there is a small increase in the active- $O$ abundance from night to day. Thus, the day-tonight difference in $\mathrm{O}_{3}$ is primarily a result of the changing atomic $\mathrm{O} / \mathrm{O}_{3}$ ratio.

At $70 \mathrm{~km}$, the constant nighttime $\mathrm{O}_{3}$ density and the sharp transitions at sunrise and sunset have the same explanation as at $60 \mathrm{~km}$. However, at $70 \mathrm{~km}$, the photolytic source of active-O increases more rapidly than the photolytic source of active-H, resulting in an early rise in the active-O abundance leveling off toward midday as a balance 

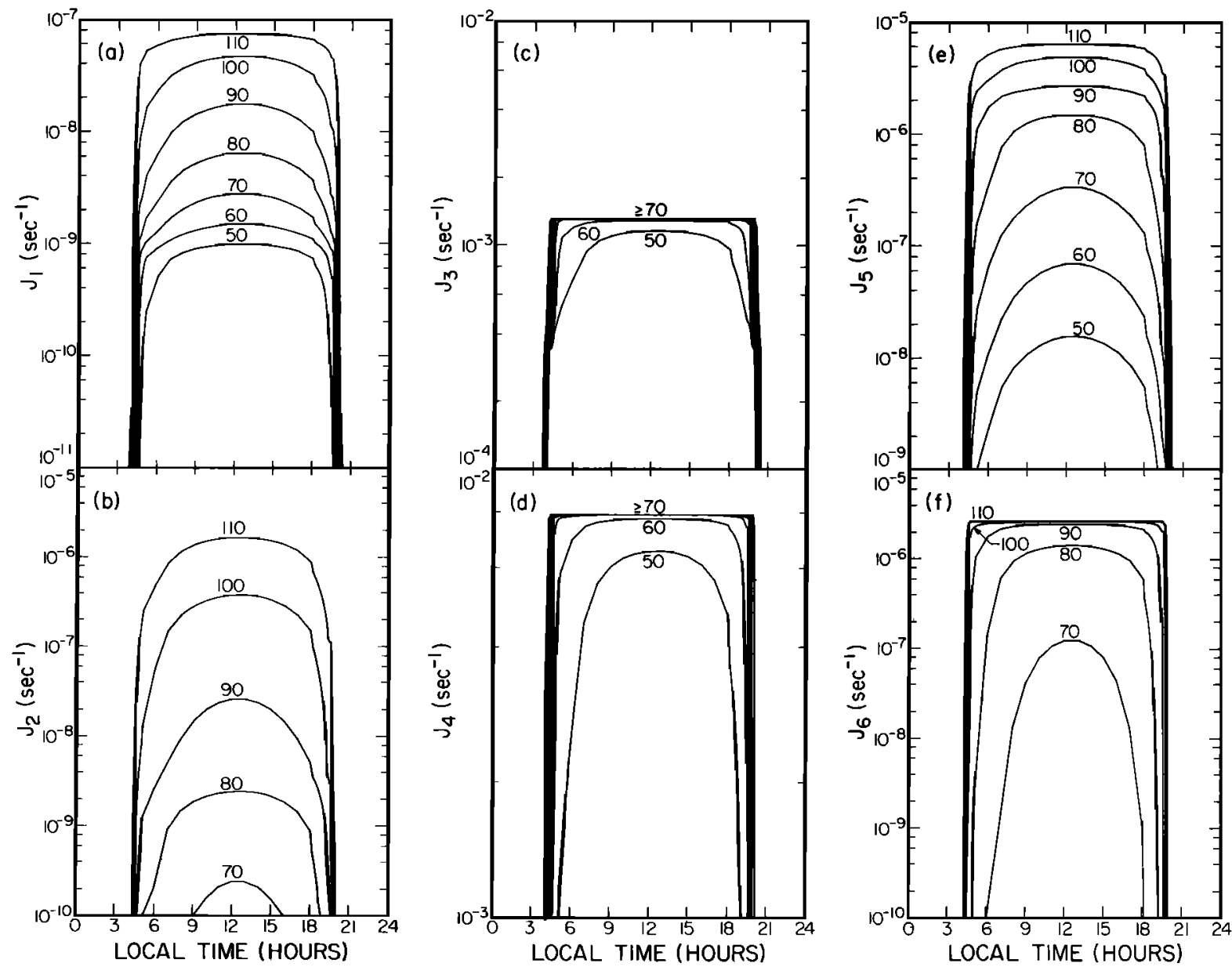

Fig. 10. The diurnal variation of the photodissociation rate constants $(a) J_{1},(b) J_{2},(c) J_{3},(d) J_{4},(e) J_{5}$, and $(f) J_{6}$ for the illumination conditions appropriate for the basic model. Results shown for 50,60, 70, 80, 90, 100, and $110 \mathrm{~km}$ altitude.

with active-H catalyzed active-O loss is established, keeping the $\mathrm{O}_{3}$ profile nearly constant throughout the remaining daylight hours. The fundamental cause of the daylight variation is the fact that the crucial wavelength range for $\mathrm{O}_{2}$ photodissociation is optically thinner at $70 \mathrm{~km}$ than the wavelength range for $\mathrm{H}_{2} \mathrm{O}$ photodissociation. Thus, at 70 $\mathrm{km}$, there is an appreciable night-to-day increase in active$O$, but the daytime photolytic redistribution between atomic $\mathrm{O}$ and $\mathrm{O}_{3}$ results in the calculated night-to-day decrease in $\mathrm{O}_{3}$.

The complex nature of the $\mathrm{O}_{3}$ chemical cycle at the mesopause is reflected in a most unusual diurnal profile for $\mathrm{O}_{3}$ at $80 \mathrm{~km}$. Somewhat similar structure is seen in the calculations of Keneshea et al. [1979], Prather [1981], and Wang et al. [1981]. The sharp changes at sunrise and sunset are due to the instantaneous appearance and disappearance of $\mathrm{O}_{3}$ photodissociation, $J_{3}$ and $J_{4}$. The analytical expression for $\mathrm{O}_{3}$ at $80 \mathrm{~km}$ (equation (17)) shows that changes in the production of active-O with the varying sun angle are amplified relative to the changes in active- $\mathrm{H}$ catalytic destruction. If active- $O$ were truly in photochemical steady state throughout the daylight period, the diurnal variation of $\left(J_{1}+J_{2}\right)^{2} / J_{5}$ would lead to a daylight $\mathrm{O}_{3}$ variation similar to what is shown in Figure 8. However, the morning net increase in active-O, resulting in both increasing $\mathrm{O}_{3}$
(Figure 8) and atomic $O$ (Figure 9), is accentuated by the reality that the production of active-O is somewhat larger than its rate of loss. By noon, production and loss of active- $\mathrm{O}$ are in balance. In the afternoon, production of active- $O$ declines, and, owing to the longer lifetime of active-H, active-H is still increasing somewhat, resulting in active- $O$ destruction exceeding its production. At sunset there is a brief increase in $\mathrm{O}_{3}$ with the elimination of photodissociative loss, but then the abundance declines due to the continuing chemical loss of active-O. As the rate of active$O$ loss is proportional to the abundance of active-O, the decrease slows as active- $O$ and active- $H$ are depleted. Moreover, the flow of active-O from higher altitudes becomes comparable to the rate of chemical loss (Figure $4 f$ ). Thus, the abundance of active- $O$ becomes relatively constant after midnight. During the nighttime period, some atomic-O recombines to form $\mathrm{O}_{3}$ such that the percentage of active-O in the form of $\mathrm{O}_{3}$ steadily increases. As a result, the decrease in active- $O$ is more than offset and the $\mathrm{O}_{3}$ abundance starts increasing near midnight.

Above $85 \mathrm{~km}$, the chemical lifetimes of atomic $\mathrm{O}$ and $\mathrm{H}$ are longer than 1 day, so their abundances are constant over the diurnal cycle. Therefore, the active-O abundance and the production and chemical loss terms for $\mathrm{O}_{3}$ are constant throughout the diurnal cycle, while the photolytic par- 
titioning between atomic $\mathrm{O}$ and $\mathrm{O}_{3}$ (reactions (R3) and (R4)) appears and disappears sharply at sunrise and sunset. This then produces a constant nighttime and lower constant daytime profile for $\mathrm{O}_{3}$ in the lower thermosphere.

\section{VERTICAL DISTRIBUTION OF $\mathrm{O}_{3}$}

\section{Aladdin 74 Ozone Observations}

One of the most detailed observational data sets covering the distribution of ozone in the mesosphere and lower thermosphere resulted from the Aladdin 74 rocket program [Weeks et al., 1978]. Much of the altitude range between 50 and $110 \mathrm{~km}$ was monitored nearly simultaneously by more than one experimental technique. In Paper I, measurements of the major constituents of the atmosphere obtained with a mass spectrometer on one of the Aladdin 74 flights [Trinks et al., 1978; Trinks and Fricke, 1978; H. Trinks, private communication, 1979] allowed a determination of the eddy diffusion profile above $90 \mathrm{~km}$ appropriate for the time of the Aladdin 74 program and gave some sense of eddy diffusion and mesospheric water content below that altitude. These data in conjunction with Millstone Hill incoherent scatter radar results (W. Oliver, private communication, 1980) also allowed a good estimate of the temperature profile in the lower thermosphere. Thus more information about general background atmosphere conditions is available for the epoch of the Aladdin 74 ozone measurements than is generally available for other $\mathrm{O}_{3}$ data sets. For these reasons, the Aladdin $74 \mathrm{O}_{3}$ data seemed to present a nearly ideal case for testing in detail model results for the $\mathrm{O}_{3}$ distribution. Preliminary work in this regard suggested that the $\mathrm{O}_{3}$ concentration at the mesopause is reflective of certain aspects of the background atmosphere and of the validity of kinetic rate constants used in the model. These results briefly quoted in Paper I will be discussed more fully in the current paper.

Four different rocket-borne procedures for measuring high altitude ozone were flown on June 29 and 30, 1974, during rocket flights originating from Wallops Island, Virginia ( $38^{\circ} \mathrm{N}$ latitude). The chemiluminescent sondes, ultraviolet absorption and airglow photometers, and mass spectrometer had different operational altitude ranges, but the overlap of the varying altitude coverages allowed $\mathrm{O}_{3}$ concentrations to be measured by more than one technique at most levels in the mesosphere and lower thermosphere. The intercomparisons allowed an assessment to be made of the systematic differences between the various measurement techniques.

The rocket flights that carried aloft the various instruments occurred during a late afternoon period and a period after dawn. An ozone vertical profile is shown in Figure 11, which is a composite of the Aladdin 74 results. The range of uncertainty in the value at each altitude reflects (1) the sum of the spread between the results of equally precise methods (as judged from the relative magnitudes of the published error analyses) and the error bars of the measurement being combined or (2) the errors of a lone measurement (where only one was available or where one technique was significantly more precise than the other available at the particular altitude). The $\mathrm{O}_{3}$ values between 50 and $60 \mathrm{~km}$ come from the chemiluminescent sonde and UV absorption

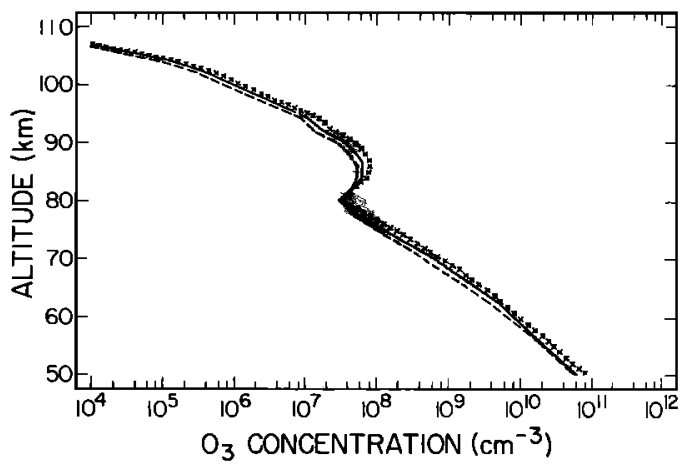

Fig. 11. The compiled Aladdin 74 rocket measurements of ozone with associated measurement errors (shaded area) and the diurnally averaged $\mathrm{O}_{3}$ results of the basic model (solid line), the 4 P.M. LST results of a diurnal calculation (dashed line), and the diurnally averaged results of the basic model when the temperature is reduced uniformly by $20 \mathrm{~K}$ (crosses).

photometer post-dawn flights. The values from the chemiluminescent sonde for this altitude range taken during the late afternoon and the post-dawn periods are very similar, as is predicted by model calculations (Figure 8). The data from the UV absorption technique extend to about $83 \mathrm{~km}$. These data taken during the post-dawn period should be comparable with late afternoon data, given the error bars for these results and the small daytime $\mathrm{O}_{3}$ variation below $80 \mathrm{~km}$ expected from the model calculations. The airglow photometer results obtained during the late afternoon flight period contribute to the composite profile between 72 and $98 \mathrm{~km}$. In the altitude range in which the UV and airglow photometer measurements overlap, the agreement is very good and supportive of the aforementioned assumption. Between 90 and $108 \mathrm{~km}$, the composite $\mathrm{O}_{3}$ distribution reflects the late afternoon mass spectrometer measurements.

Since variability during daylight hours is significant near the mesopause, the composite $\mathrm{O}_{3}$ vertical profile shown in Figure 11 is best compared with model calculations for late afternoon (solar zenith angle $\chi$ between 43 and $53^{\circ}$ ). Because the active- $O$ and active- $H$ species are at, or near, photochemical steady state during daylight hours, or are very long-lived, a steady state calculation with a diurnally averaged (and therefore late afternoon) radiation field should provide results appropriate for comparison with the Aladdin 74 data much more economically than running a diurnal calculation for every test parameter change. The validity of this procedure is demonstrated in Figure 11 where the results of a diurnally averaged calculation using the basic/final atmosphere and kinetic parameters (see Table 1) are seen to be very similar to results for 1600 LST ( $\chi$ $47^{\circ}$ ) from an explicit diumal calculation (from which the results shown in earlier sections are derived). The good agreement between our model results and the observed $\mathrm{O}_{3}$ profile in the 50 - to $95-\mathrm{km}$ altitude range only results after a variety of parameters are modified.

\section{Derivation of Basic Model Parameters}

When we initiated this investigation, the most currently available rate constants were those summarized in Hudson and Reed [1979]. In the interim, laboratory investigations 
resulted in revision to some of these values (summarized most recently in DeMore et al. [1982]). With these new rate constant values, model calculations match $\mathrm{O}_{3}$ observations much better. In this section, we will show the importance of some of these modifications in rate constants and illustrate how a careful comparison between model calculations and observations can indicate potential changes in the accepted values for key rate constants and climatological variables.

The first test comparison is between the Aladdin 74 data and model computations utilizing the Hudson and Reed [1979] rate constants, a diurnally averaged radiation field, the density-temperature profile for the background atmosphere discussed in Paper $I$, and the eddy diffusion coefficients above $90 \mathrm{~km}$ whose derivation is also discussed in Paper I. The eddy diffusion profile $K(z)$ below $90 \mathrm{~km}$ (see profile 1 in Figure 12a) is that recommended by Hudson [1977], which is basically double the magnitude of the eddy diffusion profile suggested by Hunten [1975] and results in good agreement between models and observations of the vertical profiles of stratospheric tracer species. The lower boundary condition at $\mathbf{4 0} \mathrm{km}$ for $\mathrm{H}_{2} \mathrm{O}$ in this calculation is 5 ppmv, the value suggested by the radio measurements of mesospheric water obtained by Waters et al. [1980]. A comparison between the model results thus obtained and the Aladdin 74 composite profile is shown in Figure $12 b$. The theoretical and observational results are in good agreement, except between 75 and $90 \mathrm{~km}$ and above $95 \mathrm{~km}$. At the mesopause the discrepancy is as large as a factor of 15 peaking around $83 \mathrm{~km}$. Although wavelike deviations from a mean value can be produced by upwardpropagating gravity waves, Frederick [1979] using gravity wave parameters derived from observations shows that this could only produce a variation of less than $10 \%$ at $80 \mathrm{~km}$ and a factor of 2 at $90 \mathrm{~km}$. This result taken together with the fact that a local minimum in the observed $\mathrm{O}_{3}$ profile near $80 \mathrm{~km}$ and a secondary maximum near $90 \mathrm{~km}$ also appear in the model calculations suggests that the structure near the mesopause is a result of phenomena already included in the model but that the sources of the differences in the magnitude of the $\mathrm{O}_{3}$ secondary maximum lie somewhere in the values for the input parameters.

Poorly known, but potentially highly variable, are the values of the climatological parameters that affect the model calculations. Least well constrained by observational data is the magnitude of vertical transport (i.e., eddy diffusion) for the altitude range from the stratopause to $90 \mathrm{~km}$. Therefore, we first consider what improvement in the model fit to observation could result from modifying the eddy diffusion values chosen initially. Above $58 \mathrm{~km}$, daytime $\mathrm{O}_{3}$ is in equilibrium with the larger reservoir of atomic $O$. From 85 $\mathrm{km}$ down to $80 \mathrm{~km}$, the lifetime of active-O ( $\approx$ atomic $O)$ rapidly decreases from $\sim 1$ day to $\sim 1$ hour (Figure 2). However, as seen in Figure 4, the downward flow of activeoxygen can contribute to the abundance of active- $O$ at 80 $\mathrm{km}$ since the magnitude of the gradient of the flux is of the same order of magnitude as local chemical production and loss processes. The abundance of $\mathrm{H}_{2} \mathrm{O}$ at $80 \mathrm{~km}$, a parameter to which mesopause $\mathrm{O}_{3}$ is sensitive, is also affected by the magnitude of vertical motion at and above the mesopause. We judged that adjusting the eddy diffusion profile between 80 and $90 \mathrm{~km}$ to introduce a stagnant layer would

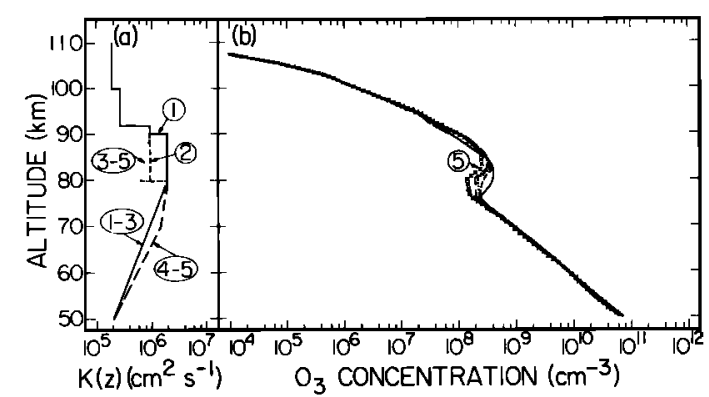

Fig. 12. (a) Trial eddy diffusion profiles and (b) consequent model $\mathrm{O}_{3}$ results. Associated profiles in Figure $12 a$ and $12 b$ are indicated by the same symbol. The $40 \mathrm{~km}$ boundary condition for $\mathrm{H}_{2} \mathrm{O}$ is 5 ppmv for profiles $1-4$ and is $7 \mathrm{ppmv}$ for 5 . All $\mathrm{O}_{3}$ profiles are derived from computations using diurnally averaged atmospheric transmission, the temperature profile of Paper I and the standard rate constants (i.e., without the adjustments suggested in this paper). Shaded area is the compiled Aladdin 74 measurement (see caption for Figure 11).

reduce the downward flux of atomic $O$ and would retard the flow of $\mathrm{H}_{2} \mathrm{O}$ through the mesopause, resulting in an increase in the abundance of $\mathrm{H}_{2} \mathrm{O}$ at $80 \mathrm{~km}$. The consequence of these two effects is to reduce atomic $O$ and, in turn, $\mathrm{O}_{3}$ concentrations at the mesopause. Trial $K(z)$ profiles (2 and 3) are shown in Figure $12 a$ and the resulting $\mathrm{O}_{3}$ distributions in Figure $12 b$. Some reduction in the model $\mathrm{O}_{3}$ values at the secondary maximum results; a comparison of the $\mathrm{O}_{3}$ values corresponding to trial $K(z)$ profiles 2 and 3 shows that further modification of $K(z)$ between 80 and $90 \mathrm{~km}$ would not result in significant further improvement. Since the abundance of $\mathrm{H}_{2} \mathrm{O}$ at the mesopause is also strongly controlled by the rate of upward transport from the stratopause, we investigated what modification of the $K(z)$ profile between 50 and $80 \mathrm{~km}$ could reduce $80 \mathrm{~km}$ $\mathrm{O}_{3}$ further. $K(z)$ profile number 4 (Figure $12 a$ ) maximizes the amount of $\mathrm{H}_{2} \mathrm{O}$ at $80 \mathrm{~km}$ and does result in a small decrease in $\mathrm{O}_{3}$.

The adjustments to the adopted eddy diffusion profile between 50 and $90 \mathrm{~km}$ do affect the $\mathrm{O}_{3}$ profile even though $\mathrm{O}_{3}$ may be short-lived. Thus, easily observable $\mathrm{O}_{3}$ can be used as a tracer of transport in the upper atmosphere. However, the discrepancy between Aladdin 74 observations and model results remains significant.

Also poorly known is the magnitude and variability of $\mathrm{H}_{2} \mathrm{O}$ at the mesopause. As seen in Table 2, the relative sensitivity of the $\mathrm{O}_{3}$ concentration to the local $\mathrm{H}_{2} \mathrm{O}$ abundance is a maximum at $80 \mathrm{~km}$, and, thus, a change in the adopted $40 \mathrm{~km}$ boundary condition for $\mathrm{H}_{2} \mathrm{O}$ would result in a change in the $\mathrm{O}_{3}$ concentration largest at $80 \mathrm{~km}$ (Table 3) leaving the $\mathrm{O}_{3}$ values little changed at the other altitudes where there is a good match between observations and model results. When the lower boundary condition for $\mathrm{H}_{2} \mathrm{O}$ is increased to $7 \mathrm{ppmv}$, a value that is still consistent with the Waters et al. [1980] measurements and in agreement with an extrapolation of the stratospheric results of Farmer et al. [1980], the resulting $\mathrm{O}_{3}$ profile (5 in Figure $12 b$ ) shows the expected reduction at $80 \mathrm{~km}$. The new $\mathrm{H}_{2} \mathrm{O}$ profile (Figure $5 b$ in Paper I) is consistent with the unpublished $90 \mathrm{~km}$ Aladdin 74 mass spectrometer $\mathrm{H}_{2} \mathrm{O}$ measurement (H. Trinks, private communication, 1979) and the recently published observational results of Deguchi and 
Muhleman [1982] and, in the lower mesosphere, with the conclusions of Bevilacqua et al. [1983] and the preliminary results from the NIMBUS 7 SAMS instrument [WMO, 1981]. Our profile is somewhat higher than the preliminary data from the SAMS instrument for the $75-85 \mathrm{~km}$ altitude range [Drummond and Mutlow, 1981] and the upper mesospheric results of Bevilacqua et al. [1983] (further discussion of this is postponed to a later section). The range of values for the water vapor mixing ratio in the lower thermosphere derived from meteoritic ion observations [Solomon et al., 1983] includes the $\mathrm{H}_{2} \mathrm{O}$ values resulting from the new model calculation. Very recently, the J. E. Frederick and A. R. Douglass (private communication, 1982) analysis of stratospheric water vapor observations and the oxidation of $\mathrm{CH}_{4}$ to $\mathrm{H}_{2} \mathrm{O}$ finds that $7 \mathrm{ppmv}$ of $\mathrm{H}_{2} \mathrm{O}$ at the stratopause is consistent with the largest group of stratospheric measurements.

The foregoing discussion is a derivation of the $K(z)$ profile between 50 and $90 \mathrm{~km}$ and the $40 \mathrm{~km} \mathrm{H}_{2} \mathrm{O}$ boundary condition that were presented in Paper I without extensive explanation. After the changes in eddy diffusion and mesospheric $\mathrm{H}_{2} \mathrm{O}$ distribution are made, the model values for $\mathrm{O}_{3}$ at the mesopause are now a factor of 10 too lange, a reduction of $33 \%$ from the initial calculation. At this point it seems necessary to consider what errors in the model results can be due to inaccuracies in the kinetic rate constants adopted, some of which are (or were) relatively poorly constrained by laboratory measurements. Studying the impact of the different parameters on the whole $\mathrm{O}_{3}$ profile above the stratopause allows the best assessment of which parameters may need to be modified since, in some cases, different altitude ranges may constrain the same rate constant in opposite senses, thus allowing little room for adjustment. Such is the case for the rate constants $\mathrm{O}+\mathrm{O}_{2}$ $+\left(\mathrm{O}_{2}, \mathrm{~N}_{2}\right)\left(k_{14-15}\right)$; when the values are reduced to lower $\mathrm{O}_{3}$ at $80 \mathrm{~km}$, the result is too little $\mathrm{O}_{3}$ at $60 \mathrm{~km}$, suggesting that these laboratory measurements are not adjustable in light of this observational data set. Thus the rate constants listed in Table 1 for $k_{14}$ and $k_{15}$ are the nominal values of Klais $e t$ al. [1980]. (In Paper I, our preliminary analysis only concerned the sensitivity of mesopause $\mathrm{O}_{3}$ to parameter values, thus leading us to suggest reducing $k_{14}$ and $k_{15}$.)

The analysis of $\mathrm{O}_{3}$ chemistry presented earlier in this paper and summarized in Table 2 shows that, particularly at $80 \mathrm{~km}$, the $\mathrm{O}_{3}$ concentration is especially sensitive to the values of $k_{28}$ and $k_{30}$ which, if increased and decreased, respectively, can cause a significant decrease in model values. Furthermore, $\mathrm{O}_{3}$ is relatively more sensitive to $k_{18}$ at $80 \mathrm{~km}$ than at any other altitude. When the values for $k_{18}$ and $k_{28}$ are modified within the latitude allowed by the measurement uncertainties quoted in Hudson and Reed [1979] and the value for $k_{30}$ reduced in concert with the error bar for the Hack et al. [1978, 1979] measurement (modifications reported in Paper I), the $\mathrm{O}_{3}$ density at the mesopause is decreased by about a factor of 5 . Since the publication of Paper I, refinements of the laboratory measurements of $k_{18}$ and $k_{30}$ have occurred. At the low temperature of the mesopause $(\sim 170-180 \mathrm{~K})$, the modified rate constant for the reaction $\mathrm{O}+\mathrm{HO}_{2}$ (reaction (R18)) reported in Paper I was a factor of 2 larger than the value derived from the recommendation of Hudson and Reed [1979], but Keyser [1982] has published a new laboratory measurement of $k_{18}$ that, at $170 \mathrm{~K}$, is even $40 \%$ larger than our value (8-83\% larger given the reported uncertainties). Another recent measurement (room temperature) of $k_{18}$ [Sridharan et al., 1982] is 10\% lower than the Keyser [1982] result and also in agreement with our conclusion that $\mathrm{O}+\mathrm{HO}_{2}$ has to occur faster than earlier laboratory measurements had indicated. If the Keyser [1982] value is used, $\mathrm{O}_{3}$ is decreased too much, so we adopt a value at the lower limit of his experimental uncertainties, but it is larger than the earlier data evaluation recommendations. Sridharan et al. [1982] also report a new value for $k_{30}+$ $k_{31}+k_{32}$ and a relative branching ratio for each of the individual reactions. They find that $k_{30} /\left(k_{30}+k_{31}+k_{32}\right)$ is $\sim 9 \%$, similar to the value of $13 \%$ adopted in Paper $I$, which was half of that reported by Hack et al. [1978]. These newest measurements for $k_{30-32}$ have been adopted for the current work and are listed in Table 1 . Table 2 shows that enhancing $k_{29}$ reduces $\mathrm{O}_{3}$ at and above the mesopause, allowing a better match to the local minimum at $80 \mathrm{~km}$ and the secondary maximum at $85 \mathrm{~km}$. Thus we use a value (see Table 1) that is the upper limits of the uncertainties of DeMore et al. [1982].

Below $70 \mathrm{~km}$, model $\mathrm{O}_{3}$ is sensitive to $k_{23}$ which we increase slightly to improve the match between model and observations and to $k_{17}$ which is decreased. The value for $k_{23}$ in Table 1 is $20 \%$ higher than the zero pressure room temperature value of DeMore et al. [1982]. Very recently, Kaufman et al. [1982] reported a positive activation energy $(\sim 436 \mathrm{~K})$ for this reaction that would result in faster reactions at mesospheric temperatures. The value for $k_{17}$ is decreased within the limits allowed by WMO [1981] and is $\sim 40 \%$ lower than the new lower limit suggested in DeMore et al. [1982].

The $\mathrm{O}_{3}$ model results below $60 \mathrm{~km}$ in Figure $12 b$ are at the lower end of the uncertainty range of the observations. Several processes affect the $\mathrm{O}_{3}$ profile only in this altitude range and can be adjusted to increase the model $\mathrm{O}_{3}$ results (see Table 2). Thus, the values in Table 1 for $k_{8}$ and $k_{9}$ are the maximum values allowed by the uncertainties in the laboratory results [DeMore et al., 1982]. Similarly, $k_{10}$ is reduced to the maximum extent [DeMore et al., 1982].

The model $\mathrm{O}_{3}$ profile resulting from making all of these adjustments in the kinetic rate constants is shown in Figure 11 (profile demarcated with crosses). The rate constants of less important reactions have been updated in accord with DeMore et al. [1982]. The discrepancy at the secondary maximum is significantly reduced. Although the largest changes allowed by the measurement uncertainties are implemented, the model secondary maximum is still higher than the observed value. One major model parameter not yet considered is the temperature profile, adjustment of which could allow the model results to better reproduce the observations. Since so many of the reactions in Table 1 are temperature-dependent, the ozone abundances at all altitudes are sensitive to some extent to the local value of the atmospheric temperature. The variability of $\mathrm{O}_{3}$ in the mesosphere and lower thermosphere resulting from changes in the temperature field is a key element in the studies of Frederick $[1979,1981 a, b]$. Gravity waves can result in oscillating temperature profiles [Frederick, 1979]; such could have been the case at the time of the Aladdin 74 observations. Variations in temperature by as much as 25 
$K$ have been observed in a short time span in the altitude range $65-85 \mathrm{~km}$ (by rocket measurements also originating from Wallops Island, Virginia) [Schmidlin, 1976]. These temperature profiles distinctly showed a wavelike structure. Wavelike vertical temperature profiles in the mesosphere along with short-term fluctuations at a given altitude can be clearly observed by ground-based lidar soundings [Chanin and Hauchecorne, 1981; Hauchecorne and Chanin, 1982, 1983]. Differences between the temperature measurements and standard atmospheric models can be as large as $20 \mathrm{~K}$.

Systematically increasing the temperature profile used in Paper $\mathrm{I}$ by $20 \mathrm{~K}$ results in an $\mathrm{O}_{3}$ distribution that is shown in Figure 11. (Actually the temperature profile of Paper I is somewhat higher than a temperature profile derived in the appendix of that paper by a hydrostatic calculation utilizing the Aladdin 74 mass spectrometer data. However, systematic error may have been introduced into that calculation due to its limited nature, as evidenced by the resulting extreme temperature gradients, leading us to adopt more standard profiles.) Whereas the secondary maximum is now reproduced extremely well by the model calculations, the results below $70 \mathrm{~km}$ only marginally agree with the observations. But as seen in the lidar temperature measurements, deviations from a more "normal" temperature sometimes may only occur in a narrow altitude range at any particular point in time. Thus the temperature modification adopted for the calculations may only have occurred at the mesopause at the time of the $\mathrm{O}_{3}$ measurements, and the standard temperature profile may be a more accurate representation of conditions in the lower mesosphere at that time. However, for the sake of simplicity, the standard atmosphere temperature profile (see Paper I) increased by $20 \mathrm{~K}$ is adopted for the basic model of this paper. This is implemented only for the purposes of comparison with the Aladdin 74 observations and other temperature profiles will be utilized in computations focussed on measurements at other epochs.

By this sequence of model/observation intercomparisons, we arrive at a basic model, the results from which were already used in earlier sections in which the important reactions of relevance to the $\mathrm{O}_{3}$ chemistry were discussed. A good fit to the $\mathrm{O}_{3}$ observations from $50 \mathrm{~km}$ all the way up to $95 \mathrm{~km}$, spanning several different regimes of $\mathrm{O}_{3}$ chemical cycles, only results when the kinetic rate constants, $\mathrm{H}_{2} \mathrm{O}$ abundance, eddy diffusion coefficients, and background temperature are modified from the initial assumptions, but in each case the changes are within the limits of current uncertainties. Some of the suggestions for changes presented in Paper I subsequently have been proven to be correct. The changes we have suggested for different parameters clearly are correlated. Better determinations of any of these parameters will affect our estimates for the others, doubtlessly resulting in future revision. This then is our basic model (the climatological parameters being most appropriate for the Aladdin 74 period): the kinetic rate constants reported in Table 1 , the $\mathrm{H}_{2} \mathrm{O}$ vapor abundance and eddy diffusion coefficients previously presented in Paper I, and the background temperature profile discussed in Paper I uniformly increased by $20 \mathrm{~K}$. The diurnally averaged $\mathrm{O}_{3}$ results and the late afternoon profile of a diurnal run (the time of day for the key Aladdin 74 measurements) are shown to be similar in Figure 11, confirming that the diumally averaged tests used to derive the basic model are appropriate when compared with observations taken at that specific time.

One group of parameters which we did not attempt to adjust to bring about better model/observation agreement is the set of photodissociation rate constants. We feel that in general these are much better known than the difficult-tomeasure free radical rate constants. The model calculations shown in this paper utilize the parameterization for the $\mathrm{O}_{2}$ Schumann-Runge bands described in Allen and Frederick (1982). After the bulk of our computations were performed, Frederick and Mentall [1982], Herman and Mentall [1982], and Froidevaux and Yung [1982] proposed that the values of the $\mathrm{O}_{2}$ Herzberg continuum cross section were smaller than the values previously used in atmospheric opacity and photodissociation calculations (for example, as in Allen and Frederick [1982]). However, when the appropriate adjustments are made to our calculations, the resulting model $\mathrm{O}_{3}$ values are reduced at most by $13 \%$ at $50 \mathrm{~km}$ and systematically less so with increasing altitude, similar to what Ko and Sze [1983] and Solomon et al. [1983] found upon including the reduced cross-section values. Such a small difference is within the uncertainties of the absolute cross-section values of the key photolytic processes. Another potential error in the model calculations related to inaccuracies in the photodissociation computations has been proposed by Cicerone and McCrumb [1980]. These authors suggest that a combination of quantum and optical depth effects may result in an enhanced dissociation rate for isotopically heavy $\mathrm{O}_{2}\left({ }^{18} \mathrm{O}^{16} \mathrm{O}\right)$ relative to the most abundant form $\left({ }^{16} \mathrm{O}^{16} \mathrm{O}\right)$ such that the current odd-oxygen production rate might be underestimated by as much as $10 \%$ in the mesosphere. A lack of detailed quantitative spectroscopic data for heavy $\mathrm{O}_{2}$ prevents a good assessment of this possibility.

Very recently new laboratory measurements of the rate constants for $\mathrm{O}+\mathrm{O}_{2}+\mathrm{M}$ were reported by Lin and Leu [1982]. When used in our model computations (still assuming that $k_{13}-k_{14}$ ), the new model values for $\mathrm{O}_{3}$ are down by $4 \%$ at $50 \mathrm{~km}$ relative to the basic model values, higher at $80 \mathrm{~km}$ by $11 \%$, higher at $90 \mathrm{~km}$ by $21 \%$, but little different at higher altitudes. This affects the simulation of the Aladdin 74 profile a little, but more importantly cannot help bring the model results above $95 \mathrm{~km}$ into better agreement with the observations (see Figure 11). Instead of the previously adopted assumption that atomic $\mathrm{O}$ and $\mathrm{O}_{2}$ are equally efficient third-bodies in the recombination process, M. T. Leu (private communication, 1982) suggested that atomic-O may behave in a manner intermediate between He and Ar, whose third-body efficiencies had been measured [Lin and Leu, 1982] and also that the M - O rate constant should be doubled to reflect the symmetry in the reaction. As atomic-O becomes more abundant than $\mathrm{O}_{2}$ above the homopause, such rate constant modifications would impact on the calculated $\mathrm{O}_{3}$ profile in this high altitude range. When the computations are adjusted in accordance with Leu's suggestions $\left(k_{13}=5.8 \times 10^{-35} \mathrm{e}^{535 / \mathrm{T}} \mathrm{cm}^{6}\right.$ $\mathrm{s}^{-1}$ ), the new $\mathrm{O}_{3}$ values are actually less than before since atoms are much less efficient third-body intermediaries than $\mathrm{O}_{2}$ in the case of this reaction and thus the new $k_{13}$ is smaller than that previously used. The $\mathrm{O}_{3}$ observations at lower altitudes do not allow other key rate constants (see 


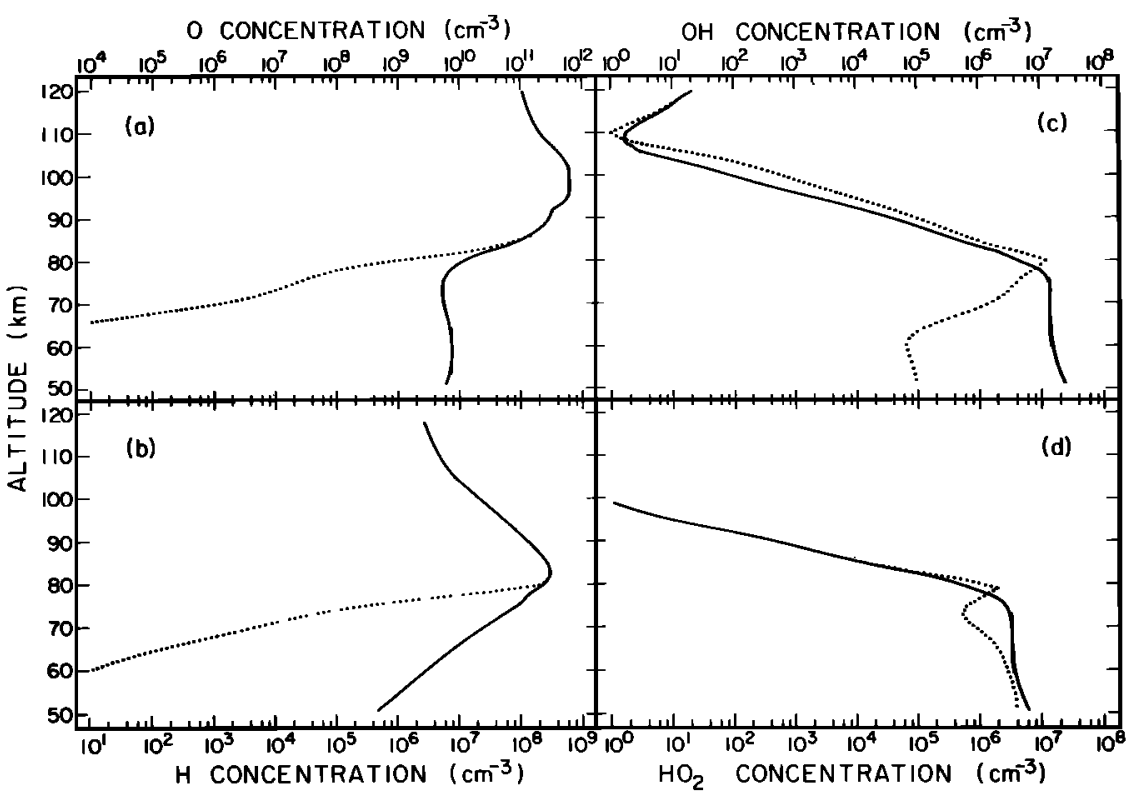

Fig. 13. Noon (solid lines) and midnight (dotted lines) altitude profiles from the basic model for (a) atomic-O, (b) atomic- $\mathrm{H},(c) \mathrm{OH}$, and $(d) \mathrm{HO}_{2}$.

Table 2) to be varied sufficiently to bring the model results into better agreement with the observed $\mathrm{O}_{3}$ profile above 95 $\mathrm{km}$. The important climatological parameters for the lower thermosphere at the time of the Aladdin 74 flights are also well constrained. We are currently evaluating a number of processes heretofore not considered in this context which could resolve this discrepancy.

\section{Calculations of Atomic Oxygen}

During daylight hours above $58 \mathrm{~km}$, ozone is a tracer reflective of the larger amount of atomic oxygen present. If one has the correct chemical model for $\mathrm{O} / \mathrm{H}$ species in the upper atmosphere, the atomic $O$ profile must be calculated correctly for a proper $\mathrm{O}_{3}$ profile to result. In Paper I, a model atomic $O$ profile matching the Aladdin 74 measurements above $90 \mathrm{~km}$ resulted upon adjustment of the eddy diffusion profile above $90 \mathrm{~km}$. The kinetic rate constants used in that study are only slightly different from what are used herein, so the atomic $O$ profile above $90 \mathrm{~km}$ calculated with the basic model of this paper (see Figure 13a) is almost exactly that in Paper I. Many other measurements of atomic $O$ in the lower thermosphere have been acquired, most of which are included in the compilation of Offermann et al. [1981]. There are very significant differences between the observed atomic profiles reported therein, and it is unclear whether the variation results from the variety of measurement techniques or from different atmospheric phenomena at different latitudes or, more generally, the temporal variation of atmospheric behavior anywhere.

A more useful test of the model of this paper can be made by using observations of atomic-O at or below the mesopause, in which altitude range atomic-O is much less sensitive to variability in eddy diffusion. Of the available measurements, two most directly comparable with the detailed calculations performed for this paper are those derived from mid-latitude summer rocket flights at solar minimum reported by Thomas and Young [1981] and Baker et al. [1982]. The observed values for atomic-O at $80 \mathrm{~km}$ are $3.5 \times 10^{8} \mathrm{~cm}^{-3}$ (midnight [Thomas and Young, 1981]) and $\sim 10^{10} \mathrm{~cm}^{-3}\left(x-77^{\circ}\right.$ [Baker et al., 1982]), both in good agreement with our diurnal computations shown in Figures 9 and 13a. Thomas and Young [1981] also observed an atomic- $O$ peak in the lower thermosphere very similar to the calculations in Paper I and the current work. Atomic-O profiles below the mesopause were measured by Dickinson et al. [1980]. Although the circumstances of these observations are not reproduced by our model runs, there is good qualitative agreement between our results displayed in Figure 13a and the observed profiles: (1) The daytime measurements show a steady decrease from the lower thermospheric peak down to $80 \mathrm{~km}$ below which the atomic-O density is relatively constant with altitude down to $60 \mathrm{~km}$, holding at a value $\sim 10^{10} \mathrm{~cm}^{-3}$; (2) nighttime atomic- $O$ decreases rapidly and steadily from the lower thermospheric peak, dropping below measurement sensitivity $\left(-10^{9} \mathrm{~cm}^{-3}\right)$ near $80 \mathrm{~km}$.

\section{Model Results for Hydrogen Species in the Upper Atmo- sphere}

The model calculations of $\mathrm{O}_{3}$ are very sensitive to the local concentrations of active- $\mathrm{H}$ species, which catalyze the recycling of active- $\mathrm{O}$ back to $\mathrm{O}_{2}$. The sensitivity of the calculated $\mathrm{O}_{3}$ profile to the changes in the $\mathrm{H}_{2} \mathrm{O}$ abundance discussed earlier results from $\mathrm{H}_{2} \mathrm{O}$ being the main source of active-H. Many of the rate constants we have adjusted to improve the $\mathrm{O}_{3}$ model/observation comparison are important in that they affect the cycling among the active- $H$ species and the rate of conversion of active-H to inactive forms.

Consequently, the calculated profiles of the various hydrogen species (Figures 13 and 14) also need to be consistent with observations to verify the validity of the model description of $\mathrm{O}_{3}$ chemistry. As discussed earlier in this 


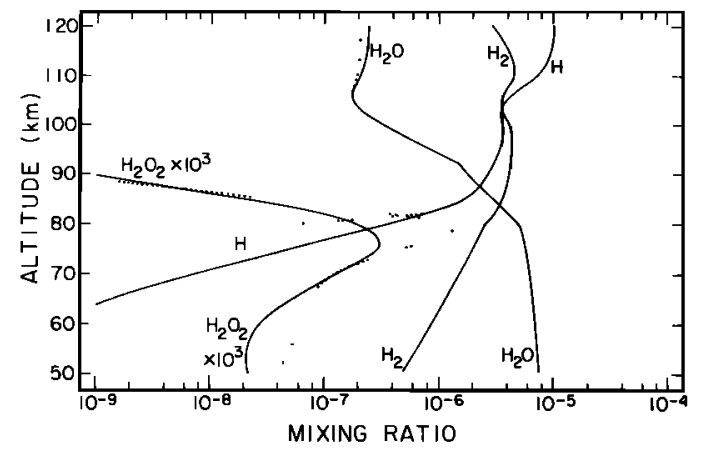

Fig. 14. The upward transport of elemental hydrogen from the stratopause to the lower thermosphere: the mixing ratios at noon (solid lines) and midnight (dotted lines) for atomic-H and the inactive- $\mathrm{H}$ species, $\mathrm{H}_{2}, \mathrm{H}_{2} \mathrm{O}$, and $\mathrm{H}_{2} \mathrm{O}_{2}$, the latter scaled upward by a factor of $10^{3}$.

paper, the adopted $40 \mathrm{~km}$ boundary condition for $\mathrm{H}_{2} \mathrm{O}$ and the resulting model profile for $\mathrm{H}_{2} \mathrm{O}$ above the stratopause are in accord with a variety of observations of $\mathrm{H}_{2} \mathrm{O}$ in the mesosphere and lower thermosphere. Above the mesopause, inactive-H is predominantly $\mathrm{H}_{2}$ (see Figure 14). As most of the $\mathrm{H}_{2}$ in the lower thermosphere is derived ultimately from the $\mathrm{H}_{2} \mathrm{O}$ flowing up through the mesosphere, the $\mathrm{H}_{2}$ concentration profile reflects the mesospheric $\mathrm{H}_{2} \mathrm{O}$ abundance, photodissociation rates (solar conditions, etc.), and upward transport velocities. The springtime solar minimum equatorial measurements of $\mathrm{H}_{2}$, using an ultraviolet stellar occultation technique [Atreya et al., 1976], yielded values ranging from $1 \times 10^{8} \mathrm{~cm}^{-3}( \pm 15 \%)$ at $95 \mathrm{~km}$ to $1 \times 10^{7} \mathrm{~cm}^{-3}( \pm 5-8 \%)$ at $108 \mathrm{~km}$. Our model values of $9.5 \times 10^{7} \mathrm{~cm}^{-3}(95 \mathrm{~km})$ and $5 \times 10^{6} \mathrm{~cm}^{-3}(108 \mathrm{~km})$ are in reasonable agreement with the observational results, the differences possibly resulting from a variety of factors, including variability of vertical motion.

Unfortunately, the dominant active-H species in the daytime in the mesosphere below $70 \mathrm{~km}-\mathrm{OH}-$ has only been directly measured once [Anderson, 1971]. The $\mathrm{OH}$ concentration profile calculated by the current basic model (Figure 13c) is very similar to what is shown in Paper I (Figure 5a), wherein the observational values are well fit by the model results. Above $70 \mathrm{~km}$ during the day and above $80 \mathrm{~km}$ throughout the diurnal period, atomic-H is the dominant form of active-H (cf. Figures $13 b-13 d$ ). The high latitude autumn solar maximum atomic-H measurements of Evans and Llewellyn [1973] are an order of magnitude smaller than lower thermosphere model results (including our own run with a "solar maximum" spectrum), leading these authors to suggest a very dry mesosphere. They also measured at the same time $\mathrm{O}_{3}$ (in fact, the atomic $\mathrm{H}$ results are dependent on the $\mathrm{O}_{3}$ observations) and found more than our models generate, but consistent with $\mathrm{O}_{3}$ chemistry as we understand it. On the other hand, the mid-latitude winter solar maximum airglow observations of Anderson et al. [1980] are consistent with atomic-H profiles larger than the Evans and Llewellyn [1973] result, but still somewhat lower than results from our model computed with solar illumination appropriate for the epoch of the Anderson et al. [1980] rocket flight. The uncertainties of their observational analysis do not clearly exclude our higher values for atomic-H. Recently, Kita and Sharp [1982] report a direct measurement of the atomic-H distribution obtained in a winter mid-latitude rocket flight $\left(\chi-102^{\circ}\right)$ when the sun was shifting to solar minimum behavior: $[\mathrm{H}]-5 \times 10^{6}$ $\mathrm{cm}^{-3}$ at $75 \mathrm{~km},-5 \times 10^{7} \mathrm{~cm}-3$ at $80 \mathrm{~km}$, a peak of $1.4 \pm$ $0.8 \times 10^{8} \mathrm{~cm}^{-3}$ at $85 \mathrm{~km}$, and $\leq 10^{8} \mathrm{~cm}^{-3}$ at $90 \mathrm{~km}$. The results for atomic $\mathbf{H}$ from our calculation using a diurnally averaged solar minimum winter sun are $10^{7}, 5 \times 10^{7}, 2 \times$ $10^{8}$, and $1.5 \times 10^{8} \mathrm{~cm}^{-3}$, respectively, in reasonably good agreement with Kita and Sharp [1982]. Although a diurnal computation specific for the circumstances of the Kita and Sharp [1982] observations is necessary for performing a detailed comparison between model and measurements, from Figure 9, one can infer the general pattern of atomicH diurnal variation, which when accounted for would result in values in the mesosphere at the local time of the Kita and Sharp [1982] measurement lower than those of a diurnally averaged sun (late afternoon) calculation. Interestingly, as shown in eqn. (13), the concentration of atomic-H in the upper mesosphere during daylight hours is relatively insensitive to the local $\mathrm{H}_{2} \mathrm{O}$ abundance. This is seen in the results of two diurnally averaged calculations with the basic model wherein the $40 \mathrm{~km}$ boundary condition for $\mathrm{H}_{2} \mathrm{O}$ in one case is $7 \mathrm{ppmv}$ and in the other case $5 \mathrm{ppmv}$; the atomic-H concentrations differ by less than $5 \%$ between 65 and $80 \mathrm{~km}$.

One further check on the hydrogen budget of the model concerns the upward flux of elemental hydrogen. As summarized most recently by Hunten and Donahue [1976], the amount of elemental hydrogen escaping from the terrestrial atmosphere $\left(-2-3 \times 10^{8}\right.$ atoms $\left.\mathrm{cm}^{-2} \mathrm{~s}^{-1}\right)$ must be supplied from the lower atmosphere. Elemental hydrogen is transported upward through the stratopause in the form of $\mathrm{H}_{2} \mathrm{O}$, converted to $\mathrm{H}_{2}$ near the mesopause, and then further transformed into atomic-H in the lower thermosphere (see Figure 14 and Liu and Donahue [1974a, b]). With our boundary conditions at $130 \mathrm{~km}$ for atomic $\mathrm{H}$ and $\mathrm{H}_{2}$ being the maximum diffusion velocity [Banks and Kockarts, 1973 , p. 431, the upward flow of elemental hydrogen is conserved from level to level in the model calculation and is $3.3 \times 10^{8} \mathrm{H}$ atoms $\mathrm{cm}^{-2} \mathrm{~s}^{-1}$. The general agreement between our value and the approximate value for the earth is a rough verification of the model mesosphere hydrogen content.

Thus, the adjustments to the model parameters (the 7 ppmv $40 \mathrm{~km}$ boundary condition for $\mathrm{H}_{2} \mathrm{O}$, the modified kinetic rate constants) that help bring the calculated $\mathrm{O}_{3}$ profile into better agreement with the Aladden 74 results can be roughly checked with a variety of other relevant

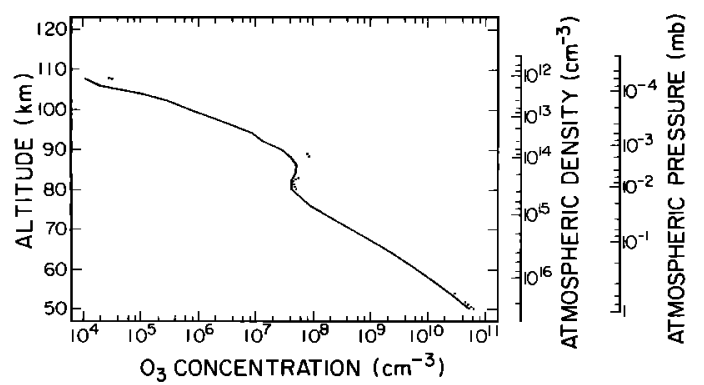

Fig. 15. The vertical distribution of $\mathrm{O}_{3}$ at noon (solid line) and midnight (dotted line) resulting from the basic model. 
observations. However, the comparisons between observations and model results, showing points of agreement and some disagreements, are only partly relevant because of the high probability of the $\mathrm{H}_{2} \mathrm{O}$ content of the atmosphere varying with time. The $\mathrm{H}_{2} \mathrm{O}$ concentration at the stratopause and consequently the mesosphere $\mathrm{H}_{2} \mathrm{O}$ and active-H profiles may have been different at the time of the Aladdin 74 rocket flights (mid-latitude solar minimum 1974 summer period) considering that the observations we have examined were at different latitudes, seasons, and/or phases of the solar cycle.

\section{$\mathrm{O}_{3}$ Secondary Maximum}

Shown in Figure 15 are the vertical profiles for $\mathrm{O}_{3}$ at noon and midnight generated by a full diurnal calculation with the basic model. While both profiles show an enhancement between 80 and $90 \mathrm{~km}$ relative to the $80 \mathrm{~km}$ value, the secondary maximum is more prominent at night, there being an overall nighttime increase in $\mathrm{O}_{3}$ above 60 $\mathbf{k m}$, but the contrast is also greater since the concentration of $\mathrm{O}_{3}$ at the $80 \mathrm{~km}$ local minimum is coincidentally similar in magnitude at noon and midnight. The temporal variation of the secondary maximum can be roughly traced in the diurnal variation of $\mathrm{O}_{3}$ displayed in Figure 8.

A secondary maximum in the ozone distribution at the mesopause was first inferred from high altitude observations of "excess" $\mathrm{O}_{2}\left({ }^{1} \Delta_{g}\right)$ airglow emissions [Evans et al., 1968; Evans and Llewellyn, 1970], resulting from $\mathrm{O}_{3}$ photolysis. From the Evans et al. [1968] flight (mid-latitude, late afternoon, fall sun at solar minimum), a peak $\mathrm{O}_{3}$ density of $\sim 10^{8} \mathrm{~cm}^{-3}$ at $\sim 83 \mathrm{~km}$ can be derived. Using high latitude rocket measurements of $\mathrm{O}_{2}\left({ }^{1} \Delta_{g}\right)$ airglow, Evans and Llewellyn [1970] deduce $\mathrm{O}_{3}$ local maximum values of 1-3 $\times$ $10^{8} \mathrm{~cm}^{-3}$ (depending on time of day), occurring a little higher in altitude, $-88-90 \mathrm{~km}$. Noxon [1982] presents the results of 10 years of $\mathrm{O}_{2}\left({ }^{1} \Delta_{\mathrm{g}}\right)$ airglow observations, and he too finds an $88 \mathrm{~km}$ secondary maximum of $\sim 4 \times 10^{8} \mathrm{~cm}^{-3}$ at high latitudes (twilight, winter solar maximum sun). Our model results do approximate these values with due allowance given for the varying circumstances of the observations. Noxon [1982] also finds that the $\mathrm{O}_{3}$ column above $80 \mathrm{~km}$ increases from summer to winter by a factor of 3 at mid- to high latitudes, a trend that models (including our own) do not reproduce. It would be important to verify this observation by additional measurements.

The $\mathrm{O}_{3}$ secondary maximum was first directly measured by Hays and Roble [1973], using occultations by the terrestrial atmosphere of ultraviolet stellar light as detected by the OAO 2 satellite, and by Miller and Ryder [1973], employing a rocket-borne solar occultation experiment. Both groups of observations show a high altitude bulge, but the structure is more clearly defined in the work of Hays and Roble [1973]. Their (nighttime) profiles show the $\mathrm{O}_{3}$ peak typically at $83-85 \mathrm{~km}$, varying between $6 \times 10^{7}$ and $3 \times 10^{8}$ $\mathrm{cm}^{-3}$ in magnitude. Our model peak value for midnight under the conditions of a summer solar minimum sun is $-1.2 \times 10^{8} \mathrm{~cm}^{-3}$, which compares well with the Hays and Roble [1973] mid-latitude summer solar maximum predawn peak value of $10^{8} \mathrm{~cm}^{-3}$. When computed with a solar maximum spectrum, the model secondary maximum is $-25 \%$ larger than at solar minimum. The altitude of the
$\mathrm{O}_{3}$ local minimum in the Hays and Roble [1973] data is at $-75 \mathrm{~km}$, whereas our model local minimum is at $\sim 78 \mathrm{~km}$, not a serious difference considering the envelope of the observational profiles. The Hays and Roble [1973] profiles and our model results are in overall agreement between 60 and $95 \mathrm{~km}$, the altitude range for which these authors expected the best retrievals from the satellite data. However, below $60 \mathrm{~km}$, the gradient of the $\mathrm{O}_{3}$ profile is a factor of 10 smaller than that calculated by most models (including our own) and observed by others (see later section in this paper). This is probably reflecting the breakdown in the retrieval scheme at low altitudes recognized by Hays and Roble [1973]. A major conclusion of theirs is that, in the altitude range of their observations, they see little change in $\mathrm{O}_{3}$ during the night. The results of the diurnal calculations (see Figure 8) are consistent with this, except for a narrow altitude range near $80 \mathrm{~km}$ where a small nighttime variation is predicted to occur.

Later satellite stellar occultation observations of mesosphere/lower thermosphere $\mathrm{O}_{3}$ were performed by Riegler et al. [1977], this time with the OAO 3 Copernicus. Their summer nighttime solar minimum equatorial measurements show the secondary maximum to be larger $(-2.5$ $\left.\times 10^{8} \mathrm{~cm}^{-3}\right)$ and higher $(97 \mathrm{~km})$ than our mid-latitude model values. The value for the density peak can be modified by changing environmental conditions (as has already been demonstrated in this paper), but the altitude is much higher than any of the previously obtained observations, including the equatorial results of Hays and Roble [1973]. In the lower mesosphere, the Riegler et al. [1977] $\mathrm{O}_{3}$ densities are 2-3 times larger than expected from models and prior observations and are in direct conflict with the results of other techniques obtained close by in space and in time (Gille et al., 1980a). However, a large $\left(-6 \times 10^{8}\right.$ $\mathrm{cm}^{-3}$ ) and high $(93 \mathrm{~km}) \mathrm{O}_{3}$ nighttime peak was measured recently at high latitudes by Vaughan [1982], using a rocket-borne lunar occultation technique.

By monitoring $\mathrm{O}_{2}\left({ }^{1} \Delta_{g}\right)$ emission, the Solar Mesosphere Explorer (SME) measured $\mathrm{O}_{3}$ to $90 \mathrm{~km}$ at 3 P.M. local time and only sometimes detected secondary maxima (Thomas et al., 1983l as is expected from the model diurnal calculations for daytime. In mid-latitudes at winter solstice, Thomas et al. [1983] find the $\mathrm{O}_{3}$ mixing ratios increasing continuously to $90 \mathrm{~km}$ from a local minimum at $-70 \mathrm{~km}$, with the $90 \mathrm{~km}$ values being $\sim 1-1.25$ ppmv $\left(7-9 \times 10^{7}\right.$ $\mathrm{cm}^{-3}$ ). These values are more than a factor of 3 larger than our model results for this season. Significant day-to-day variability is seen at $90 \mathrm{~km}$ [Barth et al., 1983], and their explanation concerns variability in the downward transport of active-O from the thermosphere. As already discussed in this paper, transport does affect $\mathrm{O}_{3}$ at the mesopause, but temperature fluctuations can also produce similar effects (see the next section). However, the high mean values for $\mathrm{O}_{3}$ at $90 \mathrm{~km}$ observed by the SME in the first 6 months of $1982(-1 \mathrm{ppmv})$ and the large secondary maximum measured by Vaughan [1982] may be due to a more systematic change at the mesopause from the time of the early 1970's. There may have been a secular change in the $\mathrm{H}_{2} \mathrm{O}$ abundance in the upper mesosphere; mesopause $\mathrm{H}_{2} \mathrm{O}$ values of Drummond and Mutlow [1981] and Bevilacqua et al. [1983] are 2-3 times smaller than our model $\mathrm{H}_{2} \mathrm{O}$ profile which was tuned to improve the model fit to the Aladdin 
$74 \mathrm{O}_{3}$ profile. A reduction in the local $\mathrm{H}_{2} \mathrm{O}$ abundance would result in an almost proportionate increase in $\mathrm{O}_{3}$. The $\mathrm{H}_{2} \mathrm{O}$ distribution could change due to a reduction in $\mathrm{H}_{2} \mathrm{O}$ at the stratopause or, as proposed by Bevilacqua et al. [1983], the upper mesosphere becoming stagnant leading to photolytic depletion of $\mathrm{H}_{2} \mathrm{O}$ starting lower in the mesosphere than in our current model. So our basic model adjusted to match the Aladdin 74 observations may still be appropriate for that epoch, but recent observations may reflect the degree to which the atmosphere varies naturally, the subject of the next section of this paper.

In the context of the chemistry incorporated in our basic model, tested through comparisons with a number of observations, we can understand the origin of the $\mathrm{O}_{3}$ secondary maximum. The $\mathrm{O}_{3}$ maximum around $85 \mathrm{~km}$ results from a maximum in the production of $\mathrm{O}_{3}$ (reactions (R13)-(R15)) at this altitude, as seen in Figure 3. Above $80 \mathrm{~km}, \mathrm{O}_{3}$ is a tracer for active-O. The concentration of the major form of active-O, atomic-O, is decreasing rapidly with decreasing altitude (and increasing atmospheric density) (Figure 9). The contrasting gradients of atomic-O and atmospheric density produce the peak in the production of $\mathrm{O}_{3}$. As discussed in Paper I, the long lifetime of atomic-O in the thermosphere results in downward transport to the mesopause where there is a rapid enhancement of the conversion of active-O to $\mathrm{O}_{2}$ (Figure 7). The lifetime of active-O has become short (Figure 2) without a proportionately increased source which would offset the effect of the extra loss. With decreasing altitude to $80 \mathrm{~km}$, the extra reactivity of active- $O$ is the result of the increasing $\mathrm{OH}$ abundance (Figure 13c), which catalyzes the active- $\mathrm{O}$ conversion to $\mathrm{O}_{2}$ (Figure 4). Thus, ultimately the $\mathrm{O}_{3}$ secondary maximum is tied to the presence and photochemistry of $\mathrm{H}_{2} \mathrm{O}$ at the mesopause. The rapid decrease of $\mathrm{OH}$ with increasing altitude above 80 $\mathrm{km}$ results from the increasing photolysis of $\mathrm{H}_{2} \mathrm{O}$, leading to a sharp dropoff in the $\mathrm{H}_{2} \mathrm{O}$ profile (Figure 14) and the consequent decrease in active-H production. The active-H produced is rapidly converted to $\mathrm{H}_{2}$, from which little active-H can be derived (Figure 7). Moreover, the active- $\mathrm{H}$ that is present is predominantly atomic-H rather than $\mathrm{OH}$. The depth of the local minimum at $80 \mathrm{~km}$ varies significantly as a function of time of day as discussed earlier in this paper. The subsequent increase in $\mathrm{O}_{3}$ concentration with decreasing altitude through the mesosphere results from the increasing atmospheric density causing in turn an increase in the production of active-O from the photodissociation of $\mathrm{O}_{2}$ (reactions (R1)-(R2)) and an increase in the ratio of $\mathrm{O}_{3}$ to atomic-O. Throughout this lower altitude range, the $\mathrm{OH}$ concentration profile is relatively constant so active- $H$ chemistry plays a less important role in affecting the shape of the $\mathrm{O}_{3}$ profile.

Above the altitude of the local maximum in the $\mathrm{O}_{3}$ density in the lower thermosphere, the $\mathrm{O}_{3}$ concentration progressively decreases with increasing altitude, for example, as observed in the Aladdin 74 flight (see Figure 11). Although the basic model of this paper is able to reproduce the $\mathrm{O}_{3}$ profile right above the mesopause, the calculated falloff with increasing altitude is very different than what was observed, in spite of the fact that the important species affecting the $\mathrm{O}_{3}$ profile (equation (1)) are properly calculated (see Paper I). The difference between our model results and the Aladdin 74 observation is a factor of $2.5-7$ at $100 \mathrm{~km}$. In addi- tion to the Weeks et al. [1978] Aladdin 74 daylight measurement of $\mathrm{O}_{3}$ above the secondary maximum, other observations of $\mathrm{O}_{3}$ in this altitude range have been made at night. The results of the basic model of this paper are 4.7 $\times 10^{6}$ and $4.2 \times 10^{3} \mathrm{~cm}^{-3}$ for the $O_{3}$ densities at 100 and $110 \mathrm{~km}$, respectively, at midnight. At a different season and phase of solar cycle, with variations in environmental factors, the model midnight value at $100 \mathrm{~km}$ could be higher by a factor of 5 and at $110 \mathrm{~km}$ higher by a factor of 50. The measurements of Hays and Roble [1973] of between $10^{6}$ and $10^{7} \mathrm{~cm}^{-3}$ for $\mathrm{O}_{3}$ at $100 \mathrm{~km}$ can be accounted for by the model. However, the Riegler et al. [1977] values of $2 \times 10^{8}$ and $2 \times 10^{7} \mathrm{~cm}^{-3}$ at 100 and 110 $\mathrm{km}$, respectively, and the Vaughan [1982] measurement of $6 \times 10^{7} \mathrm{~cm}^{-3}$ at $100 \mathrm{~km}$ are not readily explained by our current model. One possibility is that the $\mathrm{O}_{3}$ chemistry above $95 \mathrm{~km}$ may be different from that between 50 and 95 $\mathbf{k m}$. Further discussion of this point will appear in another paper.

\section{NATURAL VARIABILITY OF OZONE}

To improve the agreement between the $\mathrm{O}_{3}$ profile measured in the Aladdin 74 program and model results generated for the purposes of intercomparison, a number of critical parameters were considered and modified within reasonable limits: chemical rate constants and the climatological factors of atmospheric composition, mass transport rates, and temperature field. Along with changing solar zenith angle that results in diurnal variations in the $\mathrm{O}_{3}$ profile, natural fluctuations of environmental parameters will result in different $\mathrm{O}_{3}$ distributions being observed. A good test of our model description of the $\mathrm{O}_{3}$ chemistry would be to explain the natural variability of $\mathrm{O}_{3}$ as reflected in the accumulation of $\mathrm{O}_{3}$ measurements, much of which have been recently acquired by a variety of sensors in earth orbit.

In Table 3, we present a systematic summary of the sensitivity of $\mathrm{O}_{3}$ to changes in various atmospheric parameters. There is no entry for the $\mathrm{O}_{3}$ perturbation resulting from variability in vertical transport because of the difficulty in characterizing a change in a simple fashion, but a sense of this effect is presented earlier in this paper. The impact of the diurnal cycle in solar insolation was discussed from a theoretical point of view earlier in this paper, the model results will be compared with a number of recently obtained observations in the next section.

Variations in the solar illumination also result from seasonal changes in the mean solar illumination angle and from the 11-year cycle in the spectral output of the sun (the spectral changes of the 27-day solar cycle being similar but smaller in magnitude, as clearly measured by the Solar Mesosphere Explorer [Rottman et al., 1982]). Sensitivity tests were run for these two cases and the results are in Table 3.

The reduction in solar illumination from summer to winter (mean zenith angle is increased) increases the daytime ozone level below $80 \mathrm{~km}$ because the photolytic source of active-H decreases proportionately more than the photolytic production of active-O or the photodissociation of $\mathrm{O}_{3}$, the ratio of the last two remaining relatively constant (see Table 2). Above $80 \mathrm{~km}$, the reduction in photolytic rate 
constants has the opposite effect; $\mathrm{O}_{3}$ decreases as a consequence of more $\mathrm{H}_{2} \mathrm{O}$ at the mesopause and a decreased abundance (and downward flux) of atomic-O. These results assume that all other parameters, including temperature and transport parameters, will not change with season. However, at latitude $40^{\circ} \mathrm{N}$, the mean December temperature is about $10 \mathrm{~K}$ less than the mean June value at $50 \mathrm{~km}$ altitude but is $-20 \mathrm{~K}$ warmer at $80 \mathrm{~km}$ (CIRA, 1972). This temperature variability enhances the summer to winter increase in $\mathrm{O}_{3}$ in the lower mesosphere and can double the summer to winter reduction at $80 \mathrm{~km}$ (see Table 3). The additivity of the effects of variation in illumination and temperature is correct only when these changes are referred to the same pressure level in both seasons (see later discussion).

When the solar zenith angle is constant (fixed season) and the solar spectrum is changed from solar minimum to solar maximum, the calculations predict minimal change in mesospheric $\mathrm{O}_{3}$, but an appreciable increase in $\mathrm{O}_{3}$ at and above the mesopause. The altitude trend in the magnitude of the variation in summer shown in Table 3 is similar to that reported by Garcia et al. [1983]. Brasseur et al. [1983] calculate an increase throughout most of the summer mesosphere and also a smaller increase in the lower thermosphere than in Garcia et al. [1983] or our model. Although they are both two-dimensional calculations, Brasseur et al. [1983] find $\mathrm{O}_{3}$ decreasing at the winter mesopause while Garcia et al. [1983] see minimal seasonal effects. Computations we have performed using a winter sun support the conclusions of Garcia et al. [1983].

The solar minimum to solar maximum increase in $\mathrm{O}_{3}$ at the mesopause and in the lower thermosphere is a consequence of two effects [Garcia et al., 1983; S. Solomon, private communication, 1983], tied to the increase in solar flux at Lyman $\alpha$ by almost a factor of 2, while at the same time solar flux longward of $180 \mathrm{~nm}$ changes very little [Mount and Rottman, 1981]. If the $\mathrm{H}_{2} \mathrm{O}$ profile in the calculations were to be fixed, the increased photolysis of $\mathrm{H}_{2} \mathrm{O}$ at Lyman a would result in less $\mathrm{O}_{3}$. But the photolytic lifetime of $\mathrm{H}_{2} \mathrm{O}$ is comparable to the time scale for replenishment by upward transport at and above the mesopause such that over the course of the 11-year solar cycle (or the 27day cycle) the $\mathrm{H}_{2} \mathrm{O}$ abundance will change, becoming lower at solar maximum as illustrated in Figure $5 b$ of Paper I. In addition, at solar maximum, $\mathrm{O}_{2}$ photodissociation and the downward flux of atomic-O increases. Because the atmosphere is optically thick at the Lyman $\alpha$ wavelength below the mesopause, the model predicts little change in the $\mathrm{O}_{3}$ profile below $80 \mathrm{~km}$ over the course of either solar cycle. These conclusions are contrary to some earlier model calculations of the solar cycle effects on mesospheric $\mathrm{O}_{3}$. The 11-year solar cycle computations of DeBaets et al. [1981] show large decreases in $\mathrm{O}_{3}$ above $70 \mathrm{~km}$ at solar maximum. This result is probably because the $\mathrm{H}_{2} \mathrm{O}$ profile was held constant for the comparison, although this detail is not addressed in the paper. Similarly, the 27-day solar cycle model calculations of Frederick [1977] show large negative changes in $\mathrm{O}_{3}$ above $-65 \mathrm{~km}$ at the maximum of Lyman $\alpha$ emission. In this case, Frederick [1977] clearly states that the $\mathrm{H}_{2} \mathrm{O}$ profile was left unchanged. Since the time scales for photolysis of $\mathrm{H}_{2} \mathrm{O}$ and eddy diffusion transport are less than or about a few days below $100 \mathrm{~km}$ (see Figure 1 in
Paper I), actually not much change in $\mathrm{O}_{3}$ should be expected during the course of a 27-day cycle. To examine this point further, we did a 14-day calculation (diurnally averaged radiation field) using a solar maximum spectrum but starting at the basic model $\mathrm{O}_{3}$ profile for solar minimum illumination. Minimal change $(\leq 1 \%)$ occurred below $80 \mathrm{~km}$, but above there were increases in $\mathrm{O}_{3}$ of $8 \%$ at $84 \mathrm{~km}, 28 \%$ at $90 \mathrm{~km}$, and $16 \%$ at $100 \mathrm{~km}$. Since the actual variation in the solar spectrum over a 27 -day cycle is less than over the 11-year cycle, such changes in $\mathrm{O}_{3}$ in a 14-day period would not be expected, but the trend is suggestive.

The sensitivity of the $\mathrm{O}_{3}$ profile to the local values of $\mathrm{H}_{2} \mathrm{O}$ and temperature has already been discussed at several points in this paper. The distribution of $\mathrm{H}_{2} \mathrm{O}$ above the stratopause is very dependent on the upward transport from the stratosphere as represented in our model computations by the $40 \mathrm{~km}$ (lower) boundary condition entered for the $\mathrm{H}_{2} \mathrm{O}$ mixing ratio. Table 3 shows the consequences of the different values used in our calculations. To enhance the ability of the calculations to reproduce the Aladdin 74 observations, the adopted temperature feld was increased by $20 \mathrm{~K}$. The effect of such a change is also summarized in Table 3. The enhanced sensitivity to variation in temperature at the stratopause and in the lower thermosphere is due to the increased importance of $\mathrm{O}+\mathrm{O}_{3}$ (reaction (R16)) to the loss of $\mathrm{O}_{3}$ at these altitudes. Among the reactions to which $\mathrm{O}_{3}$ is most sensitive, the activation energy of (R16) is one of the largest. The change in $\mathrm{O}_{3}$ due to temperature fluctuations at a given altitude actually will be somewhat different from the values reported in Table 3 because at a specific altitude temperature and pressure are inversely correlated, leading to changes in photolytic rate constants. However, in the calculations reported in Table 3, the density profile has been held constant so that the indicated degree of variation roughly represents the sensitivity at the pressure associated with the stated altitude in the basic model. Measurements of the response of $\mathrm{O}_{3}$ to temperature changes have been derived from an intercomparison of near simultaneous NIMBUS 4 observations of temperature and ozone abundance at the same pressure level and solar illumination angle (and therefore relatively unvarying photolytic rates) yielding the relation that $d\left(\ln \left[\mathrm{O}_{3}\right]\right) / d(1 / T)=$ $1000-1200 \mathrm{~K}$ at $0.9 \mathrm{mbar}\left(-50 \mathrm{~km}, 45^{\circ} \mathrm{S}\right.$, September 5 , 1970) [Barnett et al., 1975]. Also with data from NIMBUS 4, an analysis of temperature and ozone variations at the stratopause at $60^{\circ} \mathrm{N}$ over a 12 month period in 1970-1971 yields an $\mathrm{O}_{3}$ temperature sensitivity of $1062 \mathrm{~K}$ [Krueger et al., 1980]. In our model, the sensitivity at $50 \mathrm{~km}$ (constant density) to temperature fluctuations occurring on time scales less than -12 hours shows a covariance of $-1120 \mathrm{~K}$. If all species, including long-lived ones such as $\mathrm{H}_{2} \mathrm{O}$, are allowed to relax to steady state with varying temperatures, the covariance increases to $1300 \mathrm{~K}$.

Tuned for the circumstances of the Aladdin 74 measurements, our model results can also be compared with a larger group of mid-latitude $\mathrm{O}_{3}$ observations if the variability of solar insolation and climatological parameters (Table 3) is kept in mind. Indeed, the variety of conditions under which the available measurements have been made can be used to check the predictions of our model. The discussion of model results and $\mathrm{O}_{3}$ observations at the mesopause is 
presented elsewhere in this paper. However, most measurements have been of the lower mesosphere, which is fortuitous for the purposes of this comparison since solar cycle effects are expected to be minimal and the daytime variability due to changing solar zenith angle is only $\sim 13 \%$ at $50 \mathrm{~km}, 25 \%$ at $60 \mathrm{~km}$, increasing to $41 \%$ at $70 \mathrm{~km}$ in our model. The variability of seasonally changing illumination and local $\mathrm{H}_{2} \mathrm{O}$ abundance potentially can add variance from model predictions (see Table 3) of $16 \%$ at $50 \mathrm{~km}, 18 \%$ at 60 $\mathrm{km}$, increasing to $46 \%$ at $70 \mathrm{~km}$. The exact value of the local temperature is the parameter in the lower mesosphere that can have the biggest impact on the observed value of $\mathrm{O}_{3}$, adding a potential variability factor of $34 \%$ at $50 \mathrm{~km}$, $22 \%$ at $60 \mathrm{~km}$, and $26 \%$ at $70 \mathrm{~km}$ for a $20 \mathrm{~K}$ change in temperature.

Since the temperature profile of our basic model has been modified to improve the agreement with observations at a particular epoch, it is best to compare model computations utilizing a standard temperature profile with the larger set of published mid-latitude measurements (with the focus on northern hemisphere data obtained since 1971). As all model and observational profiles smoothly decrease from the stratopause to $70 \mathrm{~km}$, selected altitudes can reliably represent more detailed profiles. Resulting from a calculation using the temperature profiles of Paper $I$, the diurnally averaged (approximately mean daylight) solar minimum mid-latitude summer $\mathrm{O}_{3}$ values are $3.4 \mathrm{ppmv}\left(8.0 \times 10^{10}\right.$ $\left.\mathrm{cm}^{-3}\right)$ at $50 \mathrm{~km}, 2.1 \mathrm{ppmv}\left(2.7 \times 10^{10} \mathrm{~cm}^{-3}\right)$ at $55 \mathrm{~km}, 1.3$ ppmv $\left(9.1 \times 10^{9} \mathrm{~cm}^{-3}\right)$ at $60 \mathrm{~km}, 0.78 \mathrm{ppmv}\left(3.1 \times 10^{9}\right.$ $\left.\mathrm{cm}^{-3}\right)$ at $65 \mathrm{~km}$, and $0.39 \mathrm{ppmv}\left(7.9 \times 10^{8} \mathrm{~cm}^{-3}\right)$ at $70 \mathrm{~km}$. Krueger and Minzner [1976] determined a mean ozone profile, nominally for $45^{\circ} \mathrm{N}$ latitude, by averaging the results of a variety of measurement techniques (balloon-, rocket-, and satellite-borne sensors) to obtain annual mean daylight values of $3.1( \pm 17 \%)$ ppmv at $50 \mathrm{~km}, 1.1( \pm 34 \%)$ ppmv at $60 \mathrm{~km}$, and $0.31( \pm 57 \%) \mathrm{ppmv}$ at $70 \mathrm{~km}$, which are in very good agreement with our model results. It is interesting to note the increase in the uncertainty in the mean value with increasing altitude, varying as expected if just diurnal changes are considered. Most relevant for comparison with our model tuned for the epoch of Aladdin 74 are the midlatitude summer measurements obtained by several satellite experiments the next summer (July 1975) when the solar activity was still at a minimum. The NIMBUS 6 LRIR instrument measured daytime $\mathrm{O}_{3}$ values for $38^{\circ} \mathrm{N}$ of -3.3 ppmv at $50 \mathrm{~km}$ and $-1.5 \mathrm{ppmv}$ at $60 \mathrm{~km}$ [Gille, 1980; Gille et al., 1980c). Mid-latitude $\mathrm{O}_{3}$ values from the OSO 8 ultraviolet solar occultation (sunset) experiment obtained during the same time period are $-2-2.2 \times 10^{10} \mathrm{~cm}^{-3}$ at 55 $\mathrm{km}, \sim 8.5 \times 10^{10} \mathrm{~cm}^{-3}$ at $60 \mathrm{~km}$, and $\sim 2.5 \times 10^{9} \mathrm{~cm}^{-3}$ at $65 \mathrm{~km}$. Ogawa and Watanabe [1981] report $\mathrm{O}_{3}$ densities for late summer at $31^{\circ} \mathrm{N}$ acquired during a 9 year (19701979) series of rocket ultraviolet solar absorption measurements; the mean values are $\sim 7 \times 10^{10} \mathrm{~cm}^{-3}$ at $50 \mathrm{~km}, \sim 8$ $\times 10^{9} \mathrm{~cm}^{-3}$ at $60 \mathrm{~km}$, and $-8 \times 10^{8} \mathrm{~cm}^{-3} \mathrm{~cm}$ at $70 \mathrm{~km}$. The agreement between the model results and observational values is very good, considering that most of these observations have measurement uncertainties of at least $10 \%$.

During late fall 1979 (solar maximum), two series of rocket-borne solar and lunar ultraviolet absorption experiments were carried out to determine detailed vertical $\mathrm{O}_{3}$ profiles at different times of the day. The Lean [1982] series was launched at $38^{\circ} \mathrm{N}$ latitude over a 2-week period. At a more northerly latitude a few weeks earlier, Vaughan [1982] had several flights in a 24-hour period. A discussion of the diurnal variability observed by these experiments is saved for the next section; at this point we will compare the model results with representative points on the vertical profiles. The Lean [1982] noontime value for $\mathrm{O}_{3}$ at $50 \mathrm{~km}$ was $\sim 5.5 \times 10^{10} \mathrm{~cm}^{-3}$, and the sunset $\left(\chi-87^{\circ}\right)$ values were $-6 \times 10^{10} \mathrm{~cm}^{-3}$ at $50 \mathrm{~km},-6 \times 10^{9} \mathrm{~cm}^{-3}$ at $60 \mathrm{~km}$, and $-2.5 \times 10^{8} \mathrm{~cm}^{-3}( \pm 50 \%)$ at $70 \mathrm{~km}$. The midmorning values $\left(\chi-70^{\circ}\right)$ observed by Vaughan [1982] were $6 \times 10^{10}$ $\mathrm{cm}^{-3}$ at $50 \mathrm{~km}$ and $6 \times 10^{9} \mathrm{~cm}^{-3}$ at $60 \mathrm{~km}$. The corresponding values of our model, calculated with a solar maximum sun at equinox at $34^{\circ} \mathrm{N}$ latitude and a March 1 background atmosphere (see next section) are at 9 A.M. ( $\chi$ - 64') $7.1 \times 10^{10} \mathrm{~cm}^{-3}(50 \mathrm{~km})$ and $7.5 \times 10^{9} \mathrm{~cm}^{-3}(60$ $\mathrm{km})$, at noon $6.4 \times 10^{10} \mathrm{~cm}^{-3}(50 \mathrm{~km})$, and at sunset $(\chi-$ $\left.88^{\circ}\right) 7.3 \times 10^{10} \mathrm{~cm}^{-3}(50 \mathrm{~km}), 7.8 \times 10^{9} \mathrm{~cm}^{-3}(60 \mathrm{~km})$, and $3.2 \times 10^{8} \mathrm{~cm}^{-3}(70 \mathrm{~km})$. Our computations are systematically 15-20\% larger than the late fall observations. However, this can be explained by seasonal differences in the background atmosphere (the pressure at a given altitude in fall is lower than in spring, resulting in larger photolytic rate constants and slower three-body reactions) which result in spring $\mathrm{O}_{3}$ values being larger than fall values by about $20 \%$ in both model calculations and observations [Prather, 19811.

Observations by the Solar Mesosphere Explorer (SME) satellite of scattered solar ultraviolet [Rusch et al., 1983a] and infrared airglow [Thomas et al., 1983] during the first winter of the recent onset of low solar activity find values for mid-latitude $\mathrm{O}_{3}$ in the afternoon (local time) of $\sim 3$ ppmv at $50 \mathrm{~km}, \sim 0.8 \mathrm{ppmv}$ at $60 \mathrm{~km}$, and $\sim 0.25 \mathrm{ppmv}$ at $70 \mathrm{~km}$. The results of our model run with a winter sun (set to the epoch of the Anderson et al. [1980] flight) and a January 1 background atmosphere (CIRA, 1972) are 2.8 ppmv at $50 \mathrm{~km}, 1.1 \mathrm{ppmv}$ at $60 \mathrm{~km}$, and $0.28 \mathrm{ppmv}$ at 70 $\mathrm{km}$, in good agreement with the observations considering the measurement uncertainties and the degree of variability in the observations [Barth et al., 1983].

Systematic changes in $\mathrm{O}_{3}$ due to seasonal variability of key climatological parameters are implicit in the differences in the $\mathrm{O}_{3}$ profiles (models and observations) for the different seasons just discussed. Using data from different experiments to determine secular variations will probably introduce errors due to systematic differences between the experiments, so the following discussion will emphasize comparison with single instrument data sets. As discussed by Prather [1981], model seasonal trends must be referred to a constant pressure or altitude, whichever is appropriate for the comparison observational data set, since the results in the two cases are different. In agreement with his model computations, we find that, upon using the appropriate background model atmosphere and solar illumination, at a specific altitude the $\mathrm{O}_{3}$ density in winter is $25-45 \%$ less $\left(\mathrm{O}_{3}\right.$ mixing ratio $15-30 \%$ less) than in summer, between 50 and $90 \mathrm{~km}$. On the other hand, at a constant pressure level (to which the constant density calculations reported in Table 3 are very similar) there is a summer to winter increase of $28 \%$ near 1 mbar, $-20 \%$ increase near 0.1 mbar (where there is little seasonal temperature variation), and a $73 \%$ decrease near $\mathbf{0 . 0 0 1}$ mbar. Intercomparisons of rocket mea- 
surements reveal seasonal variations usually at a given altitude. The summer to winter decrease in the lower mesosphere calculated in our model and that of Prather [1981] is seen in the ROCOZ (rocket ozone project) results at $38^{\circ} \mathrm{N}$ from 1976 to 1979 [Wright et al., 1978; Krueger and Wright, 1979]. On the other hand, Ogawa and Watanabe [1981] find at 60 and $70 \mathrm{~km}$ at $31^{\circ} \mathrm{N}$ latitude a summer to winter increase of a factor of 2 , which is not supported by the observations of others nor can it be reproduced by any current model. Satellite experiments often measure $\mathrm{O}_{3}$ relative to pressure. At $1 \mathrm{mbar}$ at mid-latitudes, the NIMBUS 4 BUV data acquired over a 2-year period (1970-1972) and the NIMBUS 7 SBUV data obtained in 1978 and 1979 show a $40 \%$ increase in winter $\mathrm{O}_{3}$ values [McPeters, 1980; Frederick et al., 1983].

Probably the most detailed measurements of seasonal changes in $\mathrm{O}_{3}$ come from the SME satellite program [Barth et al., 1983]. Obtained continuously during the first 6 months of 1982, the SME results for $\mathrm{O}_{3}$ at $48 \mathrm{~km}$ at midlatitudes clearly show an inverse correlation between the $\mathrm{O}_{3}$ abundance and seasonal variation in temperature [Barth et al., 1983] which was measured simultaneously [Rusch et al., $1983 \mathrm{~b}$ ]. At $48 \mathrm{~km}$, the summer to winter increase in $\mathrm{O}_{3}$ is $-17 \%$ in both hemispheres, while at $64 \mathrm{~km}$ the SME measures a summer to winter decrease of $\sim 33 \%$ in the northern hemisphere and $-8 \%$ in the southern hemisphere and at 90 $\mathrm{km}$ a decrease in the mean seasonal value of $\leq 18 \%$ in both hemispheres [Barth et al., 1983]. The exact magnitude of these changes depends on whether the variation refers to a constant altitude surface, as was the case just quoted, or a constant pressure surface, as seen in the $40^{\circ} \mathrm{S}$ results of Thomas et al. [1983] where the summer to winter increase is $40 \%$ at $1 \mathrm{mbar}(\sim 48 \mathrm{~km})$ (cf. BUV/SBUV results) and $20 \%$ at $0.1 \mathrm{mbar}(-64 \mathrm{~km})$ and a decrease of $-20 \%$ at 0.001 mbar $(-90 \mathrm{~km})$. Acquired with a different instrument on the SME, the results of Rusch et al. [1983a] show little seasonal change at $0.1 \mathrm{mbar}$ at $45^{\circ} \mathrm{S}$ latitude.

Except for two instances, the various observations of seasonal trends in $\mathrm{O}_{3}$ in the lower mesosphere are in reasonably good agreement with each other and with models. As discussed before, the Ogawa and Watanabe [1981] measurements cannot be explained. The SME results at $48 \mathrm{~km}$ (constant altitude) showing a summer to winter increase [Barth et al., 1983] are not consistent with other observations and model calculations referred to a constant altitude. The difference could result from small errors in determining the SME altitude scale. However, in the lower thermosphere $(90 \mathrm{~km})$, the SME-measured summer to winter $\mathrm{O}_{3}$ decrease [Barth et al., 1983; Thomas et al., 1983] is significantly smaller than in the model. One factor that has not been included in the model estimates of seasonal variation is the possibility of systematic changes in atmospheric motion. Either as the result of summer to winter hemispheric transport [Garcia and Solomon, 1983] or as a consequence of seasonal variation in eddy diffusion [Lindzen, 1981], the upward flow of $\mathrm{H}_{2} \mathrm{O}$ to the mesopause may be enhanced in summer relative to the winter, diminishing the contrast in mesopause $\mathrm{H}_{2} \mathrm{O}$ values (that occur due to seasonal changes in solar zenith angle) and the consequent variation in $\mathrm{O}_{3}$. The interhemisphere motions will enhance the downward transport of atomic $O$ from the thermosphere in the winter and thereby contribute to higher
$\mathrm{O}_{3}$ values at the mesopause and in the lower thermosphere than our current model would produce.

The model prediction of little systematic variation in $\mathrm{O}_{3}$ in the lower mesosphere due to solar cycle effects is consistent with several different observations. The 9 years of rocket measurements accumulated by Ogawa and Watanabe [1981] show no variation correlated with the phase of the solar cycle. Indeed, the mid-latitude winter measurements obtained by OGO 4 during an earlier period of heightened solar activity (late 1960's) [London et al., 1977; Clayson et al., 1981] and the results obtained during the most recent time of maximum solar output [Remsberg et al., 1981; Sundararamen et al., 1981; WMO, 1981] are in good agreement with the measured solar minimum winter values quoted earlier. Again, one must keep in mind the potential for error when making comparisons between data acquired by different experiments.

\section{DIURNAL VARIATION OF OZONE}

Earlier in this paper the chemical interactions resulting in the diurnal variation of ozone in the mesosphere and lower thermosphere were discussed and the results of the basic model illustrated in Figure 8. This diurnal variation can play an important role in upper atmospheric phenomena. The magnitude of the variation is diagnostic of key processes affecting the ozone distribution. Therefore, a detailed comparison between models and observations of the diurnal variation is an additional and important test of our theoretical picture of ozone chemistry.

The Aladdin 74 observations, the measurements for which the diurnal results of the basic model are most appropriate, yield only a little information concerning diurnal changes, daylight values in post-dawn and afternoon periods. The chemiluminescent sonde data sets obtained during these two time periods show few differences between 50 and $60 \mathrm{~km}$, consistent with the daytime model results. In Figure 4 of Weeks et al. [1978], the ultraviolet absorption data obtained in early morning are compared with the afternoon data of the airglow photometer between 74 and $84 \mathrm{~km}$. Both measured $\mathrm{O}_{3}$ profiles show structure, but, given the indicated error bars, the reality of any of the features and of any diurnal variation's is not clear. Our diurnal calculation (see Figure 8) predicts that the local minimum in $\mathrm{O}_{3}$ in the mesopause should be enhanced in the post-dawn period compared with late afternoon, but the Aladdin 74 data is not sufficiently precise to check this theoretical result.

The NIMBUS 6 LRIR experiment had the ability to observe $\mathrm{O}_{3}$ during both day and night and preliminary analyses [Gille et al., 1980b] showed a day-to-night increase of $-20( \pm 10) \%$ in the altitude range $56-66 \mathrm{~km}$, but little diurnal change at $50 \mathrm{~km}$, similar to what is predicted by our model. In a more refined investigation employing LRIR measurements, Anderson et al. [1981] obtained an internally consistent set of data for $\mathrm{O}_{3}$ at $50^{\circ} \mathrm{S}$ latitude on December 19-21, 1975. Being from the solar minimum period and at the southern hemisphere summer solstice, these observational results are directly comparable with the model calculations shown in Figure 8 . At $50 \mathrm{~km}$, Anderson et al. [1981] report $O_{3}$ night $\left(\chi-97^{\circ}\right)$ to day $\left(\chi-35^{\circ}\right)$ ratios of 1.1 at $50 \mathrm{~km}$ increasing to $2-3$ at $67 \mathrm{~km}$ (the 


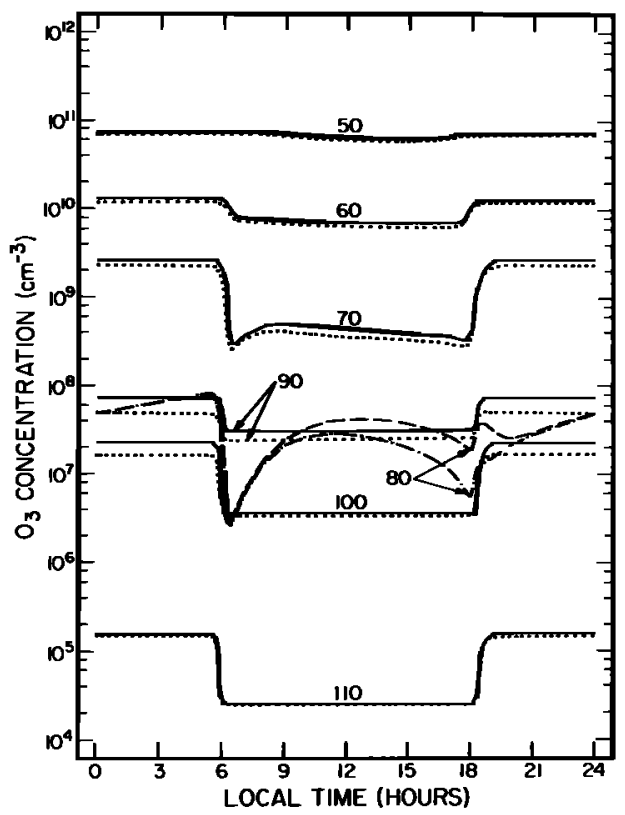

Fig. 16. The diurnal variation of $\mathrm{O}_{3}$ calculated for a near-spring equinox sun at solar maximum at $34^{\circ} \mathrm{N}$ latitude. Results are shown for altitudes $50,60,70,80,90,100$, and $110 \mathrm{~km}$. The concentration of $\mathrm{H}_{2} \mathrm{O}$ at $40 \mathrm{~km}$ is $7 \mathrm{ppmv}$ (solid and dashed lines) or 10 ppmv (dotted and dash-dotted lines). In the latter case, $k_{30}=0$ to maximize the abundance of active-H species near the mesopause.

operational ceiling of the LRIR instrument). For similar zenith angles, our corresponding model values are 1.1 at 50 $\mathrm{km}$ and 3.2 at $67 \mathrm{~km}$.

Most useful for detecting the diurnal changes of $\mathrm{O}_{3}$ are sets of data obtained by the same measurement technique, preferably the same instrument, covering the whole mesosphere and/or including many points in the diurnal cycle. Appreciating the importance of doing such measurements, a number of groups have recently reported the results of experiments that satisfy the aforementioned criterion. Since all of this observational work was conducted during the recent solar maximum time period, we performed diurnal calculations for conditions of solar maximum flux [Mount and Rottman, 1981], close to spring equinox at $34^{\circ} \mathrm{N}$ latitude, using a $30^{\circ} \mathrm{N}$ March 1 model atmosphere (temperature, total density, $\mathrm{N}_{2}$ density versus altitude) from CIRA (1972) and an appropriate thermospheric model from $\mathrm{Jac}$ chia [1977]. The kinetic rate constants, $40 \mathrm{~km} \mathrm{H} \mathrm{H}_{2} \mathrm{O}$ boundary condition of $7 \mathrm{ppmv}$, and eddy diffusion coefficients of the basic model were also used in these computations. We show in Figure 16 the equinox model $\mathrm{O}_{3}$ concentrations for a 24-hour period. The results of a calculation with similar solar illumination have been reported by Rusch and Liu [1981] and are roughly similar to Figure 16 . As might be expected from a combination of different seasonal solar illumination and model atmosphere parameters (see Table 3 ), the noontime $\mathrm{O}_{3}$ densities of this equinox model are within $\pm 20 \%$ of our basic model results below $70 \mathrm{~km}$, in which altitude range solar cycle effects are not significant.

The $\mathrm{O}_{3}$ measurements reported by Lean [1982] are a compilation of rocket results acquired over a 2-week period, October-November 1979 at $38^{\circ} \mathrm{N}$ latitude. Since these flights occurred at different local times (one of them at night [Lean, 1983]), taken together the results can provide a picture of the diurnal variation of $\mathrm{O}_{3}$. Lean [1982] adjusts the new $\mathrm{O}_{3}$ values to account for probable environmental changes occurring over the 2-week period that would affect the $\mathrm{O}_{3}$ measurements. The observational results for the change from night (0527 LST) to day ( - noon local time) are $-12 \%(50 \mathrm{~km}),-45 \%(60 \mathrm{~km})$, and $-84 \%(70 \mathrm{~km})$, the equinox model results being very similar $(-15,-45,-83 \%$, respectively). The $\mathrm{O}_{3}$ values were also observed to decrease from midmorning to early-afternoon by about $10-15 \%$ at 50 and $60 \mathrm{~km}$, model results again being similar. Interestingly, the sunset observations in the mesosphere are less than the nighttime values because the altitude range is still well illuminated.

The Vaughan [1982] rocket measurements of $\mathrm{O}_{3}$ diurnal variation come from flights that all occurred within a 24 hour period (night: 0200 LST, dawn: 0600 LST, morning: 0930 LST). The background atmosphere is not expected to have changed as much as occurred in the Lean [1982] rocket series. Since the rocket launches were at $57^{\circ} \mathrm{N}$ in early October of 1979 , the solar insolation will be similar to or even a little less than the equinox model with which the observations will be compared. Little diurnal variation was observed below $54 \mathrm{~km}$. Above that altitude, there was an observed decrease from night to morning of $-39 \%$ at 60 $\mathrm{km}$, the model predicting a $42 \%$ decrease. From nighttime to dawn $\left(\chi-95.5^{\circ}\right)$ Vaughan [1982] observed a factor of 10 decrease in $\mathrm{O}_{3}$ at $70 \mathrm{~km}$ and a similar decrease above 80 km. The model does not show such changes over a similar time span. Since the 2 A.M. flight also observed an unusually large secondary maximum, the data from this particular flight may conceivably be erroneous or conditions were such as to invalidate the comparison with our equinox model.

Resulting from ground-based radio observations of atmospheric ozone emission, the diurnal $\mathrm{O}_{3}$ measurements of Wilson and Schwartz [1981] have poor spatial resolution. However, these observations present the most detailed picture of the temporal variation of ozone yet published since data were obtained continuously throughout several full diurnal cycles. Wilson and Schwartz [1981] present their data in three different ways. In each case there may be errors due to the difficulties inherent in accurately measuring radio emission and interpreting such data in terms of vertical distribution. In Figure 2 of Wilson and Schwartz [1981], vertical profiles for $\mathrm{O}_{3}$ for noon and midnight derived from their data are shown. They find very little difference between day and night values (within their error bars of $\pm 70 \%$ ) below $60 \mathrm{~km}$, consistent with model calculations. The night-to-day ratio increases above $60 \mathrm{~km}$ to very large values. These $\mathrm{O}_{3}$ distributions are derived from the observed emission spectra shown in their Figure 1 where it is seen that the area of the central channel, sensitive to the total $\mathrm{O}_{3}$ column above $70 \mathrm{~km}$, increases from noon to midnight by a factor of $10^{3}$. On the other hand, contradicting this result are the data plotted in their Figure 4 which, averaged over a 10-day period, are the brightness temperature differences between their observing channels, each difference pairing being sensitive to the $\mathrm{O}_{3}$ column in somewhat different altitude ranges above the stratopause. The results shown in their Figure 4 display only a $150 \%$ increase in column $\mathrm{O}_{3}$ above $\sim 70 \mathrm{~km}$ compared with the $10^{3}$ increase of their Figures 1 and 2 . The observations 
presented in their Figures 1 and 2 are only from one particular day, so the mean behavior may be better represented by the average results in their Figure 4. Their Figures 1 and 2 further may be considered to have large errors because the results of other diurnal measurements (and model calculations) already discussed in our paper show changes of a factor of 10 or less. The $\mathrm{O}_{3}$ profiles shown in their Figure 2 retrieved from their Figure 1 may also be in error in that the mixing ratio at $50 \mathrm{~km}$ is $\sim 1 \mathrm{ppmv}$ and at $60 \mathrm{~km} 0.2$ ppmv, significantly lower than the range of $\mathrm{O}_{3}$ values measured in the lower mesosphere by a variety of techniques, all of which are very close to each other independent of a variety of fluctuations in environmental factors.

It seems that the results in Figure 4 of Wilson and Schwartz [1981], which are an average of 10 days of observation, hold the most promise for containing useful information, with which model computations can be compared. The solar illumination adopted for the equinox model calculation (the diurnal results appearing in our Figure 16) was specifically chosen to simulate the circumstances of these radio observations. Since the Wilson and Schwartz [1981] Figure 4 results are each convolutions over several scale heights, we smoothed our model values by the difference weighting functions in Figure 3 of Wilson and Schwartz [1981] to generate comparable diurnal profiles. The results of the model smoothing and the observed brightness temperature differences were each normalized to the minimum point of the 24-hour period and are presented as the percentage increase above the minimum point in Figure 17. Figure 5 of Wilson and Schwartz [1981] is a temporally smoothed version of their data shown in Figure 17. The convolved diurnal variations for $48-68 \mathrm{~km}$ and $58-76 \mathrm{~km}$ are similar in the model and observations (within the noise limits). However, the convolved model variation for 76$114 \mathrm{~km}$ needs to be reduced by a factor of 4 in order to match the measurements. Why the observational result for the highest altitude range could be in error by as much as a factor of 4 is as follows. The minimum value for the brightness temperature difference is only $1 \%$ of the observed signals being differenced. Considering the noise in the recorded spectra as represented by the noise in the brightness temperature differences shown in Figure 4 of Wilson and Schwartz [1981], one cannot exclude the possibility of an unremoved nonlinear baseline that varied by $\geq 1 \%$ per channel (W. Wilson, private communication, 1982). This would introduce errors in the night-to-day variation as plotted in Figure 17, the largest error occurring in the 76-114 km calculation where the differences are smallest. Furthermore, our calculations for $\mathrm{O}_{3}$ at the mesopause earlier in this paper have been shown to be consistent with other observations.

It is interesting to note from the structure in the smoothed model diurnal variabilities (Figure 17) that in each case the altitude to which the convolved profile is most sensitive is not the one at the peak of the weighting function (such would be the case only if $\mathrm{O}_{3}$ were uniformly distributed in altitude). The 76-114 $\mathrm{km}$ smoothed profile clearly shows the structure of $\mathrm{O}_{3}$ variability in a narrow range at the mesopause, far below the peak of the weighting function.

When the 76-114 model convolution is reduced by a factor of 4 , the observed variability in $\mathrm{O}_{3}$ is reproduced by the model. In particular, the model shows a night-to-day decrease an hour before ground sunrise as a result of the sphericity of the terrestrial atmosphere. Both the symmetry around noon in daylight $\mathrm{O}_{3}$ values in the lower mesosphere and the asymmetry in the upper mesosphere as seen in the radio data are reproduced by the model calculations. When appropriately scaled to match the gross night-to-day variation, the smoothed model result for $76-114 \mathrm{~km}$ shows that some structure due to the unusual mesopause variability (see Figure 16) is not washed out but is comparable to the noise level of the observational results. Thus, an observational measurement sensitive enough to prove or disprove the existence of this temporal structure predicted by a number of models, including our own, does not yet exist.

The observations available to date are fairly well reproduced by model calculations. It is clear that the diumal variability of $\mathrm{O}_{3}$ will change with differences in key environmental factors. A comparison of Figures 8 and 16 shows that the varying length of day due to changing season will result in very dissimilar diurnal profiles. Another factor explored by M. Prather (private communication, 1980) and Vaughan [1982] is the impact of different amounts of active

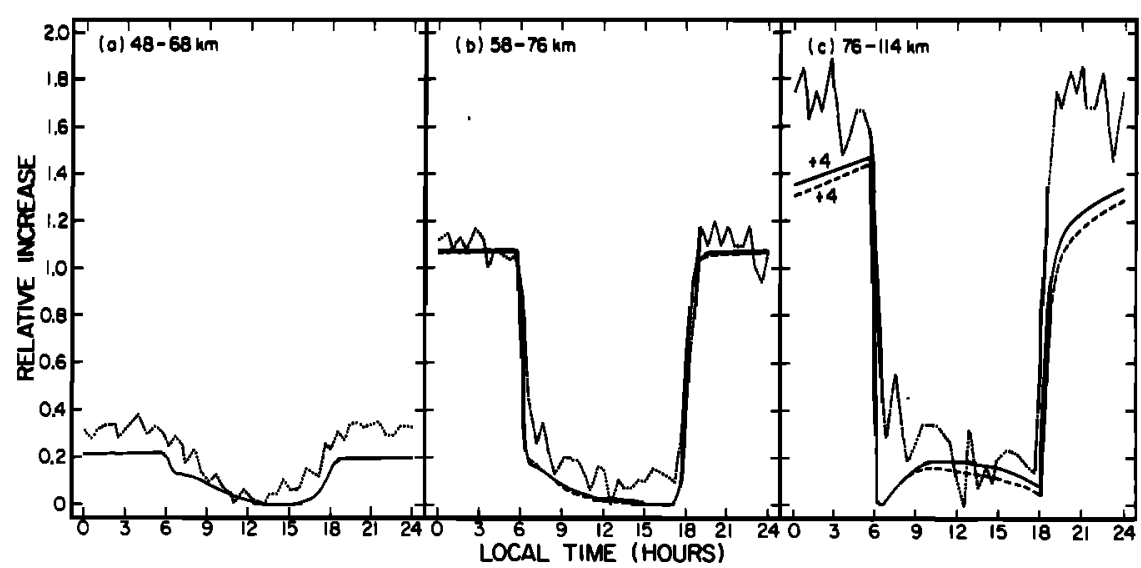

Fig. 17. The results of the calculations described in Figure 16 smoothed by the weighting functions displayed in Figure 3 of Wilson and Schwartz [1981]. The solid line is the 7 ppmv model and the dashed line is the 10 ppmv model. The dotted lines are the measured brightness temperature differences from Figure 4 of Wilson and Schwartz [1981]. In the case of the 76-114 km convolution $(c)$, the model values are reduced by a factor of 4 (see text). 
hydrogen (as controlled by the $\mathrm{H}_{2} \mathrm{O}$ abundance). We performed an equinox diurnal calculation which maximized active- $\mathrm{H}$ by increasing the $\mathrm{H}_{2} \mathrm{O}$ boundary condition at 40 $\mathbf{k m}$ to $10 \mathrm{ppmv}$ and diminishing the active- $\mathrm{H}$ to inactive- $\mathrm{H}$ conversion by setting the rate constant for (R30) $\left(\mathrm{H}+\mathrm{HO}_{2}\right.$ $\rightarrow \mathrm{H}_{2}+\mathrm{O}_{2}$ ) to zero. The resulting diurnal profiles are shown in Figure 16 and the smoothed profiles (as in Wilson and Schwartz [1981]) are displayed in Figure 17. The difference in the $\mathrm{O}_{3}$ diurnal variability due to different amounts of active-H that we have calculated is qualitatively similar to the previously published calculations of others. Given the signal-to-noise of the data, the Wilson and Schwartz [1981] measurements were not sensitive to the precise $\mathrm{H}_{2} \mathrm{O}$ profile at the time of the observations.

\section{COMPARISON WITH OTHER MODELS}

Since the models of ozone in the mesosphere and lower thermosphere that have been published within the past 10 years all have the same important reactions, variability in the results must arise from differences in computational techniques, solar illumination calculations, rate constants, and/or environmental parameters. A survey of this earlier theoretical work in light of our current model will further illustrate the sensitivity of our results to the approach and parameters we have adopted. A comparison of results at certain specific altitudes should be most instructive. At 50 $\mathrm{km}$, there is little variation due to diurnal or solar cycle changes in the solar illumination and only a weak sensitivity to different values adopted for $\mathrm{H}_{2} \mathrm{O}$ at the stratopause. The situation is similar at $60 \mathrm{~km}$, except for the slight diurnal variation between day and night. Thus, variability in the model results for the lower mesosphere will be a consequence mostly of different rate constants being used. On the other hand, the results of the different models at the secondary maximum near $80 \mathrm{~km}$ will be interesting to compare since $\mathrm{O}_{3}$ at this altitude is very reflective of climatological variables used in the computations in addition to the adopted rate constants. One point that simplifies the intercomparison is that the $\mathrm{O}_{3}$ values at noon and midnight at $80 \mathrm{~km}$ are very similar, although the values at other times are very different. A set of parameters not frequently reported is the adopted atmospheric temperature profile. While use of different standard atmospheres might result in changes in the $\mathrm{O}_{3}$ calculations of as much as $50 \%$, we will discuss in this section possible sources of differences between models of greater than $100 \%$.

Hunt [1971, 1973] demonstrated the impact on the ozone profile due to the presence of mesospheric water. His ozone densities are systematically a factor of 2-4 larger than later calculations, but it is impossible to identify a single cause of this difference because all of his key rate constants are different from ours. For one thing, his lower boundary condition (at $60 \mathrm{~km}$ ) for $\mathrm{H}_{2} \mathrm{O}$ is $5 \mathrm{ppmv}$, whereas our $\mathrm{H}_{2} \mathrm{O}$ mixing ratio at the same altitude is $-7 \mathrm{ppmv}$. The drier mesosphere will result in increased $\mathrm{O}_{3}$ (up to $40 \%$, see Table 3) at all altitude levels. Moreover, because of the adopted rate constants, the key active-H species for catalytic destruction of active-O, OH, is significantly less in Hunt [1971, 1973] than in our basic model, also causing an increase in active- $O$. The rate constant for three-body recombination forming $\mathrm{O}_{3}$ is also larger in the aforementioned work.
Differences in the computation of the photolytic rate constants enhance the $\mathrm{O}_{3}$.

The results of Thomas and Bowman [1972] are well suited for comparison with our calculations since theirs is explicitly a mid-latitude model. Their mesosphere is rather dry ( -3 ppmv at $60 \mathrm{~km}$ ). However, the reported $\mathrm{O}_{3}$ densities at $60 \mathrm{~km}$ are surprisingly similar to ours, and the mesopause secondary maximum is smaller than our value, contrary to what is expected. Their $\mathrm{O}_{3}$ can be understood as resulting from the fact that the increased efficiency of three-body $\mathrm{O}_{3}$ formation, low local $\mathrm{H}_{2} \mathrm{O}$, and, at $60 \mathrm{~km}$, a larger value for the ratio of key photolytic rate constants $\left(J_{1+2} / J_{3+4} J J_{+6}^{2}\right)$ are offset by a smaller value for the ratio of key kinetic rate constants $\left[\left(k_{23} / k_{17} k_{18}\right)^{1 / 2}\right]$. At the secondary maximum, near $80 \mathrm{~km}$, both the photolytic rate constant ratio $\left(J_{1+2}^{2} / J_{3+4} J_{5+6}\right)$ and the kinetic rate constant ratio $\left(k_{30} / k_{18} k_{28}\right)$ are lower, thus explaining the reduced $\mathrm{O}_{3}$. In general, the critical rate constants are factors of 2-5 different from what we are using, sometimes larger, sometimes smaller, necessitating the approach of comparing the two models using the simplified analytical expressions.

The Whitten and Turco [1974] and Koshelev [1976] models are very similar in choice of rate constants. The $\mathrm{O}_{3}$ densities in both papers are larger than our values by factors of 2-10. This is true at the mesopause where the development of the secondary maximum is slight and, depending on the choice of the eddy diffusion profile, occurs above 90 km. The high $\mathrm{O}_{3}$ profile is the result of a significant minimization of active-H destruction of active- $\mathrm{O}$ resulting from a very fast value for $\mathrm{OH}+\mathrm{HO}_{2}\left(k_{23}-2 \times 10^{-10} \mathrm{~cm}^{-3} ; 2.3\right.$ times larger than our $k_{23}$ ) conversion of active-H back to inactive-H. The $\mathrm{OH}$ concentration is further suppressed by extra slow cycling from $\mathrm{HO}_{2}$ to $\mathrm{OH}$ via the reaction $\mathrm{O}+$ $\mathrm{HO}_{2}\left(k_{18}-1 \times 10^{-11} \mathrm{~cm}^{-3} \mathrm{~s}^{-1} ; 6\right.$ times smaller than our value).

The model of Moreels et al. [1977] uses rate constants more similar to ours and also has an abundance of $\mathrm{H}_{2} \mathrm{O}$ at $50 \mathrm{~km}(6 \mathrm{ppmv})$ close to the value we have. Although there are some differences in rate constant values, at $50 \mathrm{~km}$ the ratios of the important rate constants are very similar to our ratios such that their calculated $\mathrm{O}_{3}$ concentration is in good agreement with our value. Although their $\mathrm{O}_{3}$ secondary maximum is at about the same altitude as in our model, it is about a factor of 3 larger. This may be most directly due to a mesopause $\mathrm{H}_{2} \mathrm{O}$ concentration 4 times smaller than ours, resulting from a combination of different eddy diffusive transport and the $\mathrm{H}_{2} \mathrm{O}$ photolysis rate constants they report being larger than our values.

With the top boundary near $80 \mathrm{~km}$, Logan et al. [1978] and Prather [1981] cannot properly calculate $O_{3}$ at the mesopause, thus explaining why no structure is seen in the $\mathrm{O}_{3}$ profiles near $80 \mathrm{~km}$. With rate constants close to what we have employed, their models yield $\mathrm{O}_{3}$ profiles in the lower mesosphere in very good agreement with our results. In both cases, the abundance of $\mathrm{H}_{2} \mathrm{O}$ in the lower mesosphere is $\sim 5$ ppmv.

Although of recent vintage, the Keneshea et al. [1979] model uses older values for the key rate constants compared with other contemporary models and our own work. Active-H is suppressed by a fast value for $\mathrm{OH}+\mathrm{HO}_{2}$ and a particularly slow value for $\mathrm{O}+\mathrm{HO}_{2}$, coupled with a drier lower mesosphere of $\sim 4$ ppmv. This can explain their 
values for $\mathrm{O}_{3}$ in the lower mesosphere being larger than ours by factors of 1.5-3. By $80 \mathrm{~km}$, the Keneshea et al. [1979] profile is very similar to our own (magnitude and altitude of secondary maximum); the values of the rate constants of particular importance at the mesopause are closer to what we have. However, no details are presented in that paper concerning the photolytic rate constant values, so further intercomparison is not possible.

Computed $\mathrm{O}_{3}$ densities larger than ours occur in the recent models of Crutzen and Solomon [1980] at $80 \mathrm{~km}$ and of Wang et al. [1981] throughout the mesosphere. In the former work, the use of the Hack et al. [1978, 1979] branching ratios for $\mathrm{H}+\mathrm{HO}_{2}$ (our (R30)-(R32)), would contribute to this result by depleting active-H at the mesopause more than would occur with the current rate constant values. In the latter paper, a slow value for $\mathrm{O}+\mathrm{HO}_{2}$ (our $k_{18}$ ) is used, which would tend to produce an $\mathrm{O}_{3}$ increase.

The multidimensional model of Garcia and Solomon [1983] is a contemporary of our own work. They present a mid-latitude annual average for the $\mathrm{O}_{3}$ vertical profile. In this case we would expect from Table 3 that their lower mesosphere $\mathrm{O}_{3}$ would be somewhat higher than ours, but actually it is lower by $20 \%$. Their mesopause $\mathrm{O}_{3}$ shows more structure than our own. However, from the experience of fitting a particular measured $\mathrm{O}_{3}$ profile, we know that small variations in the rate constants adopted would result in the profile of Garcia and Solomon [1983]. The values of key climatological variables $-\mathrm{H}_{2} \mathrm{O}$, temperature, transport - play a significant role in determining the $\mathrm{O}_{3}$ profile so that differences in these variables will also introduce differences between the results of different models when compared in as much detail as we have done in this section. A recent application of the Garcia and Solomon [1983] model involves a comparison between photochemical calculations and the vertical distribution of $\mathrm{O}_{3}$ as measured from 50 to $95 \mathrm{~km}$ by the SME [Solomon et al., 1983]. The model results are systematically lower than the observations throughout this altitude range. Their results better fit the mesopause measurements than do ours, but this probably arises from their adoption of a drier mesosphere. Both models could easily match the upper mesosphere SME results if reduced $\mathrm{H}_{2} \mathrm{O}$ abundances on the order of the Bevilacqua et al. [1983] profile were adopted, a point Solomon et al. [1983] also mention. The Solomon et al. [1983] calculations fit the SME results least well in the lower mesosphere, while our model results for the appropriate circumstances of the observations fall a little on the high side in this altitude range. They propose one solution to the deficiency that involves modifying the photolysis rates. Interestingly, the adoption of our photodissociation rate constants would result in an increase in their calculated results (S. Solomon, private communication, 1983), the differences between the models arising from the use of different radiative transfer parametrizations in the wavelength range dominated by the complex SchumannRunge bands of $\mathrm{O}_{2}$ (our techniques discussed in Paper I and Allen and Frederick [1982]). This is a clear demonstration of the sensitivity of model conclusions to the exact details of the computations.

During the past decade, modeling techniques have been refined and rate constant values standardized. In this section, we have considered our model in light of its predeces- sors. Differences between the earlier work and the results presented in this paper can be attributed to the adoption of different values for the important parameters, rather than any inconsistencies in the chemical model itself.

\section{CONCLUSIONS}

A sizeable body of mid-latitude mesosphere/lower thermosphere ozone measurements has been acquired within the last 15 years by a wide range of observing techniques. We attempt in this paper to provide a theoretical understanding of the variety of phenomena illustrated by these sets of data. We are aided in this analysis by simple analytical expressions that can well describe the ozone abundances over much of the day at the various altitude levels. Particular attention is paid to the detailed ozone profile from the Aladdin 74 rocket flights, which we found to be reproduced by model calculations when adjustments are made to key parameters within the range of their known uncertainty. This model can explain, in general, the observed natural variability of lower mesosphere ozone due to changes in environmental factors, but assumptions about the values of some critical climatological parameters always need to be made. The interesting, but less frequently measured, secondary maximum near the mesopause is shown to arise from the coupling of active-hydrogen and active-oxygen chemistry. The abundance of ozone at the mesopause seems to undergo significant variation, which may be the result of secular variation in the dynamics of that altitude range. We find that the measured ozone profile above $100 \mathrm{~km}$ cannot be matched by calculations. Since only a few reactions in the current model are important in that altitude range and the magnitude of these processes are well constrained, new reactions need to be considered.

Thus, key chemical cycles involving oxygen and hydrogen atoms that are important to ozone in the mesosphere and lower thermosphere and also in the stratosphere have been verified to a large degree. Currently, the observed variability of ozone can be ascribed to changes in climatological variables. However, this satisfying picture of our understanding of ozone above the stratopause is not truly accurate. Even though very few parameters need to be specified to calculate the ozone abundance, our knowledge of the correct values to use is surprisingly poor. The uncertainties in the laboratory measurements of the key rate constants are too large for the type of comparisons that need to be made. For example, the recently revised quantum yields for $\mathrm{H}_{2} \mathrm{O}$ photodissociation at Lyman $\alpha$ [Slanger and Black, 1982] result in a doubling of $J_{5}$ at $100 \mathrm{~km}$ (but little change below $70 \mathrm{~km}$ ) and in a decrease in $J_{6}$ by a factor of 6 throughout the atmosphere (relative to the values reported in Table 1 and shown in Figure 10). The consequences of these changes can be understood in terms of the discussion in our paper. Active-O is reduced by $50 \%$ at the mesopause and by $10 \%$ at 70 and $90 \mathrm{~km}$. The reduction in $\mathrm{O}_{3}$ is similar to that of active-O at and below the mesopause; the reduction is somewhat langer in the lower thermosphere $(90$ $\mathrm{km}, 35 \% ; 100 \mathrm{~km}, 10 \%)$. The decrease in $J_{6}$ reduces the rate of conversion of $\mathrm{H}_{2} \mathrm{O}$ to $\mathrm{H}_{2}$, resulting in an enhancement of $\mathrm{H}_{2} \mathrm{O}$ of $20 \%$ at the mesopause and above. The consequent reduction in $\mathrm{H}_{2}$ (cf. Figure 14) is $21 \%$ at $50 \mathrm{~km}$, $32 \%$ at $60 \mathrm{~km}, 64 \%$ at $70 \mathrm{~km}$, and $35-45 \%$ at and above 80 
km. As expected from equation (13), the atomic $H$ values change very little in the mesosphere but double in the lower thermosphere. Being the dominant active-H species in the mesosphere, $\mathrm{OH}$ reflects the changes in $J_{5}$ and is increased by $13 \%$ at $70 \mathrm{~km}$ and $78 \%$ at $80 \mathrm{~km}$ (and in the lower thermosphere, $88 \%$ at $90 \mathrm{~km}$ and $57 \%$ at $100 \mathrm{~km}$ ). The abundance of $\mathrm{HO}_{2}$ is coupled to that of $\mathrm{OH}$ (equation (5)), such that the changes in $\mathrm{OH}$ are echoed in $\mathrm{HO}_{2}$. The reaction (R27) involving two molecules of $\mathrm{HO}_{2}$ produces $\mathrm{H}_{2} \mathrm{O}_{2}$ and, as a result, there is a consequent amplification of the increases in $\mathrm{HO}_{2}$ seen in the $\mathrm{H}_{2} \mathrm{O}_{2}$ profile. These changes in the abundances of the trace species, however, do not affect the general trends in the $\mathrm{O}_{3}$ response to temporal and climatological variability.

To refine our investigations of upper atmospheric ozone, there is an additional need to acquire simultaneously and cospatially with ozone data the full set of important environmental factors. The solar illumination is reasonably well defined for a given pressure level at a specific local time. The temperature at each pressure level for which ozone is measured also needs to be determined. The critically important water profile, from which the catalytically significant active hydrogen species are derived, and the nature of atmospheric transport could be obtained by simultaneous measurements of other easily observable species, in particular, water itself and carbon monoxide. An example of an observing program designed to acquire a sufficient complement of measurements to test our understanding of ozone chemistry is the Solar Mesosphere Explorer (SME) satellite [Thomas et al., 1980; Barth, 1981; Barth et al., 1983]. However, the SME obtains the necessary set of measurements only near the stratopause. Future experiments need to be developed to extend the program of complementary measurements through the mesosphere to the complex and interesting mesopause region. In addition, the apparent deficiency of model ozone above $95 \mathrm{~km}$ (which we shall discuss further in another paper) needs to be verified by more measurements of ozone in this altitude range.

Briefly outlined in the introduction to this paper is the importance of ozone to the physics and chemistry of the upper atmosphere in a variety of ways. If an understanding of the "normal" variability of ozone is achieved, "abnormal" ozone values can be recognized and the fact that the atmosphere is being "unusually" perturbed also can then be recognized. In this way, new correlations of terrestrial atmospheric behavior with other phenomena may be identified. Furthermore, an understanding of ozone chemistry and related processes permits better analyses of the future response of the atmosphere to a variety of anthropogenic modifications.

Acknowledgments. The many conversations we have had with S. Solomon have been of significant help in writing this paper. We also gratefully acknowledge the variety of assistance received from D. Anderson, G. Anderson, T. Clancy, W. DeMore, J. Gille, D. Hunten, F. Kaufman, L. Keyser, M. Leu, J. Logan, D. Muhleman, M. Prather, S. Sander, P. Schwartz, J. Waters, and W. Wilson. This research was supported by NASA grant NAGW 413 and JPL49-649-20320-0-3270 to the California Institute of Technology. Contribution number 3876 from the Division of Geological and Planetary Sciences, California Institute of Technology.

\section{REFERENCES}

Ackerman, M., Ultraviolet solar radiation related to mesospheric processes, in Mesospheric Models and Related Experiments, edited by G. Fiocco, pp. 149-159, D. Reidel, Hingham, Mass., 1971.

Allen, M., and J. E. Frederick, Effective photodissociation cross sections for molecular oxygen and nitric oxide in the SchumannRunge bands, J. Atmos. Sci., 39, 2066-2075, 1982.

Allen, M., Y. L. Yung, and J. W. Waters, Vertical transport and photochemistry in the terrestrial mesosphere and lower thermosphere (50-120 km), J. Geophys. Res., 86, 3617-3627, 1981.

Anderson, D. E., P. D. Feldman, E. P. Gentieu, and R. R. Meier, The UV dayglow, 2, LY alpha and LY beta emissions and the $H$ distribution in the mesosphere and thermosphere, Geophys. Res. Lett., 7, 529-532, 1980.

Anderson, G. P., J. C. Gille, P. L. Bailey, and S. Solomon, LRIR observations of diumal ozone variation in the mesosphere, in Proceedings Quadrennial International Ozone Symposium, edited by J. London, pp. 580-585, International Ozone Commission, Boulder, Col., 1981.

Anderson, J. G., Rocket-borne ultraviolet spectrometer measurement of $\mathrm{OH}$ resonance fluorescence with a diffusive transport model for mesospheric photochemistry, J. Geophys. Res., 76, 4634-4652, 1971.

Atreya, S. K., T. M. Donahue, W. E. Sharp, B. Wasser, J. F. Drake, and G. R. Riegler, Ultraviolet stellar occultation measurement of the $\mathrm{H}_{2}$ and $\mathrm{O}_{2}$ densities near $100 \mathrm{~km}$ in the earth's atmosphere, Geophys. Res. Lett., 3, 607-610, 1976.

Baker, K. D., J. C. Ulwick, C. R. Philbrick, and R. Picard, Midlatitude measurements of atmospheric minor species, EOS Trans. $A G U, 63,1048,1982$.

Banks, P. M., and G. Kockarts, Aeronomy, Part B, Academic, New York, 1973.

Barnett, J. J., J. T. Houghton, and J. A. Pyle, The temperature dependence of the ozone concentration near the stratopause, $Q$. J. R. Meteorol. Soc., 101, 245-257, 1975.

Barth, C. A., Solar Mesosphere Explorer to study ozone, Nature, 293, 259-260, 1981.

Barth, C. A., D. W. Rusch, R. J. Thomas, G. H. Mount, G. J. Rottman, G. E. Thomas, R. W. Sanders, and G. M. Lawrence, Solar Mesosphere Explorer: Scientific objectives and results, Geophys. Res. Lett., 10, 237-240, 1983.

Bates, D. R., and M. Nicolet, The photochemistry of atmospheric water vapor, J. Geophys. Res., 55, 301-327, 1950.

Battaner, E. and R. Rodrigo, Meospheric $\mathrm{O}_{3}, \mathrm{H}$ and $\mathrm{H}_{2} \mathrm{O}$ at high latitudes: a theoretical model, Planet. Space Sci., 29, 819-823, 1981.

Bevilacqua, R. M., P. R. Schwartz, J. M. Bologna, D. L. Thacker, J. J. Olivero, and C. J. Gibbons, An observational study of water vapor in the mid-latitude mesosphere using ground-based microwave techniques, J. Geophys. Res., 88, 8523-8534, 1983.

Brasseur, G., P. DeBaets, and A. DeRudder, Solar variability and minor constituents in the lower thermosphere and in the mesosphere, Space Sci. Rev., 34, 377-385, 1983.

Carver, J. H., H. P. Gies, T. I. Hobbs, B. R. Lewis, and D. G. McCoy, Temperature dependence of the molecular oxygen photoabsorption cross section near H Lyman alpha line, J. Geophys. Res., 82, 1955-1960, 1977.

Chamberlain, J. W., Theory of Planetary Atmospheres: An Introduction to Their Physics and Chemistry, Academic, New York, 1978.

Chang, J. S., and W. H. Duewer, Modeling chemical processes in the stratosphere, Ann. Rev. Phys. Chem., 30, 443-469, 1979.

Chanin, M.-L., and A. Hauchecorne, Lidar observation of gravity and tidal waves in the stratosphere and mesosphere, J. Geophys. Res., 86, 9715-9721, 1981.

CIAP, The Natural Stratosphere of 1974, Monogr. 1, DOT-TST75-51, Climatic Impact Assessment Program, Department of Transportation, Washington, D. C., 1975.

Cicerone, R. J., and J. L. McCrumb, Photodissociation of isotopically heavy $\mathrm{O}_{2}$ as a source of atmospheric $\mathrm{O}_{3}$, Geophys. Res. Lett., 7, 251-254, 1980.

Clayson, M. H., J. London, and G. P. Anderson, The global distribution of stratospheric ozone from OGO-4 BUV observations, in Proceedings Quadrennial International Ozone Symposium, edited 
by J. London, pp. 558-564, International Ozone Commission, Boulder, Col., 1981.

Crutzen, P. J., and S. Solomon, Response of mesospheric ozone to particle precipitation, Planet. Space Sci., 28, 1147-1153, 1980.

DeBaets, P., G. Brasseur, and P. C. Simon, Chemical response of the middle atmosphere to solar variations, Solar Phys., 74, 349353, 1981 .

Deguchi, S., and D. O. Muhleman, Mesospheric water vapor, $J$. Geophys. Res., 87, 1343-1346, 1982.

DeMore, W. B., and Y. L. Yung, Catalytic processes in the atmospheres of Earth and Venus, Science, 217, 1209-1213, 1982.

DeMore, W. B., L. J. Stief, F. Kaufman, D. M. Golden, R. F. Hampson, M. J. Kurylo, J. J. Margitan, M. J. Molina, and R. T. Watson, Chemical Kinetics and Photochemical Data for Use in Stratospheric Modeling, Eval. 4, JPL Publ. 81-3, Jet Propul. Lab., Calif. Inst. of Tech., Pasadena, Calif., 1981.

DeMore, W. B., R. T. Watson, D. M. Golden, R. F. Hampson, M Kurylo, C. J. Howard, M. J. Molina, and A. R. Ravishankara, Chemical Kinetics and Photochemical Data for Use in Stratospheric Modeling, Eval. 5, JPL Publ. 82-57, Jet Propul. Lab. Calif. Inst. of Tech., Pasadena, Calif., 1982.

Dickinson, P. H. G., W. C. Bain, L. Thomas, E. R. Williams, D. B. Jenkins, and $N$. D. Twiddy, The determination of the atomic oxygen concentration and associated parameters in the lower ionosphere, Proc. R. Soc. London Ser. A, 369, 379-408, 1980.

Drummond, J. R., and C. T. Mutlow, Satellite measurements of $\mathrm{H}_{2} \mathrm{O}$ fluorescence in the mesosphere, Nature, 294, 431-432, 1981.

Evans, W. F. J., and E. J. Llewellyn, Molecular oxygen emissions in the airglow, Ann. Geophys., 26, 167-178, 1970.

Evans, W. F. J., and E. J. Llewellyn, Atomic hydrogen concentrations in the mesosphere and the hydroxyl emissions, $J$. Geophys. Res., 78, 323-326, 1973.

Evans, W. F. J., D. M. Hunten, E. J. Llewellyn, and A. Vallance Jones, Altitude profile of the infrared atmospheric system of oxygen in the dayglow, J. Geophys. Res., 73, 2885-2896, 1968.

Farmer, C. B., O. F. Raper, B. D. Robbins, R. A. Toth, and C Muller, Simultaneous spectroscopic measurements of stratospheric species: $\mathrm{O}_{3}, \mathrm{CH}_{4}, \mathrm{CO}, \mathrm{CO} 2, \mathrm{~N} 2 \mathrm{O}, \mathrm{H}_{2} \mathrm{O}, \mathrm{HCl}$, and $\mathrm{HF}$ at northern and southern mid-latitudes, J. Geophys. Res., 85, 1621 $1632,1980$.

Frederick, J. E., Chemical response of the middle atmosphere to changes in the ultraviolet solar flux, Planet. Space Sci., 25, 14, 1977 .

Frederick, J. E., Influence of gravity wave activity on lower thermospheric photochemistry and composition, Planet. Space Sci. 27, 1469-1477, 1979.

Frederick, J. E., Seasonal variations in high-latitude ozone and metastable molecular oxygen emissions: A theoretical interpretation, J. Geophys. Res., 85, 1611-1617, 1980.

Frederick, J. E., Photochemical processes induced by a major warming of the upper atmosphere: Variations in mesospheric trace constituents, J. Geophys. Res., 86, 3148-3152, $1981 a$.

Frederick, J. E., Radiative-photochemical response of the mesosphere to dynamical forcing, $J$. Geophys. Res., 86, 5224-5230, $1981 b$.

Frederick, J. E., and R. D. Hudson, Atmospheric opacity in the Schumann-Runge bands and the aeronomic dissociation of water vapor, J. Atmos. Sci., 37, 1088-1098, 1980.

Frederick, J. E., and J. E. Mentall, Solar irradiance in the stratosphere: implications for the Herzberg continuum absorption of $\mathrm{O}_{2}$, Geophys. Res. Lett., 9, 461-464, 1982.

Frederick, J. E., F. T. Huang, A. R. Douglass, and C. A. Reber, The distribution and annual cycle of ozone in the upper stratosphere, J. Geophys. Res., 88, 3819-3828, 1983.

Froidevaux, L., and Y. L. Yung, Radiation and chemistry in the stratosphere: Sensitivity to $\mathrm{O}_{2}$ absorption cross sections in the Herzberg continuum, Geophys. Res. Lett., 9, 854-857, 1982.

Garcia, R. R., and S. Solomon, A numerical model of the zonallyaveraged dynamical and chemical structure of the middle atmosphere, J. Geophys. Res., 88, 1379-1400, 1983.

Garcia, R. R., S. Solomon, R. G. Roble, and D. W. Rusch, A numerical study of the response of the middle atmosphere to the 11 -year solar cycle, submitted to $J$. Geophys. Res., 1983.

Gille, J. C., Ozone distributions by infrared limb scanning: Preliminary results from the LRIR, in Proceedings NATO Advanced Study Institute on Atmospheric Ozone: Its Variation and Human
Influences, edited by A. C. Aikin, pp. 103-121, FAA-EE-80-20, U.S. Dept. of Transp., Washington, D. C., 1980.

Gille, J. C., G. P. Anderson, and P. L. Bailey, Comparison of near coincident LRIR and OAO-3 measurements of equatorial night ozone profiles, Geophys. Res. Lett., 7, 525-528, $1980 a$.

Gille, J. C., P. L. Bailey, and J. M. Russell, Temperature and composition measurements from the l.r.i.r. and l.i.m.s. experiments on NIMBUS 6 and 7, Phil. Trans. R. Soc. London Ser. A, 296, 205-218, $1980 b$.

Gille, J. C., P. L. Bailey, R. A. Craig, F. B. House, and G. P. Anderson, Sounding the stratosphere and mesosphere by infrared limb scanning from space, Science, 208, 397-399, 1980c.

Hack, N., H. Gg. Wagner, and K. Hoyermann, Reaktionen von wasserstoffatomen mit hydroperoxylradikalen, I, Bestimmung der spezikischen geschwindigkeits- konstanten der reaktionskanale, Ber. Bunsenges. Phys. Chem., 82, 713-719, 1978.

Hack, W., A. W. Preuss, H. Gg. Wagner, and K. Hoyermann, Reaktionen von wasserstoffatomen mit hydroperoxylradikalen, II, Bestimmung der geschwindigkeitskonstanten der bruttoreaktion, Ber. Bunsenges. Phys. Chem., 83, 212-217, 1979.

Hampson, R. F., Chemical kinetics and photochemical data sheets for atmospheric reactions, $F A A-E E-80-17$, U.S. Dept. of Transp., Washington, D. C., 1980.

Hauchecorne, A., and M.-L. Chanin, A mid-latitude ground-based lidar study of stratospheric warmings and planetary wave propagation, J. Atmos. Terr. Phys., 44, 577-583, 1982.

Hauchecorne, A., and M.-L. Chanin, Mid-latitude lidar observations of planetary waves in the middle atmosphere during the winter of 1981-1982, J, Geophys. Res., 88, 3843-3849, 1983.

Hays, P. B., and R. G. Roble, Observation of mesospheric ozone at low latitudes, Planet. Space Sci., 21, 273-279, 1973.

Herman, J. R., The response of stratospheric constituents to a solar eclipse, sunrise, and sunset, J. Geophys. Res., 84, 3701-3710, 1979.

Herman, J. R., and J. E. Mentall, $\mathrm{O}_{2}$ absorption cross sections $(187-225 \mathrm{~nm})$ from stratospheric solar flux measurements, $J$. Geophys. Res., 87, 8967-8975, 1982.

Hudson, R. D., Critical review of ultraviolet photoabsorption cross sections for molecules of astrophysical and aeronomic interest, Rev. Geophys. Space Phys., 9, 305-406, 1971.

Hudson, R. D., Absorption cross sections of stratospheric molecules, Can. J. Chem., 52, 1465-1478, 1974.

Hudson, R. D. (ed.), Chlorofluoromethanes and the Stratosphere, NASA RP-1010, 1977.

Hudson, R. D., and E. I. Reed (eds.), The Stratosphere: Present and Future, NASA RP-1049, 1979.

Hunt, B. G., A diffusive-photochemical study of the mesosphere and lower thermosphere and the associated conservation mechanisms, J. Atmos. Terr. Phys., 33, 1869-1892, 1971.

Hunt, B. G., A generalized aeronomic model of the mesosphere and lower thermosphere including ionospheric processes, $J$. Atmos. Terr. Phys., 35, 1755-1798, 1973.

Hunten, D. M., Vertical transport in atmospheres, in Atmospheres of Earth and the Planets, edited by B. M. McCormac, pp. 59-72, D. Reidel, Hingham, Mass., 1975.

Hunten, D. M., and T. M. Donahue, Hydrogen loss from the terrestrial planets, Ann. Rev. Earth Planet. Sci., 4, 265-292, 1976.

Hunten, D. M., and D. F. Strobel, Production and escape of terrestrial hydrogen, J. Atmos. Sci., 31, 305-317, 1974.

Jacchia, L. G., Thermospheric temperature, density and composition: New models, SAO Spec. Rep. 375, Smithsonian Inst., Cambridge, Mass., 1977.

Johnston, H. S., and J. Podolske, Interpretation of stratospheric photochemistry, Rev. Geophys. Space Phys., 16, 491-519, 1978.

Kaufman, F., L. X. Qiu, and U. C. Sridharan, Radical-radical and atom-radical reactions of $\mathrm{HO}_{2}$, paper presented at Seventh International Symposium Gas Kinetics, Royal Society of Chemistry of Great Britain, Gottingen, West Germany, 1982.

Keneshea, T. J., S. P. Zimmerman, and C. R. Philbrick, A dynamic model of the mesosphere and lower thermosphere, Planet. Space Sci., 27, 385-401, 1979.

Keyser, L. F., Kinetics of the reaction $\mathrm{O}+\mathrm{HO}_{2} \rightarrow \mathrm{OH}+\mathrm{O}_{2}$ from 229 to 372 K, J. Phys. Chem., 86, 3439-3446, 1982.

Kita, D., and W. E. Sharp, Atomic hydrogen in the upper mesosphere, EOS Trans. AGU, 63, 896, 1982.

Klais, O., P. C. Anderson, and M. J. Kurylo, A reinvestigation of 
the temperature dependence of the rate constant for the reaction $\mathrm{O}+\mathrm{O}_{2}+\mathrm{M} \rightarrow \mathrm{O}_{3}+\mathrm{M}$ (for $\mathrm{M}-\mathrm{O}_{2}, \mathrm{~N}_{2}$, and Ar) by the flash photolysis resonance fluorescence technique, Int. J. Chem. Kinet. $12,469-490,1980$.

Ko, M. K. W., and N. D. Sze, Effect of recent rate data revisions on stratospheric modeling, Geophys. Res. Lett., I0, 341-344, 1983.

Koshelev, V. V., Diurnal and seasonal variations of oxygen, hydrogen and nitrogen components at heights of mesosphere and lower thermosphere, J. Atmos. Terr. Phys., 38, 991-998, 1976.

Krueger, A. J., and R. A. Minzner, A mid-latitude ozone model for the 1976 U.S. Standard Atmosphere, J. Geophys. Res., 81, 4477$4481,1976$.

Krueger, A. J., and D. U. Wright, Some results from rocket ozone (ROCOZ) soundings at Wallops Island, Va., EOS Trans. AGU, $60,268,1979$.

Krueger, A. J., B. Guenther, A. J. Fleig, D. F. Heath, E. Hilsenrath, R. McPeters, and C. Prabnakara, Satellite ozone measurements, Phil. Trans. R. Soc. London, Ser. A, 296, 191-204, 1980.

Lean, J. L., Observation of the diurnal variation of atmospheric ozone, J. Geophys. Res., 87, 4973-4980, 1982.

Lean, J. L., UV rocket spectroscopy measurement of the nighttime ozone distribution, J. Geophys. Res., 88, 1468-1474, 1983.

Lin, C. L., and M. T. Leu, Temperature and third-body dependence of the rate constant for the reaction $\mathrm{O}+\mathrm{O}_{2}+\mathrm{M} \rightarrow \mathrm{O}_{3}+$ M, Int. J. Chem. Kinet., 14, 417-434, 1982.

Lindzen, R. S., Turbulence and stress owing to gravity wave and tidal breakdown, J. Geophys. Res., 86, 9707-9714, 1981.

Liv, S. C., and T. M. Donahue, The aeronomy of hydrogen in the atmosphere of the earth, J. Atmos. Sci., 31, 1118-1136, 1974a.

Liu, S. C., and T. M. Donahue, Realistic model of hydrogen constituents in the lower atmosphere and escape flux from the upper atmosphere, J. Atmos. Sci., 31, 2238-2242, $1974 b$.

Logan, J. A., M. J. Prather, S. C. Wofsy, and M. B. McElroy, Atmospheric chemistry: Response to human influence, Phil. Trans. R. Soc. London, Ser. A, 290, 187-234, 1978.

London, J., Radiative energy sources and sinks in the stratosphere and mesosphere, in Proceedings NATO Advanced Study Institute on Atmospheric Ozone: Its Variation and Human Influences, edited by A. C. Aiken, pp. 703-721, FAA-EE-80-20, U.S. Dept. of Transp., Washington, D. C., 1980.

London, J., J. E. Frederick, and G. P. Anderson, Satellite observations of the global distribution of stratospheric ozone, J. Geophys. Res., 82, 2543-2556, 1977.

McPeters, R. D., The behavior of ozone near the stratopause from two years of BUV observations, J. Geophys. Res., 85, 4545-4550, 1980.

Miller, D. E., and P. Ryder, Measurement of the ozone concentration from 55 to $95 \mathrm{~km}$ at sunset, Planet. Space Sci., 21, 963-670, 1973.

Millier, F., A. Vidal-Madjar, J. Guidon, and R. G. Roble, Ozone number density profiles in the lower mesosphere as determined by the French experiment on board OSO-8, Geophys. Res. Lett., 6, 863-865, 1979.

Millier, F., B. A. Emery, and R. G. Roble, OSO-8 lower mesospheric ozone number density profiles, in Proceedings Quadrennial International Ozone Symposium, edited by J. London, pp. 572-579, International Ozone Commission, Boulder, Col., 1981.

Moreels, G., G. Megie, A. Vallance Jones, and R. L. Gattinger, An oxygen-hydrogen atmospheric model and its application to the OH emission problem, J. Atmos. Terr. Phys., 39, 551-570, 1977.

Mount, G. $H_{y}$ and G. J. Rottman, The solar spectral irradiance 1200-3184 A near solar maximum: July 15, 1980, J. Geophys. Res., 86, 9193-9198, 1981.

Mount, G. H., G. J. Rottman, and J. G. Timothy, The solar spectral irradiance 1200-2550 A at solar maximum, J. Geophys. Res., $85,4271-4274,1980$.

National Academy of Sciences, Solar-Terrestrial Research for the 1980's, Washington, D. C., 1981.

Nicolet, M., Aeronomic reactions of hydrogen and ozone, in Mesospheric Models and Related Experiments, edited by $G$. Fiocco, pp. 1-51, D. Reidel, Hingham, Mass., 1971.

Nicolet, M., The chemical equations of stratospheric and mesospheric ozone, in Proceedings NATO Advanced Study Institute on Atmospheric Ozone: Its Variation and Human Influences, edited by A. C. Aiken, pp. 823-864, FAA-EE-80-20,
U.S. Dept. of Transp., Washington, D. C., 1980.

Noxon, J. F., A global study of $\mathrm{O}_{2}\left(\mathrm{l}_{\Delta_{g}}\right)$ airglow: Day and twilight, Planet. Space Sci., 30, 545-557, 1982.

Offermann, D., V. Friedrich, P. Ross, and U, von Zahn, Neutral gas composition measurements between 80 and $120 \mathrm{~km}$, Planet. Space Sci., 29, 747-764, 1981.

Ogawa, $T$., and $T$. Watanabe, Summary of the mesospheric ozone measurements during 1970-1979 in Japan, in Proceedings Quadrennial International Ozone Symposium, edited by J. London, pp. 520-525, International Ozone Commission, Boulder, Col., 1981.

Prather, M. J., Ozone in the upper stratosphere and mesosphere, $J$. Geophys. Res., 86, 5325-5338, 1981.

Remsberg, E. E., J. M. Russell, L. L. Gordley, J. C. Gille, and P. L. Bailey, The validation of LIMS ozone profiles using correlative rocket, ECC, and Dobson data sets, in Proceedings Quadrennial International Ozone Symposium, edited by J. London, pp. 190195, International Ozone Commission, Boulder, Col. 1981.

Riegler, G. R., S. K. Atreya, T. M. Donahue, S. C. Liu, B. Wasser, and J. F. Drake, UV stellar occultation measurements of nighttime equatorial ozone, Geophys. Res. Lett., 4, 145-148, 1977.

Rottman, G. J., Rocket measurements of the solar spectral irradiance during solar minimum, 1972-1977, J. Geophys. Res., 86, 6697-6705, 1981.

Rottman, G. J., C. A. Barth, R. J. Thomas, G. H. Mount, G. M. Lawrence, D. W. Rusch, R. W. Sanders, G. E. Thomas, and J. London, Solar spectral irradiatice, 120 to $190 \mathrm{~nm}$, October 13 1981-January 3, 1982, Geophys. Res. Lett., 9, 587-590, 1982.

Rusch, D. W., and S. C. Liu, The effects of recent solar flux measurements and water vapor dissociation calculations on mesospheric chemistry, in Proceedings Quadrennial International Ozone Symposium, edited by J. London, pp. 869-875, International Ozone Commission, Boulder, Col., 1981.

Rusch, D. W., G. H. Mount, C. A. Barth, G. J. Rottman, R. J. Thomas, G. E. Thomas, R. W. Sanders, G. M. Lawrence, and R. S. Eckman, Ozone densities in the lower mesosphere measured by a limb scanning ultraviolet spectrometer, Geophys. Res. Lett., I0, 241-244, 1983a.

Rusch, D. W., G. H. Mount, J. M. Zawodny, C. A. Barth, G. J. Rottman, R. J. Thomas, G. E. Thomas, R. W. Sanders, and G. $M$. Lawrence, Temperature measurements in the earth's stratosphere using a limb scanning visible light spectrometer, Geophys. Res. Lett., 10, 261-264, 1983 b.

Schmidlin, F. J., Temperature inversions near $75 \mathrm{~km}$, Geophys. Res. Lett., 3, 173-176, 1976.

Schurgers, $\mathrm{M}$., and $\mathrm{K}$. W. Welge, Absorptionskoeffizient von $\mathrm{H}_{2} \mathrm{O}$ und $\mathrm{N}_{2} \mathrm{H}_{4}$ Zwischen 1200 and $2000 \AA Z$. Naturforsch. $A$., 23, 1508-1510, 1968.

Slanger, T. G., and G. Black, Photodissociative channels at $1216 \AA$ for $\mathrm{H}_{2} \mathrm{O}, \mathrm{NH}_{3}$, and $\mathrm{CH}_{4}, J$. Chem. Phys., 77, 2432-2437, 1982.

Solomon, S., E. E. Ferguson, D. W. Fahey, and P. J. Crutzen, On the chemistry of $\mathrm{H}_{2} \mathrm{O}, \mathrm{H}_{2}$ and meteorite ions in the mesosphere and lower thermosphere, Planet. Space Sci., 30, 1117-1126, 1982.

Solomon, S., D. W. Rusch, R. J. Thomas, and R. S. Eckman, Comparison of mesospheric ozone abundances measured by the Solar Mesosphere Explorer and model calculations, Geophys. Res. Lett., 10, 249-252, 1983.

Sridharan, U. C., L. X. Qiu, and F. Kaufman, Kinetics and product channels of the reactions of $\mathrm{HO}_{2}$ with $\mathrm{O}$ and $\mathrm{H}$ atoms at 296 K, J. Phys. Chem., 86, 4569-4574, 1982.

Sundararaman, N., T. Perry, W. Gurkin, E. Jackson, B. Horton, J. Lean, E. Llewellyn, B. Solheim, W. F. J. Evans, B. H. Subbaraya S. Lal, T. Ogawa, T. Watanabe, E. Hilsenrath, and A. Krueger, International ozone rocketsonde intercomparison, in Proceedings Quadrennial International Ozone Symposium, edited by J. London, pp. 421-422, International Ozone Commission, Boulder, Col., 1981.

Thomas, G. E., C. A. Barth, E. R. Hansen, C. W. Hord, G. M. Lawrence, G. H. Mount, G. J. Rottman, D. W. Rusch, A. I Stewart, R. J. Thomas, J. London, P. L. Bailey, P. J. Crutzen, R. E. Dickinson, J. C. Gille, S. C. Liu, J. F. Noxon, and C. B. Farmer, Scientific objectives of the Solar Mesosphere Explorer mission, Pure Appl. Geophys., 118, 591-615, 1980.

Thomas, L. and M. R. Bowman, The diumal variations of hydrogen and oxygen constituents in the mesosphere and lower thermosphere, J. Atmos. Terr. Phys., 34, 1843-1858, 1972. 
Thomas, R. J., and R. A. Young, Measurement of atomic oxygen and related airglows in the lower thermosphere, J. Geophys. Res., 86, 7389-7393, 1981.

Thomas, R. J., C. A. Barth, G. J. Rottman, D, W. Rusch, G. H. Mount, G. M. Lawrence, R. W. Sanders, G. E. Thomas, and L. E. Clemens, Ozone density distribution in the mesosphere (50-90 $\mathrm{km}$ ) measured by the SME limb scanning infrared spectrometer, Geophys. Res. Lett., 10, 245-248, 1983.

Trainor, D. W., D. O. Ham, and F. Kaufiman, Gas phase recombination of hydrogen and deuterium atoms, J. Chem. Phys., 58, 4599-4609, 1973.

Trinks, $H$., and $\mathrm{K} . \mathrm{H}$. Fricke, Carbon dioxide concentrations in the lower thermosphere, J. Geophys. Res., 83, 3883-3886, 1978.

Trinks, H., D. Óffermann, U. von Zahn, and C. Steinhauer, Neutral composition measurements between 90 and $220-\mathrm{km}$ altitude by rocket-borne mass spectrometer, $J$. Geophys. Res., 83, 2169 2176, 1978.

Vaughan, G., Diurnal variation of mesospheric ozone, Nature, 296, 133-135, 1982.

Wang, P. H., G. K. Yue, A. Deepak, and R. J. Kurzeja, A model study of the diurnal variation of mesospheric $\mathrm{O}_{3}$, in Proceedings Quadrennial International Ozone Symposium, edited by J. London, pp. 876-883, International Ozone Commission, Boulder, Col., 1981.

Watanabe, $\mathbf{K}$., Ultraviolet absorption processes in the upper atmosphere, Adv. Geophys., 5, 153-221, 1958.

Waters, J. W., J. J. Gustincic, P. N. Swanson, and A. R. Kerr, Measurement of upper atmospheric $\mathrm{H}_{2} \mathrm{O}$ emission at $183 \mathrm{GHz}$, in Atmospheric Water Vapor, edited by A. Deepak, T. D. Wilkerson, and L. H. Ruhnke, pp. 229-240, Academic, New York, 1980.

Weeks, L. H., R. E. Good, J. S. Randhawa, and H. Trinks, Ozone measurements in the stratosphere, mesosphere, and lower thermosphere during Aladdin 74, J. Geophys. Res., 83, 978-982, 1978.

Whitten, R. C. and R. P. Turco, Perturbations of the stratosphere and mesosphere by aerospace vehicles, $A I A A J ., 12,1110-1117$, 1974.

Wilson, W. J., and P. R. Schwartz, Diumal variations of mesospheric ozone using millimeter-wave measurements, J. Geophys. Res., 86, 7385-7388, 1981.

World Meteorological Organization, The Stratosphere 1981: Theory and Measurements, Rep. 11, WMO Global Ozone Res. and Monitoring Proj., Geneva, Switzerland, 1981.

Wright, D. U., A. J. Krueger, and G. M. Foster, Rocket ozone sounding network data, NASA TM-69365, 1978.

M. Allen, J. I. Lunine, and Y. L. Yung, Division of Geological and Planetary Sciences, California Institute of Technology, Pasadena, CA 91125.

(Received June 13, 1983;

revised December 5, 1983; accepted December 5, 1983.) 